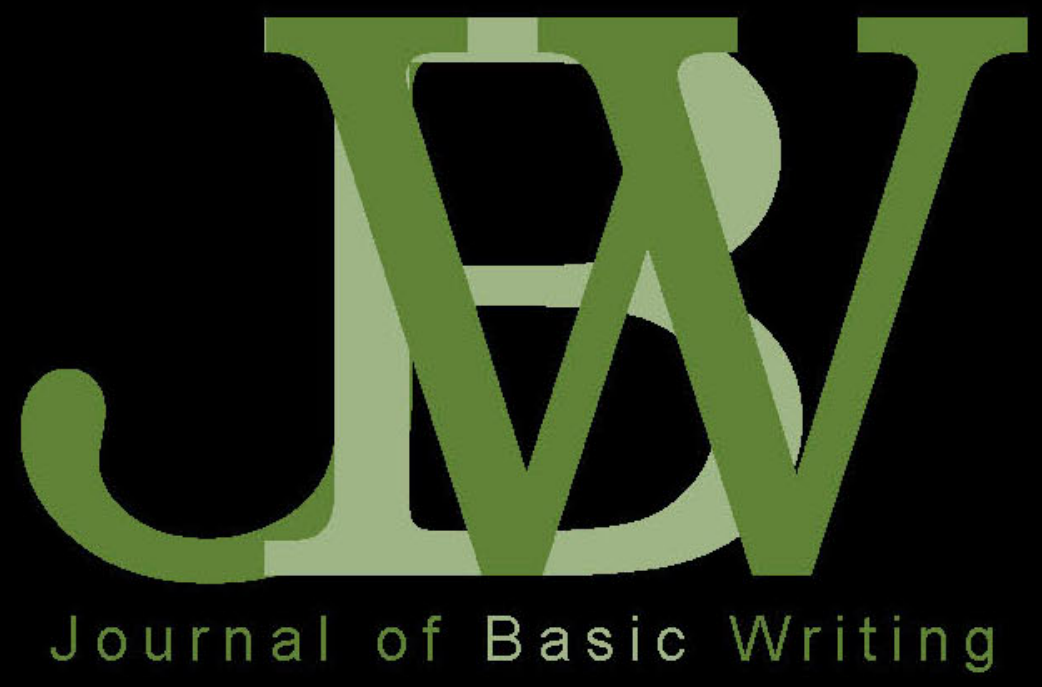

Journalism, Poetry, Stand-Up Comedy, and Academic Literacy: Mapping the Interplay of Curricular and Extracurricular Literate Activities

Kevin Roozen

Technologies for Transcending a Focus on Error: Blogs and Democratic Aspirations in First-Year Composition

Cheryl C. Smith

Assessment of Generation 1.5 Leamers for Placement into College Writing Courses Kristen di Gennaro

Material Realities in the Basic Witing Classroom: Intersections of Discovery for Young Women Reading Persepolis 2 Susan Naomi Bernstein

Feedback on Feedback: Exploring Student Responses to Teachers' Written Commentary Maria Ornella Treglia 



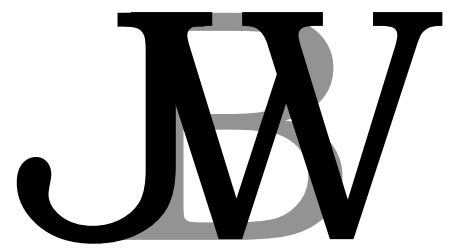

Journal of Basic Writing

VOLUME 27

The Journal of Basic Writing publishes articles of theory, research, and teaching practices related to basic writing. Articles are refereed by members of the Editorial Board (see overleaf) and the Editors.

Hope Parisi and Rebecca Mlynarczyk

Editors

\title{
Bonne August
}

Consulting Editor

\section{Karen Weingarten and Angela J. Francis}

Editorial Assistants

The Journal of Basic Writing is published twice a year, in the spring and fall, with support from the City University of New York, Office of Academic Affairs. We welcome unsolicited manuscripts and ask authors to consult the detailed "Call for Articles" in this issue. Subscriptions for individuals are $\$ 20.00$ for one year and $\$ 35$.00 for two years; subscriptions for institutions are $\$ 30$. oo for one year and $\$ 45.00$ for two years. Foreign postage is $\$ 10.00$ extra per year. For subscription inquiries or updates, contact:

\author{
Journal of Basic Writing \\ Attn. Cathie Ryan \\ 5 Sand Creek Road \\ Albany, NY 12205 \\ (800) 877-2693
}

Boyd Printing Company, Inc.

Published by the City University of New York since 1975

Cover and logo design by Kimon Frank

Copyright (C2008 by the Journal of Basic Writing

ISSN 0147-1635 


\section{JOURNAL OF BASIC WRITING}

\section{EDITORIAL BOARD}

\author{
Linda Adler-Kassner \\ Eastern Michigan University \\ Chris M. Anson \\ North Carolina State University \\ Hannah Ashley \\ West Chester University \\ David Bartholomae \\ University of Pittsburgh \\ Sarah Benesch \\ College of Staten Island, CUNY
}

Susan Naomi Bernstein

LaGuardia Community College, CUNY

Patricia Bizzell

College of the Holy Cross

Lynn Z. Bloom

University of Connecticut, Storrs

Gay Brookes

Borough of Manhattan Comm. College, CUNY

Richard Courage

Westchester Community College, SUNY

Martha Clark Cummings

Kingsborough Community College, CUNY

Donald A. Daiker

Miami University

Suellynn Duffey

Georgia Southern University

Chitralekha Duttagupta

Arizona State University

Sarah Warshauer Freedman

University of California, Berkeley

Keith Gilyard

Pennsylvania State University

Gregory Glau

Northern Arizona University

Laura Gray-Rosendale

Northern Arizona University

Karen L. Greenberg

Hunter College, CUNY

Brenda M. Greene

Medgar Evers College, CUNY

Susanmarie Harrington

Indiana University-Purdue University

Myra Kogen

Brooklyn College, CUNY
Patricia O. Laurence

City College of New York

Andrea A. Lunsford

Stanford University

Jane Maher

Nassau Community College, SUNY

Paul Kei Matsuda

Arizona State University

Geraldine McNenny

Chapman University

Susan Miller

University of Utah

Sandra Murphy

University of California, Davis

Deborah Mutnick

Long Island University

Nathaniel Norment, Jr.

Temple University

\section{George Otte}

Graduate Center, CUNY

Thomas Peele

Boise State University

Elizabeth Rorschach

City College, CUNY

Yolanda Sealey-Ruiz

Teachers College, Columbia University

Charles I. Schuster

University of Wisconsin, Milwaukee

Tony Silva

Purdue University

Trudy Smoke

Hunter College, CUNY

Ruth Spack

Bentley College

Lynn Quitman Troyka

Queensborough Comm. College, CUNY, ret.

Karen S. Uehling

Boise State University

Evelyn E. Webb

Miss. State Board for Comm. and Junior Colleges

Harvey S. Wiener

LaGuardia Comm. College, CUNY Emeritus

Vivian Zamel

University of Massachusetts, Boston 


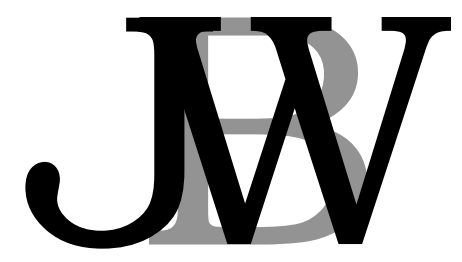

Journal of Basic Writing

VOLUME 27

NUMBER 1

Spring 2008

Editors' Column

I

Journalism, Poetry, Stand-Up Comedy,

and Academic Literacy: Mapping the

Interplay of Curricular and Extracurricular

Literate Activities

Kevin Roozen

Technologies for Transcending a Focus on Error:

Blogs and Democratic Aspirations

in First-Year Composition

Cheryl C. Smith

Assessment of Generation I.5 Learners

6I

for Placement into College Writing Courses

\section{Kristen di Gennaro}

Material Realities in the Basic Writing Classroom:

80

Intersections of Discovery for Young Women

Reading Persepolis 2

\section{Susan Naomi Bernstein}

Feedback on Feedback: Exploring Student

Responses to Teachers' Written Commentary

\section{Maria Ornella Treglia}

News and Announcements 


\section{CALL FOR ARTICLES}

We welcome manuscripts of I5-25 pages, double spaced, on topics related to basic and ESL writing, broadly interpreted. Submissions should follow current MLA guidelines. Manuscripts are refereed anonymously. To assure impartial review, include name(s), affiliation(s), mailing and e-mail addresses, and a short biographical note for publication on the cover page only. The second page should include the title but no author identification, an abstract of about I5O words, and a list of 4-5 key words. Endnotes should be kept to a minimum. It is the author's responsibility to obtain permission for including excerpts from student writing.

We prefer that contributions be submitted as Word document attachments via email to: rebecca.mlynarczyk@gmail.com. If electronic submission is not possible, mail five copies of the manuscript and abstract to:

Professor Rebecca Mlynarczyk
Co-Editor, JBW
Department of English
Kingsborough Community College,
CUNY
2OoI Oriental Blvd.
Brooklyn, NY II235

\author{
Professor Hope Parisi \\ Co-Editor, $J B W$ \\ Department of English \\ Kingsborough Community College, \\ CUNY \\ 200 I Oriental Blvd. \\ Brooklyn, NY II235
}

You will receive a confirmation of receipt; a report on the status of your submission will follow in about sixteen weeks.

All manuscripts must focus clearly on basic writing and must add substantively to the existing literature. We seek manuscripts that are original, stimulating, well-grounded in theory, and clearly related to practice. Work that reiterates what is known or work previously published will not be considered.

We invite authors to write about such matters as classroom practices in relation to basic-writing or second-language theory; cognitive and rhetorical theories and their relation to basic writing; social, psychological, and cultural implications of literacy; discourse theory; grammar, spelling, and error analysis; linguistics; computers and new technologies in basic writing; assessment and evaluation; writing center practices; teaching logs and the development of new methodologies; and cross-disciplinary studies combining basic writing with psychology, anthropology, journalism, and art. We publish observational studies as well as theoretical discussions on relationships between basic writing and reading, or the study of literature, or speech, or listening. The term "basic writer" is used with wide diversity today, sometimes referring to a student from a highly oral tradition with little experience in writing academic discourse, and sometimes referring to a student whose academic writing is fluent but otherwise deficient. To help readers, therefore, authors should describe clearly the student population which they are discussing.

We particularly encourage a variety of manuscripts: speculative discussions which venture fresh interpretations; essays which draw heavily on student writing as supportive evidence for new observations; research reports, written in non-technical language, which offer observations previously unknown or unsubstantiated; and collaborative writings which provocatively debate more than one side of a central controversy. 


\section{EDITORS' COLUMN}

As many of our colleagues have pointed out, definitions of the basic writer nearly always refer to social institutions and relationships of power. And yet we know that even as basic writing programs rely upon standards and definitions to function, students enter our classrooms with a full range of competencies, leading us to variously problematize the scenarios we have legitimated for sorting students. At the same time, students' backgrounds-their histories, interests, and locations in society-offer still more counter- narratives for considering their intellectual development. With more "time [taken] to know them" (Sternglass), we may obtain a broader view of students' experiences as they affect learning and their relationship to academic life.

This issue of $J B W$ makes clear that basic writers do not act merely as recipients of programmatic direction. Their talents, engagements, and perspectives bear upon their learning in ways that change us as teachers, instructing us to modify our practices, and our notions of what is basic. Our lead article, "Journalism, Poetry, Stand-Up Comedy, and Academic Literacy: Mapping the Interplay of Curricular and Extracurricular Literate Activities," by Kevin Roozen, presents the striking case of Charles Scott, Jr., a student at the University of Illinois at Urbana-Champaign from 2000-2005, whom Roozen followed in order to observe the pre-college and extracurricular influences that positively affected his path toward journalism. Roozen discovered a rich and inventive complexity of engagements on Charles' part as he sought to accede to the demands of entrylevel, college writing while pursuing writing and public speaking goals of his own determining. For Roozen, the factors that designated Charles' writing as basic represented a limited, quite context-specific, range of abilities. Once recognized, the obverse sides of Charles' school literacy leads Roozen to conclude that "writing ... is not so much about learning new practices in a new context as it is about coordinating and re-coordinating networks of multiple practices, artifacts, and identities." And as our views of students broaden, so do our responsibilities. Our teaching must invite students to integrate the complexity of their literacies outside of school and optimize these resources. By doing so, educators may prompt students toward key roles in defining academic writing - "to contribute to, rather than merely reproduce, academic literacy-to make it their own rather than someone else's."

In "Technologies for Transcending a Focus on Error: Blogs and Democratic Aspirations in First-Year Composition," Cheryl C. Smith shares Roozen's view of students' ability to mutually determine instructional approaches while affecting the parameters of basic writing as traditionally constituted by the classroom 
and academia. Smith's interest is in Web 2.0 platforms for social networking, including chat rooms, blogs, wikis, and sites like MySpace, which have captured students' attention, and generated waves of potential for renegotiating students' relationship to writing. Detailing her own experiment with using blogs in the classroom, Smith acknowledges how students' internet-related experience in communications bears upon a new engagement with literacy. First, as a component of classroom community, blogs have the capacity to re-situate students in relation to error. Students who blog in connection with their courses may gain access to academic discourse in a mode that does not eschew error, as chat room- and blog-type writing openly includes error as part of its discourse style. Similarly, blogs offer a palpable invitation for expression of larger ideas, as in discussion posts, with blog-mates supporting and building upon one another's commentary in collaborative, written form. Thus Smith's point, "When students bring their known modes of expression into the realm of the unknown, it eases some of the dissonance they may feel when faced with the new challenges of college writing. They may even find surprising ways to make academic writing conform to their experiences." With greater insight into the extent of students' already vibrant internet literacy, writing teachers are empowered to cultivate the "democratic aspirations" of teaching as articulated by John Trimbur.

In "Assessment of Generation I.5 Learners for Placement into College Writing Courses," Kristen di Gennaro continues in the spirit of Roozen and Smith by demonstrating that we must keep our notions of whom we teach flexible and open to inquiry. Just as Roozen calls us to consider the range of variables determining students' identities and capabilities, di Gennaro cautions us against assuming that we understand the ESL learner by way of the popular label Generation I.5. A survey of the research on $\mathrm{L} 2$ learners highlights the impressive range of second language learners' cultural and educational backgrounds; these factors manifest as various strengths and needs within the ESL student population. The implications are for improved assessments, which in turn might more productively impact placement and curriculum. Di Gennaro elaborates on the relevant variations in background, including the length of time L2 learners have been in the United States; whether they have obtained an American high school diploma; proficiency in the LI; and the level of aural versus written proficiency in the L2. When teachers and program directors neglect these factors for placement, instruction is directly affected: An L2 student who has been in the United States for many years, but who has learned English principally through immersion and aurality, may resist a curriculum that assumes he or she is a newcomer to this country. Or an L2 learner fairly able to demonstrate written proficiency in English may be at a loss in classrooms where aural comprehension and cultural understanding 
of the U.S. are assumed. Di Gennaro therefore recommends a more culturally and experientially sensitive platform for placement, including questionnaires, as well as more research into how different writing patterns may encode aspects of students' sociolinguistic backgrounds.

Susan Naomi Bernstein's “Material Realities in the Basic Writing Classroom: Intersections of Discovery for Young Women Reading Persepolis 2 " offers another instance of the self-reflective practitioner thinking back, thinking more deeply, about who the struggling writers in our classrooms say, or demonstrate, they are, as opposed to institutional or programmatic prescriptions of identity. During the Fall of 2005, Bernstein took special notice of five women in her first-year, first-quarter basic reading and writing class at a Midwestern resident college as they were encouraged to make the extracurricular of their lives bear upon their transition to college life. Bernstein uses theories of intersectionality to emphasize the inter-relatedness of all the social, cultural, and other factors that shade the borders of identity for many students, especially basic writers who strive to transcend their marginal status as students in remediation. The female, mostly minority, students of Bernstein's class seemed to feel and express their marginality quite poignantly, as they were among the last cohort of students admitted to the university through open admissions. At the same time, various economic factors of this Midwestern, rust-belt region impacted their sense of options for the future. Bernstein's creative use of Persepolis 2, a graphic novel-which as a genre embeds many intersections, of text, visuality, and nonlinear form-proved highly effective for enabling students to deal with the many interstitial gaps and overlapping layers of their own identities, making possible the construction of meaning and identity simultaneously. Students' roles in determining their course assignments and curriculum were thus of a piece with the generative activity of exploring de-centered subjectivities-their own as well as those of Marjane, the novel's main character.

In another sense, an inquiry such as this, focused on contradicting the notion of any one notion of the basic writer, is largely about asking students to talk back to what's been said of them, or to them, about who they are. The last article of this issue, Maria Ornella Treglia's "Feedback on Feedback: Exploring Student Responses to Teachers' Written Commentary," unequivocably demonstrates that students are constantly registering our impressions of them, interrogating our responses, and responding. In her study of fourteen students from two first-year composition classes, Treglia found that students are ever attuned to teachers' tone and direction as it concerns their writing, such that students see the connection between their teacher and themselves as a relationship, one that requires-as part of the larger act of "thoughtful response"-respect that is 
reflected in the right choice of words. Focused on the type of teacher response students preferred, Treglia found that they most appreciated mitigated response ("I like how you ... . Perhaps you should . ...") versus unmitigated response. And as we hear elsewhere in this issue, students' backgrounds-their past history with writing and the academy, their status as second language learners, as well as their understanding of social norms-are a key element in how students read teachers' comments. Treglia reminds us that responding to student writing is really a "two-way communication" that must include teachers' respect for their students, their awareness of response as "intellectual interaction," and their valuing of students' choices.

Obviously, we have many reasons for keeping the question of "who is the basic writer" framed in the particularities of students as much as possible. We must consider our students-their backgrounds, interests, talents, histories, locations-even as they change as circumstances alter, trends emerge, technology proliferates, and the material conditions for our teaching, and students' learning, seem to shift beneath our feet. It may at times feel overwhelming to constantly consider teaching at the threshold of change and students' continual process of becoming. For now we might let the authors of these pages lead us for part of the day.

\section{-Hope Parisi and Rebecca Mlynarczyk}




\section{Journalism, Poetry, Stand-up}

\section{Comedy, and Academic Literacy:}

Mapping the Interplay of

\section{Curricular and Extracurricular}

\section{Literate Activities}

\section{Kevin Roozen}

ABSTRACT: In an effort to live up to Elaine Richardson's dictum that educators and researchers must address "the total linguistic, cultural, and historical background of the learner" (I9), basic writing scholarship has addressed a wealth of competencies that basic writers bring with them to the university. The literate lives they lead beyond the academy, however, have received relatively little attention in terms of theory, research, and practice. In an article that draws upon text collection, interviews, and participant observations from a longitudinal ethnographic case study of one basic writer's non-school and school literate activities, I examine the synergies between this student's extracurricular journalism, poetry, and stand-up comedy and his literate activity for two undergraduate courses. Arguing that the writer's school tasks are profoundly shaped by an extensive network of non-school practices, artifacts, and activities, I contend that we need to situate the full range of basic writers' literate engagements into our research and teaching.

KEYWORDS: basic writer; extracurricular writing; sociohistoric theory; literate development

In her 2004 CCCC Chair's Address, "Made Not Only in Words: Composition in a New Key," Kathleen Blake Yancey argues for the importance of attending to the self-sponsored writing that populates what Anne Gere refers to as "composition's extracurriculum" (79), those spaces outside of school where writing plays a major role. Yancey's call to bring together "the writing outside of school and that inside" (308) signals a growing awareness that coming to terms with the complexity of undergraduates' growth as writers has increasingly meant attending to the writing students do beyond the temporal and spatial boundaries of the classroom. It likewise points to the

Kevin Roozen is an Assistant Professor of English at Auburn University. His longitudinal ethnographic studies of literate activity focus on the interplay between writing for diverse contexts and the implications such linkages have for the extended development of literate persons and practices. His work has appeared in Text and Talk: An Interdisciplinary Journal of Language, Discourse, and Communication Studies and Kairos: A Journal of Rhetoric, Technology, and Pedagogy. His article "From Journals to Journalism: Tracing Trajectories of Literate Development" is forthcoming in College Composition and Communication. 
small but rapidly growing body of scholarship mapping the richly literate landscape that undergraduates inhabit outside of school and its intersections with school writing (Chiseri-Strater; Fishman, Lunsford, McGregor, and Otuteye; Ketter and Hunter). Two recent fine-grained studies, for example, offer detailed views of undergraduates' concurrent engagement in school and non-school writing and the ways in which extracurricular writing shapes engagement with school tasks. In "Performing Writing, Performing Literacy," Jenn Fishman, Andrea Lunsford, Beth McGregor, and Mark Otuteye draw on school and non-school writing collected from I89 undergraduates at Stanford University to document the interplay between students' extracurricular "writing performances," the "live, scripted, and embodied activities they stage outside the classroom: everything from spoken-word events and slam-poetry competitions to live radio broadcasts, public speaking, and theatrical presentations" (226), and their growth as academic writers. Jean Ketter and Judy Hunter's “Creating a Writer's Identity on the Boundaries of Two Communities of Practice" offers a detailed exploration of how one undergraduate's understanding of what it means to be an effective writer arose from conflicts between her writing for a women's history class and for an internship in the college's public relations office.

Scholarship invested in mapping the non-school writing of basic writers and how it might impact their literate development, however, has been slower to emerge. While basic writing scholarship does indeed have a sustained history of attending to the resources students bring to the university, the bulk of that tradition has focused on students' oral abilities. The number of basic writing teacher-researchers who invite students to "speak themselves into their writing" (Campbell 69) by employing the spoken discourse of their homes and communities outside of school to invigorate their academic writing (Bizzell; Lu; McCrary; Gilyard and Richardson; Smitherman) mark the field's long history of both recognizing and valuing the considerable experiences with spoken language that basic writers bring to the classroom and how those experiences shape their participation in academic discourse. This trend is also reflected in the increasing number of teacher-researchers who weave these hybrid discourses together in their own writing (Gilyard; McCrary; Monroe; Smitherman; Villanueva). More recently, Shannon Carter has drawn attention to the various other kinds of competencies that basic writers possess (e.g., waiting tables, styling hair, playing video games) and the "rhetorical dexterity" they demonstrate as they "read, understand, manipulate, and negotiate the cultural and linguistic codes of a new community of practice (the academy) based on" those abilities (99). 
Still, although this growing body of scholarship lives up to Elaine Richardson's dictum that educators and researchers must address "the total linguistic, cultural, and historical background of the learner" (I9), the emphasis on basic writers' oral and other competencies only underscores the sparse attention devoted to basic writers' extracurricular experiences with writing. Non-school writing, when it has received attention, has largely been understood as disconnected from the literate activities of school. In "Remediation as Social Construct: Perspectives from an Analysis of Classroom Discourse," Glynda Hull, Mike Rose, Kay Fraser, and Marisa Castellano recount an instance where a teacher knows that Maria, a Latina undergraduate struggling in her basic writing course, has written a novel, but doesn't let that awareness trouble her conviction that Maria is the "queen of non sequiturs" (3IO) who may not have the skills to succeed in college. In Writing in an Alien World, Deborah Mutnick mentions that Joe, one of the basic writers in her study, has written and revised two science fiction novels, but characterizes such writing as being separate from the kind he is asked to produce for his college coursework.

Such work highlights the need for fuller and richer accounts of literate development that acknowledge the full range of basic writers' literate engagements. Seeking to fill this gap, this article draws from a longitudinal case study of Charles Scott, Jr., ${ }^{\text {I }}$ an African American undergraduate at the University of Illinois at Urbana-Champaign (UIUC) from the fall of 2000 to the spring of 2005. What initially drew my attention to this student was the incongruity between his placement (and the apparent appropriateness of this placement) in the basic writing course I was teaching and his extensive engagement with and successes in a range of literate activities outside of school. The longer essays he wrote early in the semester for Rhetoric IoI, the lowest composition placement at UIUC, for example, bore numerous traces of his difficulties with marshalling information from multiple sources into an analytic argument. The mechanical aspects of his writing (conventional spelling, punctuation, and grammar and usage) were also problematic. In short, Charles easily fit the dominant image of a basic writer arriving at a four-year college.

Yet while Charles was struggling with the demands of the undergraduate curriculum, his extracurricular literate efforts met with notable success. By mid-semester, four of Charles' stories had appeared in the Daily Illini, the university's student newspaper, his latest in a long string of publications stretching back several years to his high school days working for New Expression, a student-authored news magazine distributed to public and private 
high schools in the Chicago area, and for his high school newspaper before that. Several of these stories had earned him journalistic awards, including the Scholastic Press Association Excellent Sports Story Award and the Kansas City Star Ernest Hemingway Writing Award for High School Journalists. In addition to his success as a journalist, Charles had also been getting his fair share of laughs from the stand-up comedy routine he performed at the university's Open Mic Night, an opportunity for undergraduates to showcase their talents. The third Wednesday of each month would find Charles on stage at the university's Courtyard Café reading from a tattered spiral notebook containing the jokes he had crafted and a host of other written and visual texts (e.g., flyers, brochures, and advertisements) he used in his act. Other nights would find Charles on stage at the African American Cultural Center reading poetry, including some of his own, that he and some friends had collected from Chicago-area high school students and published two years before.

More than five years of observation, discussion, and textual analysis have further complicated this story. What began as an investigation of the disconnect between Charles' placement in a basic writing course (and his apparent fit there) and his extensive engagement with and successes in extracurricular literate practices evolved into a much more complicated, messy, and yet fascinating exploration (Roozen) of the role that non-school literate practices played in Charles' development as an "academic writer." For this study, I observed Charles' extracurricular and curricular literate activities and collected a wide variety of his non-school and school texts over his five years as an undergraduate. I also reached back to the earlier writing he had done both in and out of school before attending the university and explored the interplay between his non-school and school writing. Text collection, semi-structured and open-ended interviews, and participant observation of Charles' school and non-school literate activities were key sources of data. The focus of the semi-structured interviews was to find out as much as possible about the writing that Charles had done, and was currently doing, for school and non-school purposes. During the initial interview I used a protocol of specific questions to elicit information about his early experiences with reading and writing at home and in school. Later interviews ${ }^{2}$ tended to revolve around the texts I had analyzed and any new materials that Charles had provided. My observations included Charles' semester as a student in my Rhetoric Ior class, the series of stand-up comedy routines he performed over his freshman and sophomore years, his semester in an upper-division writing course, a number of interviews he conducted for his 
Daily Illini stories, and the practices and games he coached for an elementary school basketball program.

To explore the relationship between Charles' non-school and school writing, I, a white middle-class male, analyzed this data interpretively and holistically. Hundreds of pages of inscriptions (including rough and final drafts of Charles' curricular and extracurricular texts, sections of interview transcripts, portions of video- and audiotapes, and analytic notes) were read and complete audio- and videotapes of interviews were repeatedly reviewed in order to identify instances in which Charles appeared to be splicing his extracurricular journalism into his school writing or vice versa. Instances of interplay between these literate activities were identified by focusing on what Charles indicated were key practices ${ }^{3}$ in a particular literate activity and then determining whether Charles wove those practices into other writings. After initial accounts of these interplays were constructed, they were reviewed and modified by checking them against the data inscriptions (to ensure accuracy and to seek counter instances) and by working through each narrative with Charles himself in later interviews. During these interviews, I requested additional texts from Charles, and frequently Charles volunteered to provide me with additional texts that he thought might be useful in developing the narrative. It was frequently the case that the initial accounts I had generated either broke down entirely or needed significant modification as a result of closer inspection of the data, identification of additional relevant data, or discussions with Charles during interviews. The accounts were later modified according to Charles' feedback. Final versions of the narratives were shown to Charles to determine if they seemed valid from his perspective.

What started, then, as a short-term case study to explore the striking contrast between Charles' placement in a basic writing program and his success with various kinds of non-school writing grew into a longitudinal study aimed at developing a rich portrait of the relationship between his multiple literate activities. This article elaborates the synergies between Charles' extracurricular literate activities and his writing for two courses during his initial semester at the university. I argue that Charles' performance in these classes is enhanced by an extensive network of practices, artifacts, and activities from his non-school literate engagements.

\section{Far-flung Networks}

I situate my thinking about the relationship between Charles' extracurricular and curricular literate activities in a sociohistoric framework 
that emphasizes the profoundly heterogeneous networks of practices and artifacts that mediate human action. Central to this tradition is the work of Lev Vygotsky, who emphasized humans' use of culturally constructed tools as a means of mediating human action, including mental action. One of Vygotsky's crucial insights was that humans' ability to act with cultural tools did not develop solely within isolated action but rather within networks of other tools employed in other activities. The interdependent relationship Vygotsky described in Thought and Language between "everyday," or "spontaneous," concepts that develop within practical community experiences and the "scientific" concepts that develop within the formal settings of school offers one example of this co-development. Discussing the interplay between scientific and spontaneous concepts, Vygotsky writes:

an everyday concept clears a path for the scientific concept and its downward development.... Scientific concepts in turn supply structures for the upward development of the child's spontaneous concepts toward consciousness and deliberate use. Scientific concepts grow down through spontaneous concepts; spontaneous concepts grow upward through scientific concepts. (IO9)

Even though scientific and spontaneous concepts have different origins, Vygotsky saw their development as inseparably linked: scientific concepts refine spontaneous concepts and raise them to a level of conscious use, and everyday concepts serve as the foundation upon which scientific concepts are built. Thus, for Vygotsky, these "scientific" and "everyday" concepts "are not encapsulated in the child's consciousness, are not separated from one another by an impenetrable barrier, do not flow in two isolated channels, but are in the process of continual, unceasing interaction" "The Development" 365). In essence, scientific concepts develop from their interaction with spontaneous concepts, and, likewise, spontaneous concepts evolve from their interplay with scientific ones.

Informed by Vygotsky's sociohistorical approach to mediated action, Ron Scollon's account of the ontogenesis of social practice in Mediated Discourse: The Nexus of Practice theorizes an even more extensive and heterogeneous network stretching across an even broader range of co-developing activities. Scollon argues that while particular practices are situated in specific sites of engagement, they also "can be linked variably to different practices in different sites of engagement" (5) to form a "nexus of practice," a "network or matrix of intersecting practices which, although they are never perfectly 
or inevitably linked into any finalized or finalizable latticework of regular patterns, nevertheless form a network or nexus" (I6). Each "nexus," then, is comprised of a heterogeneous array of practices-some local and specific and some spun-off from other sites of engagement. Using the social practice of "handing" as an example (think of handing in stores, in religious ceremonies, in surgical operating rooms), Scollon states that "the practice of handing an object to another person may be linked to practices which constitute the action of purchasing in a coffee shop, it may be linked to practices which constitute the action of giving a gift to a friend on arriving at a birthday party, or even to handing a bit of change to a panhandler on the street" (5). In this sense, handing change to a panhandler is not an isolated act but rather is inseparably linked to and informed by various other forms of handing in which a person has engaged. In other words, the particular act of handing we witness in the present is in part the product of a historical and unique network of handings stretching across a range of interactions and far back into the history of the person. Scollon's notion of "nexus of practice" draws attention to the way seemingly disparate social practices are linked across diverse sites of engagement and thus to the interdependent nature of their development. Given persons' encounters with writing in multiple domains, including home, community, school, and the workplace, Scollon's "nexus of practice" (I6) seems an especially fitting lens for viewing literate practice as both situated in "specific purposes in specific contexts of use" (Scribner and Cole 236) and connected across multiple activities.

In thinking about literacy, then, theoretical attention to networks of literate activity foregrounds the heterogeneous and heterochronic array of practices, artifacts, and activities that mediate literate action at any moment as well as the co-development of literate practice-that it develops in relation to rather than isolated from other literate practices and activities. This framework, then, provides a way to understand the relationship between Charles' school and non-school writing. In the two documented narratives below, I partially trace the "far-flung network" (Prior and Shipka II) of extracurricular writing that shaped Charles' literate engagements for Rhetoric IOI and Speech Communication IOI, courses he took during his first semester at the university.

\section{Blending Extracurricular Journalism and Rhetoric IoI}

The first account I will present focuses on how Charles appears to weave a key practice from his extracurricular journalism-specifically his 
use of statistics from survey data-into the literate activity of first-year composition. I begin by outlining Charles' experience with extracurricular journalism, focusing especially on his use of statistics in the writing he did during his high school years for the student-authored news magazine New Expression, and then follow this practice as Charles appears to incorporate it into an essay for his Rhetoric Ior class.

Some of Charles' earliest memories of literacy center around journalism. One especially salient memory involves his great-aunt and great-uncle reading the newspaper at the kitchen table each morning, with Charles waiting rather impatiently for them to hand him the sports section. He particularly enjoyed Jay Mariotti's daily sports column in the Chicago SunTimes "because of his writing style and because he criticizes everyone, except Michael Jordan." "Ever since then," said Charles, "I've wanted to have my own sports column in a major newspaper." ${ }_{4}$ As an initial step toward this goal, Charles enrolled in the journalism course at his high school as soon as he was eligible, a course that centered around writing stories for the school newspaper. After having many of his stories published, one of which would eventually win him the Excellent Sports Story Award from the Scholastic Press Association, Charles decided to seek additional opportunities to deepen his participation in journalism. In March of his junior year of high school, Charles started writing for New Expression, a monthly news magazine written by Chicago-area teens and distributed to eighty-thousand high school students in the city.

Writing stories for New Expression presented Chares with a host of new journalistic challenges. Whereas readers of his fairly small high school paper might have been satisfied with hearing how their track team had performed at a local competition, readers of New Expression expected stories to appeal to and incorporate the views of students in high schools across the entire Chicago area. In order to elicit information from as many students in as many parts of the city as possible, Charles began conducting surveys: "At first, every story I wrote had a survey connected to it. After you conduct the survey and get the results, the story is based on those and you have quotes in there and that sort of helped me get started." Charles quickly developed a process he relied on repeatedly. After identifying a topic that appealed to his readers, he generated a series of questions, typed them on a page of paper, copied it, and passed it out to other writers on the New Expression staff. Using Charles' survey, those writers would then set about polling students at their respective high schools, keeping track of quantitative data as well as recording participants' responses. As the deadline for his story approached, 
Charles combined the reporters' data with his own and tallied the results. The quantitative data these surveys generated shaped Charles' stories in significant ways, particularly in terms of providing the general direction of the story and creating a general framework that Charles could fill in with quotations from the respondents and other information.

The following excerpt from one of Charles' earliest stories for $\mathrm{New}$ Expression, a piece titled "Students Overwhelmed by Homework," provides a good example of how heavily he relied on statistical data:

Sixty-five percent of Chicago public high school students say they get too much homework.

According to a NE [New Expression] survey of 350 students, 95 percent said teachers take homework too seriously, and it should be greatly reduced.

"I spend up to 7 hours a day doing homework, and sometimes I still don't complete it," said Teavena Hatch, a junior at Whitney Young. "I lack the time to study because I am too busy doing written homework. I don't have that much time to watch TV or listen to the radio because these teachers give us so much to do."

Fifty percent of students cited a lack of study time because they are too busy trying to complete homework assignments. (3)

The focal point of the story, that Chicago-area public high school students feel they're given too much homework, is established largely by the statistical data in these opening paragraphs. More statistical data is interspersed throughout the rest of the story in sentences such as "A majority of the students surveyed spent at least 2-3 hours doing homework daily. But nearly 40 percent of students surveyed by $\mathbf{N E}$ last month spent over 4 hours daily doing homework," and "Although 75 percent of students surveyed feel homework is necessary, 6o percent say studying for tests is more important" (3). The story closes with a long list made up entirely of statistics gained from the survey.

As other writers at the magazine recognized the utility of conducting surveys, Charles was given the title of Survey Coordinator and charged with conducting surveys for the entire New Expression staff. ${ }^{5}$ Reflecting on this promotion during one of our interviews, Charles stated, "Our surveys became very powerful. You would see them and it would be like ninety-five percent said this: surveys became the basis of our stories in our newspaper when I started conducting them. So the rest of the year I conducted surveys 
for the whole paper." Using survey data quickly became a crucial element of Charles' repertoire of textual practices for writing the news. He relied on this technique so heavily, in fact, that he found it difficult to write stories without it: "When I was the [news] editor, after I stopped conducting surveys, it was like hard to write stories because I was like 'Oh my God, how am I going to write a story now?' It was scary. It was a challenge to write a story without a survey, because I was used to writing stories with surveys."

Working with statistical data, then, proved a crucial strategy as Charles learned to assemble news stories for New Expression. This tool from his personal repertoire of journalistic practices also became quite visible as he searched for a way to incorporate material from outside sources into his essays for Rhetoric IOI, his first English course at UIUC.

Charles entered the university in the fall of 2000 intent on majoring in broadcast or print journalism. Based on his standardized test scores and a writing sample, he was placed in Rhetoric IOI, the first course in a two-semester sequence designed to address the instructional needs of those students scoring in the lowest bracket on the placement mechanism the university employed at that time. In addition to completing the coursework for this course, students were also required to attend a one-hour weekly tutorial session with the instructor. The class's major writing tasks consisted of four three- to five-page papers in which students were asked to engage with an increasing number of readings from the course textbook. As Charles' Rhetoric IOI teacher, I sensed that he was struggling to use material from the course readings to develop and support his arguments in any significant way. Although he was successful at drawing from his wealth of personal experiences in order to address the paper topics, he seemed reluctant to engage with specific issues in the readings and to incorporate information from the readings into his own essays. In cases where he did refer to the readings, it was usually only after repeated reminders from me or members of his peerreview group that this was a critical aspect of the assignment. Yet, even in these instances, information was incorporated in cursory ways, with Charles only vaguely indexing ideas expressed in the texts or perhaps just tacking a quotation from one of the readings onto an essay's final paragraph.

Charles' first two formal essays indicate the difficulties he had with the text-based writing called for in the assignments. The initial essay for the course, for example, invited students to work from a brief article by Marianne Jennings to analyze the roles and responsibilities of both students and teachers in the educating process. In his first two drafts, Charles neglected to reference the Jennings' piece, despite being reminded by his peers that he 
needed to work closely with her article. The paragraph below, excerpted from Charles' final draft, evidences his effort to engage with Jennings' essay.

In Jennings essay, she made the point that ACT and SAT scores were steadily declining. The problem is that high school teachers are no longer preparing students for college. Teachers main concern today is preparing students for standard test like the ACT and SAT. Simply studying for some standardize test, which is not going to be able to help the student once the student enters college, is not challenging students. It is the teachers responsibility to make sure that their students receive a decent education. This will not happen if student are not challenge with a challenging curriculum. It is the job of high school teachers to prepare students to college. ${ }^{7}$

The opening sentence of the paragraph does contain a loose paraphrase of Jennings' point about declining standardized test scores; however, Charles merely attached this sentence to the paragraph as it already appeared in a previous draft. Rather than attempting to employ Jennings' point to substantially develop and extend his argument about the emphasis on test preparation, Charles just seems to be making a last-ditch effort to minimally comply with the requirements of the task.

Charles' second essay, which invited students to draw from Harold Williams' "Don't Ignore the Arts" and at least one other source to address the function of the arts in education, signaled similar difficulties with writing from sources. Below is the closing paragraph from Charles' third and final draft.

In essence, we must listen to Harold Williams advice. We cannot ignore the arts. The arts are a good thing in life, the other stuff. The arts are essential and life would be boreing without them. The arts enable us to escape from our every day life, which is very hectic and filled with problems. By escaping we can relax, enjoy life, and forget our problems. And by allowing us to escape the arts will enable everyone to have happier more productive lives.

In this excerpt, Charles does incorporate Williams into the conversation after prompting from his peers, but again, as with the paragraph from his previous essay, only by way of inserting a general paraphrase of Williams' overall argument rather than a specific point raised in the reading. As in 
the previous example, Charles merely slid the brief reference to Williams' essay into the opening portion of a paragraph that appeared in his earlier drafts, the first sentence of which originally read "In essence, we cannot ignore the arts."

Given that substantial engagement with sources was a key facet of the course's writing tasks and a key learning objective of the class, Charles was disappointed with his performance at mid-semester. Although passing, his grades on his two first two major papers (C- and $\mathrm{C}$ ) were much lower than he would have liked. Further, he had failed to pass a series of six informal writing assignments that asked students to quote from and then write with and against the course readings using MLA style, which negatively impacted his overall grade. The end comments he received on all of these assignments repeatedly signaled to Charles that he needed to work more closely with the authors we were reading, as did the feedback he received from his peers and me at various points throughout the cycle of drafting, reviewing, and revising these papers.

The third essay Charles submitted, however, represented a substantial departure from his reluctance to engage with the readings. I had fashioned this assignment as a kind of mini-research paper dealing with the issue of sex and violence in mass media and provided the students with a list of readings from the textbook that addressed various aspects of this broad topic. Their "research" consisted of reading and annotating the brief essays from the book, identifying ones that addressed a specific issue, and then using information from those texts to craft an analytic argument. Charles' essay, into which he had incorporated several passages from the readings that were rich in statistical data, represented the first text he produced that I saw as successful in working with the readings. The following excerpts, which rely heavily on statistical data from two readings on the list, appeared in the first draft of Charles' third essay and functioned as a substantial part of his argument. In the first excerpt, Charles weaves together three pieces of statistical data from an essay by Susan Lamson, causally linking the violence viewers witness on television to dramatic increases in homicides and other violent crimes over the past five decades, a link he supports with a contemporary example of the "copy cat" crimes which followed the shootings at Columbine High School. ${ }^{8}$

Hollywood plays a big role in what happens in the real world. According to Susan Lamson, the US. National homicide rate has doubled since the I950s. And it is estimated that exposure to televi- 
sion is related to one-half of rapes, assaults, and other forms of interpersonal violence in the US. Seeing the acts of others on television and wondering if they can do the crime better motivates many crazy people. For example, the Columbine Shooting Massacre. Following the Columbia Massacre there were many copy crimes blamed on the media. Some saw the attention that the students involved in the Columbine Massacre got and wanted the same attention. A recent TV Guide study counted I, 845 acts of violence on average during an eighteen hour viewing time. (Lamson, 273-275)

In the excerpt that follows, Charles deploys statistical data from an Associated Press study cited in Michael Medved's essay to suggest that while a substantial number of Americans surveyed object to the amount of foul language, violence, and sex in movies, Americans in general seem reluctant to turn off their televisions or turn away at the box office.

According to Micheal Medved's essay, "Hollywood Poison Factory", a study conducted by the Associated Press in I990 revealed that 80 percent of Americans objected to the amount of foul language in motion pictures. The study also revealed that 82 percent objected to the amount of violence, and 72 percent objected to the amount of sex. The problem is that people evidently like what they are seeing. How would they know the amount of foul language, sex and violence are in the movies, if they are not watching. They are hypercritics. They are complaining about a problem they are helping to creating. If they stop watching the ex-rated movies and television shows, Hollywood would stop creating as many ex-rated television shows and movies. (Medved, 216)

In terms of the wealth of statistical data, these excerpts from Charles' third essay bear a striking similarity to his early news stories for New Expression. Not only does Charles employ the same attributive tag ("according to") to introduce material from outside sources that he used for his news stories, but he also uses the information from Lamson and Medved to effectively develop and extend the points he is working to make. In these two excerpts, we see Charles citing sources for statistics (with three citations in each paragraph) in the service of making key arguments. Overall, Charles cited statistics six times in this three-page draft and representations of statistics accounted for six out of nine of his citations of sources. Although Charles' 
lingering difficulties with the more mechanical elements of his writing are still very much present in these excerpts, he is certainly incorporating material from sources into his essay in a more substantial manner than he had done in his earlier essays for the course.

If I am correct in concluding that, in this third essay for Rhetoric IOI, Charles was repurposing, consciously or not, a literate practice that he developed from his early experiences putting together news stories as a strategy for engaging with sources, then this narrative traces part of a nexus of literate practice that includes elements of extracurricular journalism as well as first-year composition. Here, an element of creating and compiling surveys, tallying results, and using the data to build news stories is re-deployed across space, time, and genre as a key element of an analytical writing task for first-year rhetoric in what James Gee might refer to as a sophisticated kind of literate "mushfaking," employing practices and discourses from one community as a way to make do when the "real" ones of another community are not available (I3). Charles' third essay, then, might best be understood as an aggregation of literate practices, a combination of some local and specific practices and some repurposed from other literate activities. In blending together elements of extracurricular journalism and those more commonly associated with first-year writing, and perhaps from other literate experiences as well, Charles produced what Patricia Bizzell refers to as a "hybrid academic discourse," a combination of "elements of traditional academic discourse with elements of other ways of using language that are more comfortable for ... new academics" (II). Given that these excerpts from his third essay represent the first time I regarded Charles as successfully writing from and with the readings, I'd argue that repurposing this practice contributed significantly to his success on this essay in particular and toward his proficiency with the kinds of literate practices privileged in the academy in general.

\section{Blending Poetry, Stand-up Comedy, and Speech IoI}

Charles' interest in print and broadcast journalism prompted him to enroll in Speech Communication ror: Principles of Effective Speaking during his first semester at the university, a popular course with undergraduates like Charles seeking entry into the College of Communication's journalism program. Students enrolled in the course were asked to prepare and present a series of four brief informative and persuasive speeches, with an emphasis on strategies for selection and organization of material, methods of securing interest and attention, and elements of delivery. Explaining his decision 
to enroll in the course, Charles stated, "A lot of journalism people sign up for Speech Communication, plus I have a problem speaking in public, and I thought this class would help me." As was the case with his early essays in Rhetoric IOI, Charles struggled with the initial speeches he was required to give in front of the class. While the teacher was fairly satisfied with the content of his speeches, Charles received very poor marks on elements associated with his delivery. He either tended to read straight from his notes with little or no eye contact with his audience, or, when he attempted to rely less on what he had written, he nervously stumbled over his words, filling the pauses between sentences with "um" or "uh," or omitting large portions of his talk entirely. Reflecting on his first speech in the journal he was required to keep for the class, Charles wrote,

The biggest problem of my speech was that I kept saying um. I wasn't fluent. Most of my speech, especially toward the end I was groping for words. I used um and uh more than anyone in the class. I was shocked by how much I used um. I didn't feel comfortable. ... I would consider the areas I need to improve are my deliver, fewer words on my keyword outline, look more at the audience and stop reading from my paper so much.

Problems with delivery affected his second speech as well, this time with even more disastrous results. Charles explained, "On my second speech I just really messed up. I was nervous and then my Powerpoint messed up and things started taking too long, and I then I just didn't use my keyword outline. I finally gave the rest of my speech with my back turned to the audience. That's how bad it was." After the first five weeks, as a result of receiving a D on the first speech and an F on the second, Charles found himself in danger of failing the course. His concerns extended beyond just receiving a failing grade; he also worried that failing Speech Communication IoI would significantly hurt his chances of getting accepted into the College of Communication's journalism program, to which he planned to apply the following academic year as the next step in pursuing his dream of becoming a professional journalist.

Following his second speech, Charles decided to seek help: "Speech Comm was killing me, and I didn't know what to do. I went to the [university's] writing workshop, but they couldn't help me with speaking." Unable to find assistance through curricular channels, Charles began exploring extracurricular opportunities to speak in front of a live audience. Almost 
immediately, he discovered that the campus's African American Cultural Center hosted weekly poetry readings. In order to participate, Charles decided to read some of the poems from the collections of poetry he and others had published years before as members of the People's Poets Project, an organization that Charles founded with some of his co-workers at New Expression. This project had its beginnings in a conversation between Charles and the magazine's poetry editor about their common interest in poetry. Half-jokingly, the two talked about publishing their own collection of poems. Recounting their conversation during one of our interviews, Charles said, "So I was like 'Do you want to write a book? Like, you know, a poetry book?' I was just playing around and he was like 'You know what, that's a good idea."' This conversation was overheard by one of the editorial advisors at New Expression, who encouraged them to pursue their interest in publishing a book of poetry and offered to show them how do it. In April of I999, with the help of the advisor, Charles and his friend established the People's Poets Project, with Charles serving as president and editor. Drawing from the poetry written by its two founding members and students at other high schools, the People's Poets Project published its first book, Days of Our Lives, in August of 1999. This initial book sold two hundred copies, and its success prompted the Project to publish a second one, People's Poets Project: Lasting Impressions, which was published in July 2000 and sold one hundred and ninety copies.

Having these poems on hand positioned Charles to take advantage of the African American Cultural Center's weekly readings, in which he participated each week for the rest of the semester. Explaining his decision to use the poems from the published volumes, Charles stated, "I hadn't written any [poems] since we finished the last book, so I just decided to use those [his poems in the book] since that's all I had. I read other people's poems too." Browsing through the dozens of his poems that appear in these volumes during one of our interviews, Charles admitted that a few were written simply to meet the publisher's minimum page requirement. The vast majority, though, were the product of careful and sustained effort over multiple drafts and driven by his passion for writing. His poem titled "Thank You," which I include below, is a moving tribute to the great-aunt who raised him and his two older sisters after their mother passed away.

You raised six of your own

Then you raised you know who

Something I couldn't possibly have done 
Journalism, Poetry, Stand-Up Comedy, and Academic Literacy

Then you decided to take on three more, including myself

You worked, you worked, and you worked to you could work no more

To put food on the table for your family

You gave it $150 \%$ and more

You dealt with everyone problems

And forgot your own

You forgot you had Sugar and arthritis

You took care of your bad grandchildren

You lectured everyone on their mistakes

You led us the right way

You let me be, and you never told me to shut up

Thank You!

His other poems often dealt with less serious subjects. "Nightmare on $35^{\text {th }}$ Street," for example, reflects Charles' long history as a fan of the Chicago White Sox, his favorite professional baseball team. Charles used the opening stanzas of this poem as an opportunity to playfully point out that the criticisms of Comiskey Park, the Sox's recently renovated stadium, are only symptoms of more fundamental problems plaguing the team:

I love baseball

But I refuse to fall

I refuse to fall from the top of the ball mall

I love my White Sox's

But I hate their stupid new park

How can you build something that's worst that what you're tearing down

It feels like we're in the center of hell

Maybe that's why we no longer have Belle ${ }^{9}$

Maybe that's why the fans have bailed

We must stop blaming the upper deck

Because Comiskey is in a wreck

The upper deck is a small part of a larger problem

Comiskey park is mirage

It looks good on the outside

But its hell in the inside. 
In addition to entertaining and informing his audience and showcasing his abilities as a poet, these two poems and the dozens of others Charles used for the Center's weekly readings helped him to improve his public speaking for his speech communication course in ways that were not available through curricular channels. In participating in these readings, then, Charles was simultaneously creating and maintaining a connection with the university's small African American community and practicing how to use written materials during an oral presentation, maintain eye contact with his audience, avoid using "um" and "uh," and control his nervousness when addressing a live audience.

Seeking opportunities to further develop these abilities, Charles also discovered that the university hosted Open Mic Night, a monthly event that invited students to display their talents in front of their peers. After attending one of the performances, Charles realized that Open Mic Night could provide him with another regular opportunity to develop his public speaking abilities. But, according to Charles, "all the other people get up there and like played the guitar and did music stuff, and music is my one weakness, so that like wasn't a possibility." The next week, Charles attended the African American Cultural Center's annual comedy show, an event where well-known African American comedians from the Chicago area perform a series of stand-up routines for UIUC students, and he realized that he could do something similar for Open Mic Night: "I saw them and I was like, 'Oh, I could do this,' and they gave me an idea for what to do at Open Mic Night." Seeing the comedy show also prompted Charles to recall the short stand-up routine he had put together and performed at the final banquet for the People's Poets Project the previous summer. In order to celebrate the Project's success and the two collections of poetry it published and sold, Charles organized a banquet and assumed the role of master of ceremonies during the festivities. To entertain the audience before the meal was served, Charles jumped up on stage with a microphone to read a couple of humorous bits he had written and some of the poems that had appeared in the Project's collections: "I came up with the jokes. This was the first time I'd ever put together a comedy routine. It went alright. People laughed at the jokes, and then I read [some of] the poems from the book. The crowd loved hearing them."

With the next Open Mic Night a few weeks away, Charles set about amassing and creating material for his stand-up act, jotting pages and pages of rough notes to himself in a red spiral-bound notebook as he watched his favorite television shows such as ESPN Sportscenter, Saturday Night Live, and 
the Daily Show; read the joke pages of magazines like Playboy and Maxim; browsed pamphlets, flyers, and other visual texts posted around his residence hall; elicited jokes from friends; scanned through humorous e-mails his sisters had sent him; and reflected on his own life experiences. Charles also turned to his New Expression news stories as a rich source of material. For example, a passage from one of his sports editorials about drug use in professional basketball that asked whether "athletes had to get so high to get high" was incorporated verbatim into his routine. In another instance, comments from one of his sports columns about Comiskey Park were repurposed into a much longer comedy bit about the various mistakes architects had made while building the structure. It is interesting that Charles developed a bit about his disastrous second Speech Communication IoI speech. A brief note referencing this bit appears in his notebook as \#I3) Bad speech com speech." Working from these rough notes, Charles would select a series of jokes and longer bits to include in his act, determine the order in which they would appear, and then set to work writing them out more fully and neatly in his notebook so that they could be accessed more easily during his act. More elaborate bits, those too long to write out in their entirety, were worked into keyword phrases that signaled the points Charles needed to remember

Once he had about fifteen pages worth of one-liners, knock-knock jokes, impersonations (e.g., Bill Clinton reading a presidential address, Jesse Jackson addressing the issue of voter fraud during the 2000 presidential election, Harry Caray or John Madden doing the play-by-play of a baseball or football game, or Tom Brokaw doing the evening news), personal experiences, and his own observations about life's twists and turns written neatly on the pages of his notebook, Charles felt he had enough material to make people laugh for a ten-minute performance. When it was his turn, Charles would step on the stage and into the spotlight, adjust the microphone, flip to the proper page in his notebook, greet his audience by announcing "Hi. I'm Charles Scott and I'm here to do some jokes for you," and start into his act (see Figure 2). When his routine went well, Charles was able to glance at his notebook every so often and then look confidently out into the audience to smoothly deliver his jokes, make an impromptu observation, or deal with the occasional heckler. Sometimes, though, Charles stumbled through a few of his bits, resorted to reading jokes straight from his notebook, or grew visibly nervous while on stage, any of which might prompt a few boos from the audience. Charles was able to take this all in stride, perhaps because he saw his routines as an opportunity to improve his performance in Speech Communication IOI rather than preparation for a career as a stand-up comedian. As Charles stated, 
"I like the writing and making people laugh, but I'm there to work on my public speaking." Like his weekly poetry readings, then, Charles' comedy performances gave him a chance to practice speaking in public, maintaining eye contact with his audience, and producing an oral presentation from written material.

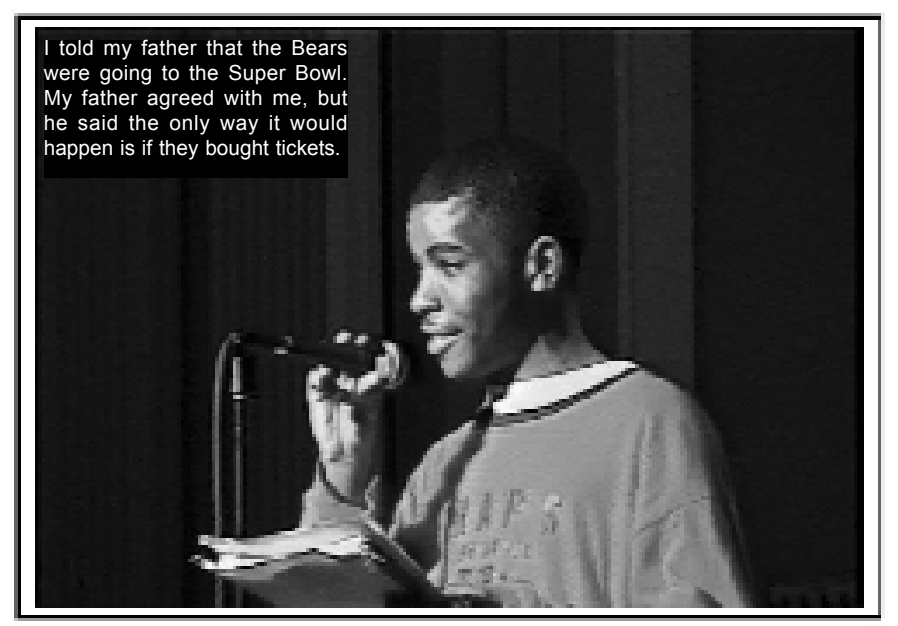

Figure I. Holding his joke notebook, Charles delivers a joke during one of his stand-up performances at Open Mic Night.

After receiving a D on his first speech and an F on his second, Charles earned As on his last two speeches of the semester, which allowed him to pass the course with a $\mathrm{C}$. According to Charles, performing in both of these venues figured prominently in his success at the end of the term. Reflecting on how his poetry readings helped his performance in the speech course, Charles said, "I read the poems there twelve or thirteen times during the semester, and I think it made a big difference for my Speech Com speeches. It helped me improve my speaking a lot. I was always scared at first when I was speaking in front of the class. And after I gave the second speech, the really bad one, being up there reading my poetry helped me to get over my nervousness." Explaining how his stand-up performances enhanced his speeches, Charles stated, "[During my early speeches] I was like real nervous all the time, but after I did the Open Mic Night I wasn't as nervous, so it helped, it helped a lot. If I could have started Speech Com over again, I'd probably get an A opposed to the $\mathrm{C}$ that I got in the class." Charles specifically mentioned that he felt injecting some of the humor from his comedy routine into the 
last two speeches also made a substantial difference: "What helped me a lot was that I used the comedy too. When I gave the last two speeches, my tone was more joking and relaxed, and so I wasn't so serious and uptight." In the evaluations he wrote for class, Charles credited his use of humor with helping him to capture and hold his audience's attention. Critiquing his performance on his fourth speech, for example, Charles wrote,

I showed substantial improvement over my first two [speeches]. I did a good job with keeping the audience interested in my speech. I could tell because the audience was laughing through the entire speech. It was humorous and I wasn't nervous.

In “Real Niggaz's Don't Die," Kermit Campbell notes the way his students deployed the linguistic resources of their homes and communities as they "spoke their way into their [academic] writing" (69). In Charles' case, we see him writing his way into his academic speaking by drawing upon a range of his own extracurricular texts to improve his performance in Speech Communication Ior. Tracing an even more profoundly heterogeneous and heterochronic latticework, this narrative highlights Charles' purposeful and systematic efforts to assemble and coordinate a constellation of texts, practices, and activities. The last two speeches Charles gave in Speech Communication IOI were heavily informed by poetry readings and standup comedy routines performed weeks or perhaps only days earlier. Those performances, in turn, were underwritten by the poems and news stories Charles had written years before and by the host of other texts from which Charles assembled his comedy routine. In addition to the heterogeneous and heterochronic complexity of this nexus, I am also struck by its profoundly multimodal nature. The texts, practices, and activities that Charles acts with have been repurposed not just across time, space, and genre, but across mode as well. The poems originally written for the People's Poets Project's collections, for example, were read aloud from those volumes at the African American Cultural Center, and portions of news stories originally written for the news magazine were later embodied, enacted, and voiced in Charles' stand-up performances.

As Charles delivered his two final speeches, he was leveraging the literate "funds of knowledge" he developed by reading poetry and performing stand-up comedy in front of live audiences. He was, as Moll and Gonzales would claim, "taking full advantage of social and cultural resources in the service of academic goals" (44I). This nexus of extracurricular and curricu- 
lar texts, practices, and activities proved to be a critical one for Charles. He was in real danger of failing the speech course, as his grades on his first two speeches attest, and earning a passing grade in the class was a key first step toward succeeding in the undergraduate curriculum, having a successful first semester at the university, making progress toward a degree, and, perhaps even more importantly, accomplishing a much longer-term goal of being a professional journalist.

\section{Writing His Way into the University}

As we've seen, Charles' extracurricular writing certainly helped him to write himself into the university's extracurriculum. The stories he wrote for the university's student newspaper, the Daily Illini, were read by thirtythousand people each morning. Charles stated that his peers frequently congratulated him when his stories made the front page, and, upon hearing his name, people often responded by saying, "Oh yeah, I've seen your name in the DI." His frequent readings at the African American Cultural Center earned him a great deal of recognition within the university's small but active African American student body. His stand-up comedy routine won him notoriety as well. Following one of his initial performances, our entire Rhetoric IoI class was abuzz with talk of Charles' routine, and for the next few days his classmates all but begged him to repeat some of his material in class. Indeed, his acclaim extended throughout his residence hall and the campus as a whole. Although these extracurricular activities were begun in response to Charles' difficulties in his speech class, he continued to read his poetry and perform his stand-up act long after he'd passed the class. His poetry readings lasted for another full semester, and his stand-up comedy continued through the middle of his sophomore year.

These extracurricular engagements also provided him with the means to inscribe himself into the college curriculum as well. Charles' success in incorporating material from outside sources into his rhetoric essay was supported by his extensive experience weaving statistical data into his news stories for New Expression, the magazine where he acquired valuable experience during his high school years. The successful delivery of his final two speeches was underwritten by his experiences reading poetry and performing stand-up comedy in front of live audiences, which in turn were supported by his poems, news stories, and an array of other extracurricular texts, practices, and activities. These successes are not miraculous; rather, 
they appear to be grounded in the literate practices Charles had employed in the past and in blendings of non-school and school literate practices. This type of blending is not unusual. Is it uncommon for a college student to draw on a personal interest or hobby in writing for a class? Is it unusual for a student writer to draw on popular, religious, or political discourses to enrich the voicing of a paper?

I do need to point out, though, that drawing upon elements of his extracurricular writing was certainly no panacea for all of the difficulties Charles encountered in the university. Despite the linkages he was able to make between his non-school and school writing, problems with the more mechanical elements of his writing continued to mark Charles' journey through the curriculum. His struggles with conventional spelling, punctuation, and grammar, for example, figured prominently in Charles' poor performance in the introductory journalism course he took at the beginning of his sophomore year as he worked toward admission to the university's journalism program. The $\mathrm{C}$ he earned in the course overall probably hurt but certainly did not help when he applied to the program, and he was eventually denied admission. Although greatly disappointed with the rejection, Charles turned once again to his extracurricular writing, particularly his journalism, as a way to pursue a career in journalism. He changed his major to political science, which he saw as another popular major for journalists, and promptly increased the number of stories he wrote for the Daily Illini and also actively sought out additional opportunities for publication. These published stories, in the form of the clips Charles submitted with numerous applications for internship positions, helped to earn him a summer internship with the Duluth News Tribune in Duluth, Minnesota, and a second internship the following summer with the Wausau Daily Herald in Wausau, Wisconsin. Pursuing his dream of working at a larger newspaper after he graduated from UIUC, Charles eagerly accepted an internship with the New Jersey Star Ledger in the summer of 2005.

This portrait of Charles' literate development points to the interdependent nature of these seemingly separate experiences with writing and to the continual, unceasing interaction of extracurricular and curricular literate activities that are so profoundly interconnected that it becomes difficult to see where one ends and others begin. In this sense, understanding Charles' development as an academic writer and speaker means taking into account his experiences with non-school journalism, poetry, and stand-up comedy as well as with Rhetoric IOI and Speech Communication IOI and how such engagements motivate, facilitate, and invigorate one another. Whether 
assembled tacitly or consciously, these densely textured networks that link apparently disparate literate activities are the very fabric of Charles' literate life. Or, one might say that writing, whether for first-year composition or stand-up comedy or any other purpose, is not so much about learning new practices in a new context as it is about coordinating and re-coordinating networks of multiple practices, artifacts, and identities; about reading those diverse currents of literate activity and understanding how they are and might be related, and then writing at the confluences where they meet.

In terms of research into the literate development of basic writers, Charles' story serves as a cogent reminder that the term "basic writer" only applies to a narrow range of literate abilities (see Bartholomae; Horner; Lu and Horner), and thus to how much more we need to know about the literate landscapes basic writers inhabit. Thinking back some seven years to the Rhetoric Ior tutorial sessions and subsequent interviews during which Charles initially introduced me to the richly literate life he led outside of school, I can still vividly recall how powerfully this revelation hit me both as a teacher and a fledgling writing researcher who had just begun a doctoral program in Writing Studies that same semester. I had spent the previous decade teaching writing at a variety of secondary and post-secondary institutions, and it had never struck me that the students in my classes might write for purposes other than school, or even to ask them if they did. In terms of writing research that addressed this issue, I had begun to read a number of studies that focused on undergraduates' school writing, but only a precious few provided even a cursory glimpse of their non-school literate activities. Had it not been for Charles showing me his Daily Illini stories during one of our weekly tutorial sessions, which then prompted an ongoing discussion about the various other kinds of extracurricular writing he was and had been deeply involved in, I would have missed a crucial element in his construction of a literate self.

And yet, merely mapping basic writers' extracurricular literate lives is not enough. In "The Problem and Method of Investigation," Vygotsky cautions against trying to understand complex psychological activity by parsing it into discrete elements and studying them in isolation. He likened, for example, attempts to understand human action by reducing it into isolated parts to adopting

the strategy of the man who resorts to the decomposition of water into hydrogen and oxygen in his search for a scientific explanation of the characteristic of water, its capacity to extinguish fire .... 
This man will discover, to his chagrin, that hydrogen burns and oxygen sustains combustion. He will never succeed in explaining the characteristics of the whole by analyzing the characteristics of its elements. (45)

Charles' story suggests that the same is true of our search to understand how basic writers develop as literate persons throughout the undergraduate years. Like the man who looks separately at hydrogen and oxygen without ever coming to realize the characteristics of water, the researcher who examines non-school and school writing as separate, autonomous activities cannot see and account for how they mutually interact and inform one another. In other words, we can understand basic writers' literate development only by studying "the way literacy actually lives" (Carter II9) in the far-flung assemblages of non-school and school texts, practices, and activities that shape and texture our students' growth as writers. Such a view of literate development not only addresses the richness of non-school literacies, but also does not presuppose either that non-school discourses are relevant only to the extent that they interfere with school discourse or that non-school discourses are true and authentic and hence should simply be valorized.

In addition to underscoring just how hard our students are willing to work to succeed at school tasks, Charles' story foregrounds an all-important fact for basic writing teachers: helping students extend themselves into the privileged conventions of the university is not so much about teaching them new practices as it is about providing them with productive opportunities to negotiate a range of literate engagements, to explore the wealth of literate practices in their ever-expanding repertoires and to consider how these practices might relate to one another. Charles' experiences should encourage us to see that non-school writing has the potential to enrich undergraduates' educational experiences and thus to explore more fully how we can all learn to recognize, acknowledge, and promote the productive weaving together of diverse literate practices. By inviting our students to draw from the range of literate practices and activities they engage in outside of school and to honor the values, beliefs, and interests embedded in them, we encourage them to contribute to, rather than merely reproduce, academic literacy - to make it their own rather than someone else's. And, ultimately, we empower students to write their own way into the university. As a way to create academic environments that value and afford connections to the competencies that basic writers bring to the university, Bizzell, Campbell, and a host of others have asked students to read the hybrid discourses of others and to produce hybrid discourses of their own. We might also invite 
students to trace the far-flung networks of texts, practices, and activities that underwrite their various engagements with writing. We might begin, for example, by asking students to identify extracurricular experiences with writing and map the various resources they draw upon to accomplish those tasks. These assignments might give way to fuller analyses of those elements that are unique to or could be repurposed across various literate activities. Having students attend to the full range of their literate engagements, those in the near and distant past as well as those in the present, gives them the opportunity to locate both synergies and conflicts between them. An awareness of continuities can help students to see that taking up academic practices doesn't necessitate the displacement of the non-school practices in their repertoires. Understanding any discontinuities can throw into high relief the wealth and diversity of literate practices that students have at their disposal and can also help them to challenge and refine their sense of themselves as writers. A knowledge of both the potential synergies and conflicts, I contend, is essential if we are to develop in our students what Patricia Bizzell refers to as "a sort of craft-person attitude toward writing, in which various tools are developed and students learn to deploy them with greater facility" (20).

Attending more closely to the full range of basic writers' experiences with literacy would also help us to avoid misconstruing their writing abilities. As Carter is quick to point out, the CCCC Position Statement on Assessment acknowledges that "one piece of writing — even if it is generated under the most desirable conditions-can never serve as an indicator of overall literacy, particularly for high stakes decisions" ("Writing Assessment"). What Charles' story foregrounds so powerfully is that the same might be said for one particular kind of writing, be it academic or otherwise. To focus on only one type of writing to the exclusion of others is, in effect, to make a sampling error, mistaking performance on a narrow task or judged by a single dimension for the full multi-dimensional range of literacy. In an environment with ever greater emphasis on ever narrower regimes of literate accountability, I hope this picture of literacy as intermingled networks of literate activity, of literate development as a function of a full range of experiences with written and spoken language, reminds us how important it is in human terms to look at the whole person, to support the extracurricular activities as well as the curricular. 


\section{Notes}

I. Charles Scott, Jr., granted permission for his real name to be used when he volunteered to participate in this research in September of 2000 . He continued to grant permission to do so each year as we continued this project and after reading final drafts of conference presentations and an earlier draft of this manuscript.

2. These formal semi-structured interviews were supplemented by dozens of informal conversations Charles and I had during his time at the university. I kept notes on fifteen of these informal conversations, which occurred during chance meetings on campus, in phone and frequent e-mail exchanges, during occasional meals together, and during my observations of Charles as he engaged in a variety of extracurricular activities (e.g., at and following Charles' stand-up performances, driving to and from the basketball games and practices Charles coached).

3. For example, Charles' lengthy and detailed explanations over several different interviews of the crucial role that statistical data had played as he struggled with rapidly producing news stories for New Expression, his promotion to the role of Survey Coordinator at the newspaper, and the copious amount of statistical data in almost all of his early news stories suggested that this was a key practice in his development as a journalist.

4. Excerpts from interviews used throughout this article have been slightly edited. False starts and repetitions have been omitted; punctuation and capitalization have been added.

5. In August of I999, the Chicago-based television broadcast program Concerning Chicago focused on New Expression. As one of the student journalists who appeared on the program, Charles announced that as the Survey Coordinator for New Expression he had handled 4,607 surveys (i.e., individual responses) during the three months he worked at New Expression that year (Concerning Chicago).

6. I do not wish to imply that using survey data was the only strategy Charles used in writing his stories. His later stories for New Expression attest to the expansion of his repertoire of journalistic practices as he came to rely increasingly on intensive and repeated interviews with his sources. 


\section{Kevin Roozen}

7. Throughout this article, I present excerpts from Charles' writing exactly as written, recognizing that it frequently includes unconventional grammar, spelling, and punctuation.

8. Beyond the wealth of statistics, other features from Charles' news stories for New Expression are present as well. The bolding of "TV Guide" in the first paragraph, for example, resonates with the bolding of "New Expression" and "NE" that occurs in all of the New Expression stories Charles gave me.

9. Here, Charles refers to Albert Belle, a former Chicago White Sox outfielder.

\section{Works Cited}

Bartholomae, David. "The Tidy House: Basic Writing in the American Curriculum." Journal of Basic Writing I2.I (I986): 4-23.

Bizzell, Patricia. "Hybrid Academic Discourses: What, Why, and How." Composition Studies 27 (I999): 7-2I.

Campbell, Kermit. "Real Niggaz's Don't Die: African American Students Speaking Themselves into Their Writing." Writing in Multicultural Settings. Ed. Carol Severino, Juan C. Guerra, and Johnella Butler. New York: MLA, I997. 67-78.

Carter, Shannon. "Redefining Literacy as Social Practice." Journal of Basic Writing 25.2 (2006): 94-I25.

Chiseri-Strater, Elizabeth. Academic Literacies: The Public and Private Discourse of University Students. Portsmouth, NH: Boynton/Cook, I99I.

Concerning Chicago. WPWR-TV, Chicago. 4 August 1999.

Fishman, Jenn, Andrea Lunsford, Beth McGregor, and Mark Otuteye. "Performing Writing, Performing Literacy." College Composition and Communication 57.2 (2005): 224-52.

Gee, James. "Literacy, Discourse, and Lingustics: Introduction.” Journal of Education I7I.I (I989): 5-25.

Gere, Anne Ruggles. "The Extracurriculum of Composition.” College Composition and Communication 45.I (I994): 75-92.

Gilyard, Keith. Voices of the Self: A Study of Language Competence. Detroit: Wayne State UP, I99I.

Gilyard, Keith, and Elaine Richardson. "Students' Right to Possibility: Basic Writing and African American Rhetoric." Insurrections: Approaches to Resistance in Composition. Ed. Andrea Greenbaum. Albany, NY: SUNY UP, 2OOI. 37-5I. 
Horner, Bruce. "Discoursing Basic Writing." College Composition and Communication 47.2 (I996): 199-222.

Hull, Glynda, Mike Rose, Kay Fraser, and Maria Castellano. "Remediation as Social Construct: Perspectives from an Analysis of Classroom Discourse." College Composition and Communication 42.3 (I99I): 299-329.

Jennings, Marianne M. “The Real Generation Gap." Perspectives on Contemporary Issues: Readings across the Disciplines. $2^{\text {nd }}$ ed. Ed. Katherine Ackley. Fort Worth, TX: Harcourt College Publishers, 2000. 297-304.

Ketter, Jean, and Judy Hunter. "Creating a Writer's Identity on the Boundaries of Two Communities of Practice." Writing Selves, Writing Societies. Ed. Charles Bazerman and David Russell. Fort Collins, CO: The WAC Clearinghouse, 2003.3I3-29. <http://wac.colostate.edu/books/selves_ societies/>.

Lamson, Susan. “TV Violence: Does It Cause Real-life Mayhem?” Perspectives on Contemporary Issues: Readings across the Disciplines. $2^{\text {nd }} \mathrm{ed}$. Ed. Katherine Ackley. Fort Worth, TX: Harcourt College Publishers, 2 ooo. 273-76.

Lu, Min Zhan. "From Silence to Words: Writing as Struggle." College English 49.4 (I987): 437-48.

$\mathrm{Lu}$, Min Zhan, and Bruce Horner. Representing the "Other": Basic Writers and the Teaching of Basic Writing. Urbana, IL: National Council of Teachers of English, I999.

McCrary, Donald. “Represent, Representin', Representation: The Efficacy of Hybrid Texts in the Writing Classroom." Journal of Basic Writing 24.2 (2005): 72-9I.

Medved, Michael. "Hollywood Poison Factory." Perspectives on Contemporary Issues: Readings across the Disciplines. $2^{\text {nd }}$ ed. Ed. Katherine Ackley. Fort Worth, TX: Harcourt College Publishers, 2000. 2I6-29.

Moll, Luis, and Norma Gonzalez. "Lessons from Research with LanguageMinority Children." Journal of Reading Behavior 26.4 (I994): 439-56.

Monroe, Kelvin. "Writing da Funk Dealer: Songs of Reflection and Reflex/ shuns." College English 67.I (2004): IO2-20.

Mutnick, Deborah. Writing in an Alien World: Basic Writing and the Struggle for Equality in Higher Education. Portsmouth, NH: Boyton/Cook, I996.

Prior, Paul, and Jody Shipka. "Chronotopic Lamination: Tracing the Contours of Literate Activity." Writing Selves, Writing Societies. Ed. Charles Bazerman and David Russell. Fort Collins, CO: The WAC Clearinghouse, 2003. I80-238. <http://wac.colostate.edu/books/selves_societies/>.

Richardson, Elaine. African American Literacies. New York: Routledge, 2003. 
Roozen, Kevin. Mapping Critical Connections: Tracing Undergraduates' Literate Lives. Diss. University of Illinois at Urbana-Champaign, 2005.

Scollon, Ron. Mediated Discourse: The Nexus of Practice. London: Routledge, $200 I$.

Scott, Charles, Jr. "Nightmare on $35^{\text {th }}$ Street." The People's Poets Project: Lasting Impression. Chicago, IL: PP Publication, 2000. I7.

. "Students Overwhelmed by Homework." New Expression 22 (May I999): 3 .

. "Thank You." The People's Poets Project: Lasting Impression. Chicago, IL: PP Publication, 2000. 23.

Scribner, Sylvia, and Michael Cole. The Psychology of Literacy. Cambridge, MA: Harvard UP, I98I.

Smitherman, Geneva. Talkin' and Testifyin': The Language of Black America. Detroit: Wayne State UP, I986.

Villanueva, Victor. Bootstraps: From an American Academic of Color. Urbana, IL: National Council of Teachers of English, I993.

Vygotsky, Lev S. "The Development of Academic Concepts in School Aged Children." The Vygotsky Reader. Ed. R. van der Veer and Jean Valsiner. Translated by Norris Minick. Cambridge, MA: Blackwell, I994. 35470.

. "The Problem and Method of Investigation." The Collected Works of L. S. Vygotsky. Volume I. Ed. Robert W. Rieber and Aaron S. Carton. New York: Plenum Press, I987. 43-5I.

_. Thought and Language. Ed. and Trans. E. Hanfmann and G. Vakar. Cambridge, MA: MIT Press, I962.

Williams, Harold M. "Don't Ignore the Arts." Perspectives on Contemporary Issues: Readings across the Disciplines. $2^{\text {nd }}$ ed. Ed. Katherine Ackley. Fort Worth, TX: Harcourt College Publishers, 200o. I7I-76.

"Writing Assessment: A Position Statement." CCCC Position Statement: A Statement Approved by the CCCC Executive Committee. National Council of Teachers of English. (March I995). <http://www.ncte.org/ about/over/positions/category/write/Io76Io.htm $>$.

Yancey, Kathleen Blake. "Made Not Only in Words: Composition in a New Key." College Composition and Communication 56 (2004): 297-328. 


\title{
Technologies for Transcending a Focus on Error: Blogs and Democratic Aspirations in First-Year Composition
}

\author{
Cheryl C. Smith
}

\begin{abstract}
How are the internet and its online spaces for open exchange changing reading and writing practices, and how can we capitalize on these changes in composition instruction? This article traces the author's experiment with blogging in her first-year writing class and considers how and why blogs help students negotiate the unfamiliar demands of college writing and enter into a more democratic arena for learning where their voices and arguments gain fuller, freer expression. In particular, the article proposes that the space of the blog, which is familiar to many students, opens up possibilities for risk-taking and interactivity that teach important lessons about the role of error and audience response in the composing process. As students rethink and revise their initial ideas, working off one another's comments, they develop more authority as critics with valued opinions and voice and let go of some of their fear about making mistakes that can prevent inexperienced writers from discovering and communicating their best arguments. By embracing the inventive and often messy space of blogs in composition instruction, students and teachers alike can evolve a new view of what it means to learn to write-and write effectively -in academic settings.
\end{abstract}

KEYWORDS: blog; first-year writing; democracy and education; error

With the advent of Web 2.o, the perceived "second generation" of webbased communities, the internet has been transformed from a place primarily to retrieve information to a network for advancing and exchanging it, inviting more open participation, interaction, and creative expression. Computer users have thus moved from working independently toward interrelating in zones like chat rooms, blogs, wikis, and social networking sites. As a result of the widespread use and influence of these Web 2.o platforms, reading and writing practices are changing, especially for the younger generation. Students today write more, but in less conventionally academic ways, than

Cheryl C. Smith is Assistant Professor of English and Coordinator of the Writing Across the Curriculum program at Baruch College, where she teaches writing and American literature. Her recent articles are on Anne Hutchinson, the English department's role in general education reform, and Mina Shaughnessy's legacy. She has an article forthcoming on teaching Rachel Carson's Silent Spring in first-year composition courses and is co-editing the book Transformations in Higher Education: Designing Creative Sites for Teaching and Learning. 
students only a decade ago, and they arrive on our campuses with entirely new skills sets and a new relationship to composition and expression.

Significantly, these new literacy modes and skills are not limited to any one type of college writer. Students at all levels, from basic to advanced, and with all degrees of academic experience, are likely to have had their minds and writing styles impacted by their exposure to technology. The impact is in fact so widespread that N. Katherine Hayles argues we are "in the midst of a generational shift in cognitive styles" (I87). She explains the shift as the move away from deep attention-common in the humanities and characterized by focusing on a single object for extended time-toward hyper attention, "characterized by switching focus rapidly among different tasks, preferring multiple information streams, seeking a high level of stimulation, and having a low tolerance for boredom" (I87). In this age of internet authorship, students are developing complicated writing histories marked by quick connections and the potential for invention. Meanwhile, composition scholars remain deeply invested in studying difference. We highlight the unique needs and abilities of today's students along increasingly nuanced scales of multilingualism, for instance, and the category of basic writer expands to contain our understanding of the changing undergraduate population. Today, technology spans many of these differences. Basic writers are as likely as their peers to come to college with a determining Web 2.o fluency, along with well-honed hyper attention. Thus, in one important respect-in relation to technology and its impact on writing - the differences between students' language use and learning styles can matter less that the differences between our students and ourselves.

Further, all students are equally likely to feel threatened and insecure as they transition into college classrooms and face new academic expectations-and us-for the first time. A common response to such feelings of uncertainty is for students to eschew risk and error and take what they see as the safest route to meet the demands, both real and perceived, of their new environment, even though risk and error are often the best routes to learning. At the same time, teachers can exacerbate student anxieties with their own shortsighted or limited focus on error and correction. Thus, as Mina Shaughnessy argues in Errors and Expectations, the problem of error has as much to do with faculty beliefs and attitudes as it does with student writing. She insists that instead of mechanically correcting (and becoming frustrated by) students' mistakes, educators should pay attention to the actual capacities of students in order to appreciate the origin and meaning of their mistakes and use that knowledge to work with rather than against their abilities. She 
urges us to resist quickly assessing and just as quickly dismissing new students based on poor performance on entrance exams that do not adequately reflect their experiences with language, both in and out of school. Her book thus provides a means by which schools can articulate approaches to error that account for nuances in students' educational and personal histories. In Shaughnessy's hands, error becomes a tool for understanding students and learning to work with them more effectively.

First-year composition courses-small, intimate, intensive, and built around drafting and revision-are particularly well-positioned to use error as a tool for helping students come to terms with its role in writing and learning, and blogs can be instrumental in this process. As an online arena where error, language play, and invention are not only accommodated but actively incorporated, blogs are a surprisingly straightforward way to negotiate the tensions of error. They add a new platform for writing that increases opportunities for student-driven expression, facilitate and energize the processes of collective brainstorming and peer review, stimulate creativity and class community, and supplement more traditional platforms for writing without supplanting or detracting from them. Using a familiar, flexible, lively Web 2.o platform engages new college students in the act of writing as necessarily flawed and changeable yet interactive, powerfully creative, mentally challenging, and intellectually transformative.

To move closer to the ideal of writing as both open to error and intellectually transformative, we have to strike a balance between giving students some access to comfort zones, where they can examine and validate their own experiences and insights, while still daring them to venture beyond the known and familiar. Richard E. Miller talks about this challenge as bringing students to "the edge of the unknown" ("Fear" 37) or "the limits of [the mind's] own understanding" ("Impertinent" I52). For Miller, to operate at these edges and limits is to "encounter your own ignorance" ("Impertinent" I56). Encountering or admitting to our ignorance is not something many of us are particularly eager to do; first-year students, who often feel uniquely ignorant of their new surroundings and expectations to begin with, may especially resist confronting the limits of their understanding, particularly in the foreign land of freshman year. Yet it is precisely this edge of the unknown where most first-year college coursework necessarily lives: in the margin of entry into a new level of learning where beginning college students struggle to articulate their maturing scholarly and social identities.

So how can first-year composition bring students to the edge of the unknown without alienating and losing them, especially those basic writers 
who often face the greatest sense of being out of place, who may feel particularly threatened and insecure in their new environment, and who are most at risk for failure? How do we negotiate the tension between making students feel a comfortable sense of belonging in college and challenging them: getting them outside their comfort zones to a place where they test out new ideas, take risks, ask questions, voice opinions, and interact with people in new ways? Blogs provide a timely answer to these questions. While my main purpose here is to explore the impact of changing literacy practices on higher education-how reading and writing habits are evolving and how and why college educators should tap into new spaces being created for writing-I also want to position first-year writers-my own students-in the context of all the changes in order to advance a pedagogy of blogging as a productive response to these changes. Though the class I will discuss was a typical group of first-year composition students, not a basic writing class, I argue that blogs have a unique potential to free the writer's voice that can especially empower those students who lack confidence in their language skills or are otherwise struggling. Further, by giving participants equal access to a public voice in a forum that is familiar to many young people, blogs create a safe place for risk-taking and error, making it less likely that students will disengage in the face of the challenging transition into college expectations.

\section{Freedom to Make Mistakes: Working on the Boundary of Error}

Mike Rose has another way of talking about Miller's edge of the unknown. Rose figures it as a boundary between the familiar and unfamiliar and argues that we do not have to bring new college students to the edge; they already live there. As they struggle at the boundary that defines the transition into college, they naturally make more mistakes. "Before we shake our heads at these errors," Rose advises, "we should also consider the possibility that many such ... bungles are signs of growth, a stretching beyond what college freshmen can comfortably do" (I88). The challenge with the boundary of student ability and its inherent bungles is learning to see error as a site for productive exploration from which to challenge students and design more effective initiatives, assignments, and activities. That is, teachers have to find ways to critically engage with the errors new students commonly make. In my own first-year classes, I invariably see students make mistakes that I imagine are familiar to many composition teachers. For instance, my students have trouble moving beyond merely reading a text to interpreting its meaning or articulating an informed opinion about it; when they provide 
evidence for an argument, they stop short at summary; they may produce grammatically convoluted prose that reflects unclear or underdeveloped ideas; or their essays may be unfocused or poorly organized. According to Rose, these sorts of missteps are integral to the process of learning: "Error," he says, "marks the place where education begins" (I89).

Students, however, generally strive not to make mistakes. Their goal, understandably, is to get it right. Before they even think about striking out for new ideas, taking risks, and producing less-than-perfect first drafts in order to find unexpected, richer arguments, they tend to revert to what they know: that overly simple summary, for example. At the same time, they waste a lot of time trying to analyze the teacher. What is she looking for? What does she mean by "argue," "analyze," and "provide evidence"? Most importantly, how can I get an "A" on this paper? Students will often try to repeat back the main points of class discussions or mimic an elevated mode of language that, to their minds, seems more "college-like," while their pursuit of a grade keeps them prone to take what they see as the safer, more correct, path.

Unfortunately, the job of encouraging students to take risks is not necessarily facilitated by the dynamics of the traditional classroom. In his influential article, "Composition and the Circulation of Writing," John Trimbur argues that the classroom can be one of the most vexed sites for learning because of the way it reinstates the attitudes and rituals of middleclass family life, which feed directly into students' resistance to error. Trimbur seeks "to transcend the domestic space of the writing classroom" (I9I), where teachers act in loco parentis to regulate and monitor the products of students' composition. In this "domestic space," the student assumes the role of a child called to account for his or her knowledge and the teacher assumes the role of a powerful parent figure poised, however benevolently, to judge. To replace this model, Trimbur promotes an instruction that focuses less on the end product-the student essay-and more on the "complex delivery systems through which writing circulates" (I90). He thus resists a static notion of learning, in which the goal is a final paper that gets turned in for a grade, and instead prioritizes the development and circulation of ideas, which remain open to refinement and change. Trimbur also wants writing classrooms to tap into the channels through which writing circulates in order to heighten students' awareness of how they might use such channels to gain a voice in civic life. He frames this approach as one driven by "a democratic aspiration" for teaching that would encourage instruc- 
tors to "devise delivery systems that circulate ideas, information, opinions, and knowledge and thereby expand the public forums in which people can deliberate on the issues of the day" (I90).

If the challenge to teachers is to create platforms for writing that explore diverse possibilities for making meaning in the public sphere, Trimbur's call seems particularly timely. We now have access to a whole new arena for communication via the web networks that have literally exploded in the eight years since Trimbur published his essay. In this relatively short time, Web 2.o has radically altered the terrain of reading and writing and has real potential to further democratize literacy learning, reaching student writing where it lives: in the new social networks of the internet. Most students have grown up reading and writing to social networking sites, message boards, blogs, and other online forums. Of these spaces, blogs are especially well-suited to classroom use. Educational proponents of blogs see them as highly democratic forums for writing (Nelson and Fernheimer 3; Bloch and Crosby) that highlight rather than elide the importance of the author (Bloch I29) and encourage interactive communication (Ferdig and Trammel I6). ${ }^{\text {I }}$ These qualities that proponents attribute to blogs-free and open expression, promotion of the author, and interactive engagement with an audience-naturally resonate with many compositionists. Because anyone can post and claim a public voice in blogs, they fulfill Trimbur's democratic aspirations for promoting the civic potential of student expression. Even online course management systems like Blackboard or WebCT, which are by nature restricted by a professor's design and controls, do not come close to the expansive potential of blogs, which are open to broad audiences and shaped by both writers' creative impulses and audience response. As flexible, familiar platforms, blogs lend power to the author and may especially empower inexperienced writers who often feel uncomfortable with academic discourse but more at home with internet writing. At the same time, the open-forum quality of blogs defines them as especially democratic, connecting authors with larger audiences engaged in vibrant, ongoing conversations.

Despite all these positive qualities, I was frankly nervous about retooling my familiar composition class around unfamiliar technology. I rarely read blogs, had never written one myself, and had never even visited a site like MySpace. I had one significant advantage on my side, however; my college's Writing Across the Curriculum (WAC) program offers individualized support for faculty who wish to incorporate blogs into the classroom. ${ }^{2}$ Given access to a graduate writing fellow with expertise in blog creation and maintenance, I felt confident enough to forge ahead. After consulting with my writing 
fellow, I opted to have one communal class blog rather than individual or small-group blogs connected to a central class site. Though I could see the creative benefits of multiple, individually-designed blogs interacting with one another, I decided that one communal blog would more effectively develop class community and be a vehicle for enhancing the peer review process that I am always looking to improve. I wanted to create a space for writing that was less imposing, less structured, and less high stakes than a typical writing assignment, a space that would belong more fully to the students. The question of how to give students a sense of ownership over the blog, however, was a tough one, since I still wanted the blog to fulfill certain course goals, particularly those related to thesis development, use of evidence, and peer review. I hoped to encourage playfulness and freedom of expression, but I did not want entirely random, undirected posts. I wanted the blog to lead students toward more reflective, analytical writing. Thus, I decided to make blogs part of a variety of pre-writing exercises I called "meditations," which would lead up to the three longer, formal essays.

While all these goals drove my interest in using a class blog, one of my primary motivations was to free student voice and create a space for exploration-even, and perhaps particularly, failed exploration. I wanted students to try on writerly identities, try out ideas and claims, and test different styles for approaching those claims. For instance, they might at first be irreverent or flippant about their subject and then make an earnest call to action, gauging audience response to each approach. Along the way, they could write as much or as little as they wanted. I also hoped that the blog would combat the problem of stultified prose-tentative essays written solely for external motivation and lacking inspiration-that can be common in student writing. In such timid and frequently flat writing, sentences get long and convoluted, the main subject and verb hide behind drawn-out introductory clauses, and claims tend toward safer, highly general, history-of-the world truisms. Instead of asserting a point or opinion, the author searches for validation in large, empty social "truths" about the condition of man or the ways of the world. Adding to the problem, students are often so afraid to break certain perceived rules of writing-never start a sentence with "and," "but," or "because;" never use the passive voice or first person "I" - that their prose can lack variety and flair. In molding their work to some mythical standard of correctness, neither their voice nor their authentic arguments have much of a chance to emerge. The blog, I imagined, could demythologize college writing, making it more user-friendly.

To accommodate and empower my students' developing voices and 
arguments, I asked them to write a profile of themselves as writers for their first blog. I wanted them to explore and validate their feelings-both good and bad-about writing. I told them their profile should I) briefly outline their past experiences with writing, 2) develop one of those experiences into a more complete image of who they are as writers, and 3) discuss what kind of writers they hope to become. I prompted them to be as specific as possible (though they could be brief), explaining their relationship to writing through anecdotes of actual experiences. Finally, I instructed them to comment on at least one of their classmates' blogs. Here is the first paragraph of the inaugural post:

Write a profile of yourself as a writer? Well, that's an interesting topic for a blog. I believe that when one reads what it is that someone else wrote they will be able to judge exactly what kind of writer he or she is. A person's diction, their observation of the rules of grammar; everything that makes them a writer is displayed most truly in their blogs (or diaries). A report is one thing but when there is no force commanding a person to write they can let their ideas flow without fear of ridicule or judgment. While this is technically an assignment I don't see it as such. I've been spilling my thoughts on blogs for ages and so this is much easier than, say, writing a 4 page analysis on why Raskolnikov isn't a tragic hero. I was just interrupted by my friend who asked me for someone's email. Let me begin by stating this about myself as a writer: I hate being interrupted-my train of thought crashes. ${ }^{3}$

The writer continues for another seven paragraphs, at one point commenting on how his posts to his personal blog, which he shares with "only one other person," often run as long as five pages. He discusses coming to the U.S. from Russia as a child, knowing only one word of English (hello), being told in the third grade that he needed a language tutor to catch up to the other students, and ultimately acquiring such a precocious vocabulary that he was accused by more than one teacher of copying his written assignments. He speaks about using writing as a form of protest in school and the importance of finding a topic that the writer authentically cares about. And though he confidently asserts, "I believe I made it clear that I am a writer," he admits to his foibles: "terrible" spelling and "atrocious" grammar skills. He concedes: "I'm not even sure where to stick semi-colons, despite my using them consistently throughout this blog. In addition, the correct use of commas eludes me. I also find that I ramble to ridiculous proportions." 
I was afraid such a long, detailed, entertaining blog would intimidate the other students, but instead it seemed to inspire them. One posted the following comment:

... Wow. I have never read an essay like this before. An essay where someone just reveals the amazing writer they are. I can actually "see" that you were not writing this for an assignment, but you were writing for yourself. And I definitely agree with you. Your best work only comes when you are not writing to do a report or for others, but when you are writing for yourself. By writing for yourself, you are allowing yourself to actually think about what you want to write. And that is the best part about it. You get to write what you want, not what someone else wants. After reading your essay (I actually read this whole thing. Might have been very long, but it was interesting), I have to say you are an amazing writer. I would not have guessed that you have bad grammar or that you are bad at spelling.

I was immediately struck by the "chatty" style of this comment. It very closely captures the writer's train of thought and his natural quality of speaking, in part by flouting those rules of writing that students are so afraid to break. He begins his passage with an ellipsis, starts sentences with "and," and includes sentence fragments and a parenthetical aside-bold moves, especially for his first college writing assignment. Further, he does not compose an overly general response but instead directly engages with specific details, including the blogger's claims of having poor grammar and spelling and his argument that writing in response to assignments produces less authentic prose because the writer is afraid of "ridicule or judgment." The commenter concurs, adding, "By writing for yourself, you are allowing yourself to actually think about what you want to write," a fairly profound statement about the composing process of thinking and questioning, freewriting, drafting, and revising and its ability to inspire fresh ideas and to clarify thought. In this exchange, then, students were beginning to discuss the dynamics of composition. Further, the stultified prose problem was either nearly gone or being actively interrogated, without any prompting by me. I saw considerably less posturing and more relaxed, natural writing.

Yet while they relaxed on the blog, they took it seriously. They referred to one another's posts as "essays" and wrote to the space earnestly, crafting what indeed amounted to mini-essays with beginnings, middles, ends, and 
solid evidence. At the same time, they seemed quite willing to let their guard down and write more freely than they might otherwise write for school, with little self-editing. While this produced grammatical and mechanical mistakes that might have been edited out of more formal assignments, I found that students' blogs were comparable to their other work in terms of number and type of errors. And the blogs provided an organic forum for discussing issues such as the ubiquitous question of correctness that writers struggle with. For instance, most students confessed in their writing profiles that they did not consider themselves to be good writers-but they did not stop there. They explored specific struggles, shaping our future discussions of what makes writing difficult and what makes it work:

- When it comes to essays, and papers it's difficult for me to write because I tend to feel pressured to write well, instead of writing how I feel.

-... writing has always been my foe, enemy, nemesis, and whatever other bad names you can think of to give it. ... My parents would asked if I'm trying hard enough, but I would simply tell them that I think I'm trying a little too hard.

- I have this bad habit of constantly revising my writing because I'm never satisfied with it. Sometimes I wind up modifying my entire paper. I guess you can say I'm a perfectionist and ... I care too much about what others think of me.

- I was born and raised in America but was put into ESL when I was in first grade. Embarrassing I know. I liked to draw I was never a number person or a letter person. I know what your thinking "she's Asian and she hates math?!” .. I do worry about grammar which is probably the reason why I'm constantly reading my essays over and over, paranoid that I might make some silly mistakes.

- In my junior year . . . an English teacher remarked on my style in class during review for the Regents [standardized tests for high school students in New York] one day. He said "[His] style is good because it's what the grader wants to see, he tells you what he's going to talk about in the intro. Then he analyzes those topics in his body, very clear." I didn't really take this as a compliment. The way in which he said it described my writing perfectly, but I really didn't like that. "Very clear", to me meant boring and predictable. 
Posts like these bring out a number of issues students face in college composition: the fear that writing what one feels will not be good enough, the pressure to be perfect and try "a little too hard," and the perceived tension between clarity and creativity-if it is clear, it can not be original or interesting. I made a list of such issues drawn from students' blogs and we talked about them in the next class session. We thus began to address topics that I planned to focus on throughout the semester anyway, but I could broach them using the students' own insights as the starting point. For example, beginning with the blogs that talked about being overly obsessive about rereading and revising one's work, I asked the class: What is the purpose of revision? How much revision should a writer do? How much is too much? Does revision ever backfire, making a piece of writing less effective? Because discussion began from their own reflections about the often-scary process of writing and everyone had already read and commented on each other's blogs, students had a sense of ownership in the discussion.

This ownership led to the quick development of a coherent class community. Blogging enabled my students to bounce ideas off one another and develop new trains of thought that they might not have considered on their own. It also helped them think about how they communicate in different arenas and to various audiences. My students may have been living on the edge of their college experience, struggling to make the difficult transition into new modes of knowing and communicating, but they were not alone. The blog invited them to collectively voice their concerns, even as it welcomed all unpolished thoughts and first attempts. Connecting their prior academic experiences, as well as their lives outside the academy, with the work they were being asked to do in their first semester of college, students saw their own histories as a legitimate part of college. Blogs encouraged students to insert themselves-their voices and authentic arguments-into developing academic narratives, "mistakes" included.

\section{Shuttling Between Contexts and Toward Student Voice: New Platforms for New College Writers}

Aligning the familiar world of students' lived experiences with the world of school is not a new idea, but technology suggests new ways and reasons for doing it. Students are using internet forums and tools in their personal lives and often understand the dynamics of online writing spaces better than academic ones. Indeed, this is true to the extent that their computer use is shaping their attention spans and how they process and apply 
information. Recently, I presented Hayle's idea of the generational cognitive shift from deep to hyper attention to a colleague, who contended that if computer-literate students can navigate the complexly networked world of the internet so adroitly, then they should be able to make other cognitive leaps, including the kinds of connections we commonly ask them to make in college classes. One context and its moves, that is, should translate fairly directly to the other. Yet, can we assume that students who can scan a web page and navigate its many links should also be able to find good evidence in a reading and use it to argue the implications of their thesis, or that they should be able to intuit a relationship between their biology class and intro to anthropology? Unfortunately, we cannot know whether students can make these leaps unless we bring a more conscious focus on the evolving channels for communication to our classrooms. Most students do not easily move from reading to evidence to analysis to claims without explicit and logical tools for doing so-along with a lot of practice. In fact, they may often fail to see the interplay between their courses until years later. Likewise, they will probably require direct and repeated exposure to new media in classroom settings in order to make thoughtful connections between internet and academic writing. Given opportunities to make these kinds of connections, students will benefit in multiple ways because their new learning is more meaningfully grounded in their own experiences.

As educators bring the new technologies into academic settings to include the purpose of advancing critical thinking for college, they will also provide fair access to knowledge-making, empowering students as cultural critics with valued opinions. First-year students who find little that is familiar in the new standards and norms of college may feel like its discourses and platforms are not really meant for them. Non-traditional or first-generation college students, or those labeled as basic writers or non-native English speakers, may be especially prone to feeling like outsiders. According toJames Paul Gee, the potential to equalize both access to high level discourses and success with them is a key benefit of new technologies. He argues that as technology transforms literacy, it creates opportunities for more innovative, democratic teaching and learning. "We are living amidst major changes," Gee insists, "changes creating new ways with words, new literacies, and new forms of learning. These changes are creating, as well, new relationships and alignments within, between, and among the spheres of family, school, business, and science" (43). The new relationships and alignments affect literacy education because they create "new kinds of people" (43) with new opportunities for advancing their ideas. The networks opened up by Web 
2.O are redrawing routes of access to public expression that precede our classrooms, driving new kinds of students into academia, and challenging us to develop pedagogies that accommodate and empower them as intellectuals who may take part in the dominant social debates.

Though I am heralding the democratic potential of bringing technology into the classroom, I recognize it is no panacea. Much of the discussion regarding technologies in the classroom is optimistic to the point of waxing utopian about the potential they have to transform literacy learning by creating unique spaces for writing that can be made to accommodate students who may have been limited in or even excluded from more traditional spaces. While non-traditional writing and teaching undoubtedly empower some non-traditional writers and learners, the reality of working with the new tech-savvy writing public in our schools is complicated. The spaces of computer-mediated instruction, not unlike the space of the classroom itself, can be vexed by considerable limits. Web 2.0 and blogs are no exception. Students may not share equal access or exposure to internet forums, making it a challenge to fairly make blogging a central component of a class. Meanwhile, teachers may frame blogs in limited ways: as one type of writing representing one type of intellectual, or more likely social, act that accomplishes one type of learning goal, which ultimately remains peripheral to the primary writing of a course. Or, blogs get associated with one course in the curriculum, most likely first-year composition, perhaps because they fit so easily with composition's longstanding practice of informal writing or because they are not regarded as serious enough for most upper-division courses. As we confront the first wave of historic changes to writing and begin to shape the spaces for technology and literacy instruction, we should remain aware of how and where we are fixing and entering into them.

I remain optimistic yet cautious after my own blog experiment, which necessarily included expanding students' range of knowledge-making within academic and public/ internet forums. But it was certainly not without its problems. Early in the semester, for instance, I took students to a public reading by Edwidge Danticat and asked them to write about the event on our blog. The reading was free to students and required; it was integral to our class discussion, since we were reading one of the author's books in conjunction with our freshman text, Tracy Kidder's Mountains Beyond Mountains. Yet most students failed to see any value to the reading and instead complained that the event was "not for them," seemed more suited to an audience of "people over 40," and was "frankly boring." I even watched in horror as one student clamored noisily over a row of chairs to avoid passing me when he 
made an early exit. Of course, students' overall negative impression of the event got full expression on our class blog:

- I was already bored by the time the intro [of the author] was done. ... I can't exactly write about something I was not conscious for.

- I did not fall asleep, although I would have very much liked to. I believe that as a college freshman I cannot sit in halls and listen to readers for entertainment. It's as simple as that. . . . I would much rather go see Rent.

- I just blanked out.

While a handful of students used the blog space to try to engage seriously with the reading, most simply declared it dull and uninteresting. I felt disheartened by the overall class response and began to fear that our blog was becoming a space primarily for venting. It is not so easy to walk that fine line between giving students access to comfort zones, where they can examine and validate their own experiences, and daring them to venture beyond their first responses. I wanted them to feel free to write through their honest reactions, but I also wanted to push them toward the kind of serious, earnest, critical examinations they produced in their first blogs, their writing profiles.

So I posted a blog asking them to speculate on my reasons for taking them to the Danticat reading. What might have been my purpose? How did the reading relate to and add a different perspective on our class work? Then I dedicated a significant portion of the next class to a discussion of the purpose of a liberal arts education, emphasizing the role of events like Danticat's reading in the college experience. As with the blog, however, I faced a challenge in mediating the class discussion. I was unsure how to move students beyond their first impulses and simplest claims toward the kind of reflective, analytical thinking more commonly associated with college-level work without making them feel chastised. The discussion on liberal education seemed to go well overall, but I found that students approached their next couple of blogs with some hesitancy. They seemed to have intuited the message: watch what you say. While setting boundaries on class discussions or writing content is perfectly legitimate, I had unwittingly effected an overly timid attitude in my students. I went from fearing that their attitude was too flippant to seeing it become too cautious. 
To help students reclaim the blog space and their own voices, I quickly restructured the second major essay unit around contemporary music. I thought that since students are often already authorities on the topic, or at least interested in it, the assignment would encourage personal investment and self-expression while also challenging students to do closer readings and more careful, critical analysis of their target text: songs they chose. Their main task was to analyze the lyrics of a song that they felt had an important political message. Leading up to the essay, we read some theoretical and critical pieces on the social impact of music and I played examples of political songs. Then students selected their songs to focus on throughout the rest of the unit, which would include three short meditations, an oral presentation, and a draft and revision of an essay.

Their first charge was to write a blog introducing their songs. I prompted them to embed YouTube videos in their blogs so everyone could listen to one another's choices; our writing fellow prepared a detailed instruction sheet on how to embed the videos. I thought students would struggle with this requirement, but in fact they met it quite easily. For them, the challenging part was to briefly quote and discuss some lyrics that best illustrated their points about the political messages they identified in their songs. Instead of getting into the specifics of targeted lyrics, students took a broad view of the music and its politics. The first blog posted, on "The Cause of Death" by Immortal Technique, typifies this approach:

Immortal Technique is an Underground Hip-hop MC and a political activist. Most of his lyrics focus on socio-political issues such as poverty, religion, and racism. He has collaborated with activist and former death row inmate Mumia Abu-Jamal, and released songs commenting on the George W. Bush administration and its agenda. Songs such as "The Cause of Death" express his views on terrorism and the Iraq War as well as his scorn for the current American government and structure of power. He also discusses the newscast on September II, 200I that spoke of bombs planted on the George Washington Bridge and the subsequent arrest of four non-Arabs that suddenly disappeared from news coverage.

Like most of his classmates, this student chose one of his favorite artists and songs. He immediately made it clear that his song had personal resonance to him as a New Yorker of Arab descent. The assignment thus gave the student the opportunity to project a specialist perspective. Going in, he knew quite a 
bit about his subject and held many opinions on it, and his first blog sticks to what he knew best: the bigger picture of the artist's oeuvre and how the song addresses one particular, personally relevant, political scandal. Yet in focusing on these familiar elements, he fails to attend to the complex lyrics-to take a line and attempt to explain its connotative meaning or examine its symbolic value-as we practiced doing in class with sample songs.

The more interactive spaces of both the blog and the classroom, however, helped nudge the students into their often dense and difficult lyrics. Over the course of the unit, they would come to look at their songs in ways they never had, refine their arguments, and find unexpected ways to communicate their passion for the music. Significantly, students had ample opportunity to get input from classmates and reconsider their ideas because they published their song choices, videos, and commentary a full week and a half before their essay drafts were due. By getting such thorough insight into one another's topics so early in the unit, the class had time to form a more coherent community of researchers and writers. Further, students could respond to each other and offer tips and information in ways I often could not, since I was less familiar with many of their chosen songs. They were also able to give each other encouragement and ideas for their upcoming oral presentations, which many students were dreading. One student's comment on the Immortal Technique blog illuminates this dynamic of encouragement and idea sharing:

I like the song. . . . I especially like the video and its added content about the "business" that war has become, and its a very profitable business unfortunately. I didn't think the song was to offensive. We all curse, it's nothing we haven't heard before. Besides, if you listen closely at the end he says "father, forgive them". Good song choice, looking forward to your presentation.

This comment addresses some of the issues that students worried about when I first gave them the assignment. Could they choose songs with questionable lyrics? How offensive is too offensive? What could they say in their presentation that will not already have been said on the blog; how could they keep people interested? Small gestures of support from their peers gave students confidence and pushed them to reconsider their very familiar subject matter in a new light. For example, by putting the word "business" in quotation marks and pointing out the quick, almost 
throwaway line at the end, the commenter forced the writer away from the big picture that he was defaulting to: the larger social context of 9/II or the politics of Immortal Technique's music overall. Instead, he nudged the writer toward analyzing the lyrics, a much needed push as students entered the essay drafting stage.

While helping students accomplish closer, deeper analysis is a goal of many college classes, today's changing reading and writing habits may be making this goal tougher to meet—or at least challenging us to meet it in new ways. Focusing on one fixed text over a long period of time may prove profoundly boring to minds schooled in the hyper attention that Hayles argues is increasingly common among today's internet-savvy writers, who prefer working in bigger, faster-paced, shifting contexts. My students certainly showed a particularly low tolerance for boredom at the Danticat reading. Perhaps their attitude reflected a negative outcome of the shift toward hyper attention. However, their blog writing also demonstrates the shift's positive side. While we may lament the loss of deep attention in our students, hyper attention has its merits. In particular, it cultivates the ability to attend to a variety of angles at once. Ibelieve my students' approach to analysis reflected their naturally broad, inclusive perspectives. It may have been a stretch for them, but they did write their way toward insightful analysis of their song lyrics; they just got there through a different route: by overlaying their classmates' insights and responses with their own views. Students are developing quick minds that are not only unfocused or restless but also agile and broad, able to account for different angles simultaneously and incorporate external influences and ideas. My experience suggests that as students make the shift into hyper attention, we may be arriving at a pedagogical crossroads for rethinking how we define, assign, and recognize analysis.

At the very least, we have arrived at a moment for rethinking how to most meaningfully engage our students' increasingly agile minds. I found that the contemporary music assignment accommodated how my students processed information and viewed their songs. It was not uncommon for them to write posts that, while relatively brief, were nonetheless packed with information and took multiple slants on their target texts. This approach is evidenced by the following blog that, in only a handful of sentences, covers the social conditions surrounding the song's message, the author's personal feelings about the song, and the artist's place in the world of urban rap:

"American Terrorist" is a song from the highly underrated emcee Lupe Fiasco. It was released in 2006, but it's message spans far 
beyond that date. It is true that history repeats itself and therefore even though many of the lyrics touch on our war in Iraq, it still incorporates everlasting themes such as racism. Lupe brings to the table the fact that religion was once used to seek enlightenment, but now it is used as a reason for war. The main message of the song is how capitalist America profits from other peoples pain and misery. This is hands down one of my favorite songs, I could go through every single line and write how it relates to the world, but i won't because that'll take a lot of time and it would take away the intensity of the lyrics. Instead i will only analyze this line for now: "The ink of a scholar is worth a thousand times more than the blood of a martyr;" such a great line. A person could have a lot of power to persuade through words instead of violence.

This student overtly resists close reading, arguing that "it would take away the intensity" of the message. To his mind, analysis amounts to a destructive parsing of the lyrics that drains the song of its impact, a fairly common bias against close reading that most teachers have heard. When he does briefly attend to one line, he does little more than restate it in his own words. Rather than look closely at the lyrics, he chooses to take a broad perspective on the song, born, I believe, of his relationship to music and information gathering. For our students, contemporary music lives in the interconnected, fast-paced world of the internet, where videos can be watched, musicians' lives and viewpoints studied on personal web pages, and songs played and downloaded. Accordingly, this student's reflection on his song begins with quick references to politics, war, and corporate greed; racism and religion; the song's overarching message; and his personal opinion of the song. He writes about what he knows or has already considered based on his exposure to the world, the artist, and his music. Most students approached their songs in this way, emphasizing the larger social influences on and impact of their songs and their personal connections to them. The blog thus provided a means for bringing in all the multiple streams of information that informed students' understanding of and interest in the music. The sustained close reading of the song's lyrics would come in the later stage of drafting and revising, after everyone received feedback from peers that began to reveal which parts of the song might be unclear or interpreted differently.

Because young people have honed their skills at hyper attention through years of internet surfing, writing, and gaming, they have learned to 
shuttle between ever-changing contexts. Suresh Canagarajah uses the phrase "shuttling between languages" to describe multilingual writers who draw from different experiences and resources when they read, write, and speak. He urges teachers to be aware of and responsive to this shuttling tendency in order to empower student writers. He explains: "Texts are not simply context-bound or context-sensitive. They are context-transforming. It is for this reason that students should not treat rules and conventions as given or pre-defined for specific texts and contexts. They should think of texts and discourses as changing and changeable. Students can engage critically in the act of changing rules and conventions to suit their interests, values, and identities" (603). Canagarajah insists that multilingual writers be allowed to bring their known experiences with language to their writing for school. Further, they should see rules as flexible; depending on the context, a broken rule may not equal an error. Similarly, with Web 2.o, students have developed new fluencies and unique perspectives on how to handle different discourses and their rules. Even those who are not multilingual are nonetheless multivoiced by virtue of their experiences in online writing environments. They have developed an affinity for code switching and discourse combining that teachers should not only embrace but encourage. When students can bring their known modes of expression into the realm of the unknown, it eases some of the dissonance they may feel when faced with the new challenges of college writing. They may even find surprising ways to make academic writing conform to their own experiences. And even if the learning process is more about them conforming to academic literacy than the other way around, students who shuttle between modes of expression learn to make powerful choices and appreciate how those choices define an authorial voice, frame their audience, function differently in different contexts, and create shifting meanings and effects. We must allow students to take risks, stumble into error, and move toward a democratic ideal for learning to write that helps students appreciate how different spaces for authorship function in multiple forums both in and beyond the classroom.

\section{The Democracy of Error:}

\section{Teaching and Learning in the Age of Web 2.0}

For most of our students' lives, the internet has supported both their freedom to write in formats that authentically interest them and their ability to control public access to their ideas, but few undergraduates have seriously pondered the significance of this freedom and control. Peter Elbow asserts: 
"What a huge change the internet has brought to the experience of writing: so many more writers; so much more writing in the world; so much writing for strangers!" (I7I, italics in the original). All this writing in the world circulates on many scales, reaching local, targeted, or special interest audiences all the way up to an international readership; it creates unprecedented opportunities for personal expression, ranging from informational, how-to posts to expression of opinion and protest. How are we in higher education helping students think about the power this opportunity affords? What are we doing to keep up with all these platforms for expression and exchange? What should we be doing?

In her 2004 chair's address to the Conference on College Composition and Communication, Kathleen Blake Yancey wondered if we are keeping up at all or if our methods for teaching writing had "become anachronistic" (302) because of the extent to which technology had altered the terms of literacy. She speculated further by calling into question the fate of traditional English departments: would they, or had they already become, obsolete? Those who lament the bleak future of the humanities generally lay blame on the increasing corporate quality of higher education, along with the professional or vocational interests of students. Yancey, however, ascribes our questionable future to a slightly different cause: our resistance to innovation in literacy practice. According to Yancey, we in English commit a potentially fatal error in failing to keep up with the new writing public that has evolved in tandem with technology: "Never before has the proliferation of writings outside the academy so counterpointed the composition inside. Never before have the technologies of writing contributed so quickly to the creation of new genres. The consequence of these two factors is the creation of a writing public" (298). One crucial way to tap into this new writing public and "all the writing in the world" is to evolve pedagogical innovations for connecting what students know with the distinctive ways of knowing that we value in the academy. They will not only transition to academic literacies more easily but also make better sense of Web 2.o's potential if they experience it in academic spaces that make use of and newly contextualize their familiar spaces for reading and writing. And students and teachers alike will benefit from remaining open to reconsiderations of what constitutes academic writing.

In a recent College English Symposium, "What Should College English Be?" Jeff Rice proposes that we respond to the changes in reading and writing practice by actively refocusing our conception of college English around "Networks and New Media" (I27). His compelling explanation of how net- 
working refigures our relationship to text both highlights an urgent need for change and lends insight to why English departments may well resist it:

In [the] process of making networks, writers, through their work, see themselves connected to information in ways the space on the page does not allow. The space on the page keeps bodies of information (and, thus, bodies) separate. In contrast, networks alter current understandings regarding how learning functions in social spaces. By social, I do not mean "people," or "friendliness," or "mingling." Instead, I mean the ways bodies of information socialize, the ways they interact, or ... associate. (I30-3I, italics in the original)

To put students into networks for writing requires relinquishing some familiar notions about what it means to generate and receive text. Writing in networks like Web 2.o becomes less an individual, isolated act of composition-one that can be read and assessed in traditional ways-and more a connected and communally experienced act. The changes redefine the spaces where writing and literacy education occur and force us to wrestle with some of our most deeply held assumptions about writing and teaching. We in English studies are, by and large, deeply committed to "the space on the page." We are familiar with it. We relish it, slow down and unpack it, assign it to be read and composed, and evaluate it. We appreciate and celebrate its beauty even as we judge its ideological meanings and impact. Our particular brand of appreciation and valuation, however, has a troubling effect. It can lead to teaching that, as Trimbur argues, "foreshortens the delivery system, the circuits of production, distribution, exchange, and consumption through which writing circulates as it takes on cultural value and worldly force" (I94). Now more than ever, with Web 2.0 shifting the ground beneath our students' feet (and if we let it, our own feet), we should guard against the danger of foreshortening the systems and circuits through which people make meaning. Due to the rapid nature of technological advances, students are becoming active writers well before they sit in our classes and tackle our assignments. We have to interrogate the effect their Web 2.o writing practice has on them: their thinking, style, and approaches to college writing. In this time of profound change, it may be especially necessary to open ourselves up to seeing reading and writing beyond the space of the page, through eyes trained on the spaces in between, and as acts of circulation that emphasize both expression and reception, composer and audience, hits and misses.

Perhaps most importantly, in continuing to move beyond a focus on fi- 
nal products held to a limited standard of error, we will come closer to achieving the democratic vision for higher education that Shaughnessy advocated more than thirty years ago-a vision that has not lost its currency. At the end of Errors and Expectations, she predicts that if we manage to "reconcile the entitlements and capacities of [the] new [open admissions] students with our traditional ways of doing things . . . we will be improving the quality of a college education for all students and moving into the realizations of a democracy" (293-94). Similar to Shaughnessy's generation of teachers, we face a new kind of student in our classrooms. Quite unlike their predecessors, undergraduates today have been fundamentally shaped by technology and its means of expression. Their related entitlements and capacities now need to be reconciled to our traditional ways of doing things.

Though it might be her best-known and most significant work, Errors and Expectations is not the only place where Shaughnessy advocates for a more democractic academy that approaches students' ways of thinking and writing with curiosity and respect instead of dismissal and condemnation. In "Diving In: An Introduction to Basic Writing," she lambastes the academy that either flat-out dismisses or attempts to "convert" the most inexperienced writers. She wonders at teachers who fail to see that "competing logics and values and habits ... may be influencing ... students" (236). Such teachers, Shaughnessy claims, harmfully decontextualize the act of writing and/or default to grammar instruction, assuming less experienced writers have nothing to say or can not handle higher order tasks of writing: "Sensing no need to relate what he is teaching to what his students know, to stop to explore the contexts within which the conventions of academic discourse have developed, and to view these conventions in patterns large enough to encompass what students do know about language already, the teacher becomes a mechanic of the sentence, the paragraph, and the essay" (236). For Shaugnessy, choosing to understand students and how to teach them better "demands professional courage" (238) because it forces teachers to both admit what students fail to learn and commit to improving their own knowledge and capabilities as teachers. She argues, however, that such a choice is "not only suitable but challenging work for those who would be teachers and scholars in a democracy" (239). To achieve this democratic vision certainly involves transcending a focus on error and correction, taking into account both "what students know" and "the contexts within which the conventions of academic discourse have developed," and putting greater emphasis on processes and delivery systems and less on results and delivered products. Such moves would facilitate students entering into the conversation on their 
own terms, through which they can muster their own brand of courage to articulate arguments that have personal resonance for them.

It can be scary to write and even scarier for students to confront and even embrace their limits and errors, but having an education means developing an informed voice, which is accomplished through trial and error, risk and reward. We have to encourage students to be bold. In Writing at the End of the World, his study of the value of the humanities and literacy education in the twenty-first century, Richard Miller examines the increasingly high stakes of the conversations in our contemporary world and proposes ways to help students gain a voice in them. He poses the question: "Can secular institutions of higher education be taught to use writing to foster a kind of critical optimism that is able to transform idle feelings of hope into viable plans for sustainable action?" (27). We need to help students engage with problems in such a way that they can find meaningful ways to articulate solutions. For Miller, the transformation of hope into action requires combining "the personal and the academic, the private and the public, the individual and the institution" (3I). Bringing blogs from personal into academic settings exposes the internet's full potential and helps students imagine how they might use the arenas they regularly access on their own in different, more critical ways. They thereby can appreciate more fully the internet's potential to authorize them as informed participants in fundamental social debates. Blogs help us, in Miller's words, "[learn] how to hear what [our] students are saying" so we can teach them to "write in ways that [we] can hear" (48) in the academy.

Without hearing one another in this fundamental way, we cannot possibly reconcile our students' needs and entitlements to our traditional ways of doing things and develop practices that meaningfully respond to contemporary concerns. Evolutions in writing demand evolutions in pedagogy, and the new, alternative writing spaces like blogs encourage us to evolve. For students, blogs provide a forum for collective discussions about and practice with writing through uncertainty. They facilitate interactive reading and responding to alternative ideas. And for teachers, blogs expose the varied and often unanticipated rhetorical moves that students make, shaping the contexts for literacy instruction today. They push us beyond overly simple notions of composition, error, and correctness to more sophisticated, current ideas about how writers think, interact, make meaning, and enter into the important discourses of the day. 


\section{Acknowledgment}

I wish to acknowledge the hard work and creative, courageous writing of my Fall 2007 English 2Ioo students: Kapil Dave Balkaran, Susan Chey, Anthony Ciaccio, Eric Favaloro, Paul Gianatiempo, Colvin Goddard, Manuel Guerrero, Jr., Mairaj Haider, Tedesha Henry, David Iulo, Yasemin Kizil, Anton Leynov, Jericho Manalo, Dan Patsis, Richard Swanson, Andrew Torres, Shaif Uddin, and Linda Yao. Interested readers can visit the class blog at http://cherylsmith.blsci.org/.

\section{Notes}

I. Not surprisingly, users do not unilaterally attribute all these positive qualities to blogs. Steven D. Krause, for instance, used blogs in a graduate class, "Cyberspace Rhetoric and Culture," and found that for his purposes, "Blogs don't do a good job of supporting interactive discussion" (B34). He prefers email lists, which allow replies to go automatically to all participants, and online bulletin boards included in course management sites like WebCT and Blackboard, which "thread" discussions based on individual posts. Depending on how the tool is used-how, for instance, a blog is regulated and integrated into the course-instructors define its usefulness differently.

2. The Bernard L. Schwartz Communication Institute at Baruch College employs a graduate writing fellow dedicated to supporting faculty members who want to incorporate blogging into their classes. I am indebted to writing fellow Luke Waltzer and the Institute for their support.

3. I quote from students' work with their permission; excerpts are quoted directly from the blog with no modifications. 


\section{Works Cited}

Bloch, Joel. "Abdullah's Blogging: A Generation I.5 Student Enters the Blogosphere." Language Learning and Technology II.2 (June 2007): I28-4I.

Bloch, Joel, and Cathryn Crosby. "Creating a Space for Virtual Democracy." Essential Teacher 3.3 (2006): 38-4I.

Canagarajah, Suresh. "Toward a Writing Pedagogy of Shuttling between Languages: Learning from Multilingual Writers." College English 68.I (2006): 689-704.

Elbow, Peter. "Voice in Writing Again: Embracing Contraries." College English 70.2 (2007): I68-88.

Ferdig, Richard E., and Kaye D. Trammell. "Content Delivery in the 'Blogosphere'." T.H.E. Journal 3I.7 (2004): I2-20.

Gee, James Paul. "New People in New Worlds: Networks, the New Capitalism and Schools" Multiliteracies: Literacy Learning and the Design of Social Futures. Ed. Bill Cope and Mary Kalantis. London and New York: Routledge, 2000. 43-68.

Graff, Gerald. Clueless in Academe: How Schooling Obscures the Life of the Mind. New Haven, CT: Yale UP, 2003.

Hayles, N. Katherine. "Hyper and Deep Attention: the Generational Divide in Cognitive Modes." Profession 2007. New York: The Modern Language Association of America, 2007: I87-99.

Kidder, Tracy. Mountains Beyond Mountains. New York: Random House, 2003.

Krause, Steven D. "Blogs as a Tool for Teaching." The Chronicle of Higher Education Supplement: Information Technology (24 June 2005): B33-B35.

Miller, Richard E. “The Fear Factor.” Academe 93.6 (November-December 2007): 33-37.

. "Interchanges: On Asking Impertinent Questions." College Composition and Communication 57.I (2005): I42-68.

_. Writing at the End of the World. Pittsburgh: Pittsburgh UP, 2005.

Nelson, Thomas, and Jan Fernheimer. "Welcome to the Blogosphere: Using Weblogs to Create Classroom Community." Computer Writing and Research Lab (CWRL), Department of Rhetoric and Writing, University of Texas at Austin. White Papers Series. PDF 0030822-I (22 Aug. 2003): I5 pages.

Rice, Jeff. "Networks and New Media." College English 69.2 (2006): I27-33. Rose, Mike. Lives on the Boundary: A Moving Account of the Struggles and Achievements of America's Educationally Underprepared. New York: Penguin, I989. 


\section{Cheryl C. Smih}

Shaughnessy, Mina. Errors and Expectations. New York: Oxford UP, I977.

_. "Diving In: An Introduction to Basic Writing." College Composition and Communication 27.3 (1976): 234-39.

Smith, Cheryl C. English 2roo Class Blog. <http://cherylsmith.blsci. org/>.

Trimbur, John. "Composition and the Circulation of Writing." College Composition and Communication 52.2 (2000): I88-219.

Yancey, Kathleen Blake. "Made Not Only in Words: Composition in a New Key." College Composition and Communication 56.2 (2004): 297-328. 


\title{
Assessment of Generation I.5 Learners for Placement into College Writing Courses
}

\author{
Kristen di Gennaro
}

\begin{abstract}
Higher education settings in the United States typically include several types of writing assessments. Since tests determining students' placement into writing courses are often high-stakes, it is imperative for those who make placement decisions to be knowledgeable of the different types oflearners entering higher education in order to make appropriate placement recommendations. This article investigates the existence of different types of second language learners in the U.S., with particular emphasis on the population currently identified as Generation I.5. After describing several defining characteristics, I draw on results of studies identifying how these learners are different from other L2 learners. I use this exploration to highlight findings that can inform writing program administrators interested in adopting assessment procedures leading to fairer and more accurate placement of $L 2$ students. Such findings could serve as a foundation for a writing placement framework that takes into consideration different types of learners based on their writing performance as well as cultural and educational backgrounds.
\end{abstract}

KEYWORDS: Generation I.5; placement testing; second language learners; writing assessment

\section{Introduction}

Students pursuing higher education in the United States are typically subjected to several types of writing assessments. For example, before they enter a college or university, many future students are required to complete the SAT exam, which now includes a writing component with both multiplechoice and essay sections. Upon entry, students then take placement exams to determine which first-year writing courses are most appropriate for them. In some cases, students are also compelled to take exit exams verifying their writing proficiency before they continue in their coursework. While the practical purposes for each of these testing situations may differ (college applications, course placement, proficiency measures), one feature they have in common is that each of these testing situations serves the purpose of door-opener or gate-keeper (Bachman and Purpura), depending on the

Kristen di Gennaro is the Director of ESL at Pace University's New York City campus, where she oversees writing placement for ESL students and teaches ESL composition. She also teaches in the TESOL and Applied Linguistics programs at Teachers College, Columbia University, where she is pursuing a doctorate in Applied Linguistics with a focus on assessment of second language writers.

(C) Journal of Basic Writing, Vol. 27, No. I, 2008 
outcome. Additionally, in each case test users may consider results from these tests sufficient for making inferences about test takers' writing ability. Such inferences, however, are complicated by the fact that an increasing number of students in U.S. higher education are non-native speakers of English.

Assessment of students' writing to determine their initial placement into writing courses is an area of particular concern, since students' success in college depends in great part on their first-year experiences. Though often labeled placement tests, most of these assessments are actually diagnostic tools, used to identify students' strengths and weaknesses (Bachman and Palmer). Many colleges and universities offer various placement alternatives for new and transferring students, such as first-year composition, advanced composition, developmental or basic writing courses, ESL writing sections, and in some cases, intensive English courses through a non-credit intensive English program. When colleges offer several options for writing placement, they demonstrate sensitivity to the various needs new students have; however, fair and appropriate placement is potentially more complex than even these many options reveal. For example, while it may be relatively easy for placement test readers to identify writers whose first or only language is English (LI writers) from those for whom English is a second language (L2 writers), it is much less simple to distinguish among different types of L2 learners based on their writing alone. Such a distinction among learners is critical, however, to ensure that the courses students are placed into will address their specific needs-both academic and psychological— rather than those of a similar population with a different set of strengths, weaknesses, and educational experiences.

In this article, I first investigate the existence of more than one type of L2 writer in the U.S., placing particular emphasis on the population currently identified as Generation I.5. After describing several defining characteristics, I draw on results of studies examining Generation I.5 students, especially those maintaining that these learners are different from other L2 learners. I use this exploration to highlight findings that can inform writing program administrators interested in adopting assessment procedures leading to fairer and more accurate placement of L2 students. Such findings could serve as a foundation for a writing placement framework that takes into consideration different types of L2 learners. I conclude by noting that the type of research that is currently needed to further our understanding of the differences between Generation I.5 and other L2 learners is that which investigates students' writing performance and preferences in more detail in addition to their educational and cultural backgrounds. 


\section{Different Types of L2 Learners}

Learning to write in any language can be a challenge, since literacy is a type of "technology" (Purves 36) not acquired naturally or effortlessly, but which requires a great deal of attention and time. In this sense, writing and learning to write may be considered similar regardless of whether one is writing in one's first language or a second language. Clearly motivated by the need to contest assumptions that LI and L2 writing are similar beyond a superficial level, in his article "Toward an Understanding of the Distinct Nature of L2 Writing: The ESL Research and Its Implications," Tony Silva summarizes 72 empirical studies comparing LI and L2 writing, finding that "though general composing process patterns are similar in LI and L2 ... L2 writers' texts were less fluent (fewer words), less accurate (more errors), and less effective (lower holistic scores)" (668). In addition to describing more specific differences at both the sentence and discourse levels, Silva notes differences in composing processes, stating that L2 writers planned and re-read their drafts less than LI writers, and were less able to rely on intuition for revising and editing. Given these findings, Silva concludes that "L2 writing is strategically, rhetorically, and linguistically different in important ways from Li writing" (669), findings which thus "have important implications for assessment, placement, and instructional procedures and strategies" (670).

To address the different writing behaviors and products that $\mathrm{L} 2$ learners appear to exhibit, many colleges offer L2 students the option to take writing courses taught by instructors trained in ESL teaching methods. The position promoted by the Conference on College Composition and Communication in their "Statement on Second Language Writing and Writers" (CCCC Committee) is that colleges should offer students a variety of placement options, and inform them of the consequences of these various choices. More specifically, providing students with alternative ESL courses allows students to choose classes where they may feel more at ease, and possibly offers them greater chances of success (Braine). For this reason, at the university where I teach, in addition to ESL developmental writing courses, we offer credit-bearing ESL versions for each of the three English courses required for graduation. While these courses are intended to help L2 students overcome some of the disadvantages they may face in writing in English, such courses cannot serve this purpose if (I) students are not made aware of these course options because they do not self-identify with the ESL label attached to such courses; (2) students are not identified as need- 
ing ESL support through other means, such as placement testing; or (3) the courses fail to address students' actual needs by focusing instead on those of other types of L2 learners. For example, many L2 learners are long-term U.S. residents who enter college with a U.S. high school diploma, and thus they are not required to submit scores from proficiency exams such as the TOEFL (Test of English as a Foreign Language) or IELTS (International English Language Testing System). College administrators are likely to evaluate these students along with Li speakers of English, which may deny L2 learners access to courses and services created specifically for them, as they may not be identified as L2 learners until they have already been placed into courses designed to address LI writers' needs (Fox). In contrast, some L2 graduates from U.S. high schools are too readily identified as L2 learners and then placed into intensive English programs, where they are treated as newcomers to the U.S.-an equally inappropriate result. Either of these placement decisions, which neglect to consider L2 learners' backgrounds and specific needs, may result in students' dissatisfaction with their writing performance and themselves, making them more likely to fail or withdraw from courses and even from higher education in general.

The usual focus on the LI-L2 dichotomy in much of the literature in second language acquisition often disguises the diversity within the population of L2 writers in U.S. higher education. Specifically, many findings from research on L2 writers in higher education are based on the assumption that these learners share the experience of international students who come to U.S. colleges and universities after having completed formal education in their home countries and, by implication, in their Lis. Practitioners who interact closely with L2 learners, however, have come to recognize the large numbers of students in U.S. higher education who have completed some of their secondary, or even primary, education in the U.S.; that is, there are many L2 students who already have extensive experience with English and who may have limited formal experience with their LIs (Bosher and Rowecamp; Harlau, Losey, and Siegal; Matsuda). In fact, students in ESL courses may range from international students who have achieved advanced degrees in their Lis and intend to return to their home countries, to refugee and immigrant students who have settled permanently in the U.S. with their families and may have received very little, if any, formal education in their LIs, as well as long-term resident bilingual students whose linguistic experience is unevenly divided between their LI and L2 in a diglossic-like manner. Suresh Canagarajah adds that, in addition to its reference to linguistic minorities in the U.S., Canada, and Britain, the ESL label can be 
extended to include students learning English for academic purposes in former British colonies, such as India, Nigeria, and Jamaica. This increasing recognition of different types of ESL learners and the contexts in which they study English calls into question the practice of treating them as one group during placement decisions into college writing courses, defined primarily by their non-native speaker status.

\section{Generation I.5 Students: Defining Characteristics}

More than fifty years ago, William Slager wrote about differences between the "foreign student and the immigrant," and the corresponding differences they exhibit in college English courses. Emphasizing that course books and assessments designed for one population of L2 learners are often inappropriate for the other, Slager concludes "that there is a need for such specialized materials, there can be no doubt" (p. 29). More recently, Rubèn G. Rumbaut and Kenji Ima coined the term "I.5 generation" students in a I988 paper about Southeast Asian refugee students, having recognized that L2 students who arrive as immigrants to the U.S. while still in school share certain traits with newly arrived L2 students as well as second generation immigrants (who were born in the U.S.), placing them somewhere in between these two populations. Though Linda Harklau, Kay Losey, and Meryl Siegal note that such a generational definition is inadequate for defining these L2 writers, they adopted the term "Generation I.5" in the title of their I999 landmark book, thus codifying the label for this previously unacknowledged segment of L2 learners whose presence in U.S. institutions of higher education is growing.

Perhaps the one common denominator in most definitions of Generation I. 5 students is that they have completed their secondary education in U.S. schools before entering college, unlike international F-I visa students who arrive in the U.S. having already finished high school in their home countries. While useful, such a definition is problematic, however, since some L2 students may attend boarding schools in the United States prior to college. Indeed, the range of experience in U.S. schools may vary, with some students educated almost entirely in the U.S. K-I2 system and others just finishing their final high school years in the U.S., blurring the boundaries between traditional L2 and Generation I. 5 learners in some cases. As a result of their experience in U.S. schools, many Generation I.5 learners are familiar with U.S. education, teenage popular culture, and current slang, in contrast with most international students, who may require a period of orientation 
and adjustment to these aspects of U.S. higher education (Harklau, Losey, and Siegal; Reid).

Another defining feature of Generation I.5 students-one that is often overlooked-is their experience with their LIs. In fact, as a result of their experience in U.S. schools, Generation I.5 learners have received part, if not all of their formal education in English, while international L2 students have received all of their primary and secondary education in their LIs. Thus, international L2 students have academic literacy competence in their LIs, but Generation I.5 students often do not have such advanced LI academic experience.

Other researchers have viewed the distinction between different types of L2 writers from the perspective of societal bilingualism. Guadalupe Valdés notes that some L2 students are elective bilinguals who, after having spent most of their lives in a society where their LI has majority status, have opted to learn an L2. That is, immersion into an L2 society is a choice for elective bilinguals. Students who come to the U.S. as foreign exchange students, or to study abroad and then return to their home countries, would be examples of elective bilinguals. Other L2 learners, however, are circumstantial bilinguals, forced into the L2 environment as immigrants, refugees, or citizens of post-colonial states, all cases where the Li lacks prestige. Examples of such students would be the children in families who have moved permanently to the United States, often for political or economic reasons, and do not have a choice but to remain in the U.S. for education. Given these examples, it should be clear that elective bilinguals correspond in great part with international L2 students and circumstantial bilinguals with Generation 1.5 students. Furthermore, one can speculate that most international students who have chosen to come to the U.S. to study are from families with higher socioeconomic status than Generation I.5 learners, whose families have often immigrated to the U.S. to improve their financial situation.

Valdés further subdivides circumstantial bilinguals into incipient or functional bilinguals. Incipient bilinguals, who are still in the early stages of L2 acquisition, differ from functional bilinguals, who, despite a great deal of experience with the L2, remain clearly non-native. While incipient bilinguals will probably benefit from continued L2 instruction and exposure, functional bilinguals may reach a plateau in the L2, rendering some types of language instruction less effective for them. Using this framework, recently arrived L2 learners are most likely still incipient bilinguals, while long-term U.S.-resident L2 learners may have achieved functional bilingual status. By this categorization, L2 learners young enough when they arrived to attend 
high school in the United States, yet still considered recent arrivals by the time they reach college, may share some characteristics with international L2 students and others with their Generation I.5 peers. Such overlap confirms that classifying Generation I.5 students solely on the basis of a U.S. high school diploma is inadequate, as some of these high school graduates may still benefit from ESL courses, while others may not.

Finally, many have observed that Generation I.5 learners have acquired the L2 primarily through immersion, often in casual, non-academic situations, which allows them to rely more on oral/aural skills than literacy skills, unlike international L2 students who often acquire the L2 in classrooms and through vast amounts of reading and written grammatical practice (Reid). As a result of these differences in their L2 learning environments, Generation I.5 learners tend to have strong oral fluency and listening comprehension, yet weak writing skills and little knowledge of L2 grammatical terms, in contrast with international L2 students who tend to have strong L2 reading skills and metalinguistic knowledge of the L2 (Bosher; Harklau).

The cultural and linguistic differences outlined here can be used by program coordinators to better identify different types of L2 learners and their corresponding needs in first-year college courses. Fifty years after Slager's article was written, his terms ("foreign student" and "immigrant") appear outdated, but the distinguishable differences between the L2 learners he described are still meaningful. And nearly a decade since Harklau, Losey, and Siegal's seminal volume introduced composition scholars to "Generation I.5," this term has also become somewhat problematic, as it is all too easy for program coordinators and writing instructors to brand students with this label, perhaps assuming that by assigning these formerly unrecognized L2 learners to their own category, their needs are being addressed better. Despite the real possibility of overgeneralization and misuse attached to the term "Generation I.5," the fact that noticeable differences exist among L2 learners in U.S. colleges and universities makes it necessary to discuss the characteristics typical of different groups of L2 learners. We should exercise caution, however, in using this and other labels since such cover terms often lead to stereotyping.

\section{Generation I.5 and the Development of Writing Ability: The Claims}

Concerning writing ability in particular, many claim that Generation I.5 and traditional international L2 students make different types of sentence-level and discourse errors. For example, noting that Generation 
I. 5 students tend to be "ear" learners, Joy Reid states that they form grammatical and vocabulary rules based on how they have heard the L2 spoken and, as a result, their use of the $\mathrm{L} 2$ often includes errors in inflectional morphemes, such as verb endings and plural markers, as these are not audibly salient nor do they interfere with comprehension during oral interaction. Other common errors are a result of inappropriate use of idiomatic expressions, both in terms of form and differences in register. "Eye" learners, on the other hand, a characteristic more typical of international L2 students, tend to have more experience with grammatical rule-learning and reading skills, but lack practice with listening and speaking skills due to their lack of experience using the L2 for communication with native L2 speakers. Typical writing errors by these L2 learners are the use of false cognates, incorrect word order, applying plural inflections to adjectives, and other errors as a result of interference from the LI (Reid). Given their advanced LI writing ability, international L2 students may be able to transfer composing skills and strategies from their LI writing, but show signs of lacking linguistic control when writing in an L2. Generation I.5 students, on the other hand, may not have advanced composing skills and control of the linguistic code used in academic writing, yet their fluency in the L2 can compensate for some of these shortcomings.

As Reid points out, many students' writing performance may not reflect typical errors or behavior from only one of these two sets, but a combination. It would be more accurate, perhaps, to describe different ESL students and their writing abilities as falling along a continuum, or series of overlapping continua, one for the progression of writing development in typical international L2 students, another for mainstream Li students, and Generation I.5 students' development overlapping each of these for various characteristics. Placement testing that aims to assess L2 students' writing and identify students' strengths and weaknesses for accurate placement decisions must account for these major differences in L2 learners' development.

\section{Empirical Research Findings}

The above observations about Generation I.5 students' strengths, weaknesses, and overall characteristics are helpful as a point of departure, but if writing program administrators wish to argue that their placement decisions are both accurate and fair, they need empirical evidence supporting

their recommendations. Indeed, many of the assertions above concerning students' writing ability appear to be based mainly on anecdotal evidence 
or impressionistic claims, yet these putative differences are often accepted without question. In recent years, researchers have begun to collect empirical evidence as to the differences between Generation I.5 and international L2 writers.

Most of the empirical research to date concerning these differences is qualitative in nature, often based on case studies. For example, Linda Harklau conducted a year-long ethnographic case study of three ESL students as they transitioned from a U.S. high school to a community college ESL program. Based on interviews, observations, and students' written work, Harklau noted that the same ESL students who had achieved success in high school, when placed in ESL courses at the college level, found themselves both insulted and at a disadvantage, making it difficult for them to succeed. The curriculum in many college-level intensive ESL programs is primarily oriented toward international L2 students' needs, with assignments and texts reflecting the assumption that students are newcomers to the United States who need orientation to U.S. education and culture. As Harklau notes, U.S.-educated students may find the content in such courses irrelevant to their needs as well as offensive in that it suggests they are cultural novices. Furthermore, many of these courses tend to involve grammar exercises and the discussion of English-language structure in metalinguistic terms, favoring international L2 students who have studied English from this perspective while putting U.S.-educated "ear" learners at a disadvantage, and potentially making them feel less secure of their knowledge of English. While it is difficult to generalize from three case studies to a larger student population, U.S.-educated ESL students have a vast knowledge of the English language, but it is different from the type of linguistic knowledge that international L2 students have acquired. To avoid marginalizing one of the other type of ESL learner, writing placement should take into account the different backgrounds of ESL learners.

Another qualitative study, more directed at students' linguistic needs, is Jan Frodesen and Norinne Starna's case study including detailed profiles of two students who had completed at least part of their high school education in the U.S. Focusing on students' errors, they noted that one student's writing exhibited few, yet systematic errors, and greater fluency than typical international L2 students, while the other student made many more errors, mainly in word choice and sentence structure. Such comparisons indicate the need to examine students' linguistic profiles in more detail in an attempt to discover the kinds of errors that might distinguish L2 students still in incipient stages of L2 development from those who are functional 
bilingual writers (Frodesen and Starna). As with most case studies, the results are not easily generalizable to larger populations, but this study illustrates the potential for discovering developmental patterns found in students' writing and the potential for using observations of such patterns to make appropriate placement decisions.

A few quantitative studies in this area of research also exist. Susan Bosher and Jenise Rowekamp conducted a study examining a series of factors to see which were most relevant for immigrant students' success in U.S. higher education. Noting that some immigrant students may be more like international students in some respects, they divided their 56 study participants into two groups based on whether they had completed high school in their home countries or the U.S. Data were collected on participants' length of residence in the U.S., years of schooling in the U.S. and in their home countries, and their scores for three different sections of the Michigan English Language Assessment Battery (MELAB): objective, listening, and composition sections. Not surprisingly, participants who had completed high school in their home countries scored significantly higher on the objective section of the MELAB, while those who had completed high school in the United States scored significantly higher on the listening section. Surprisingly, however, there were no significant differences in the composition scores. The background factors and standardized test scores were then compared with participants' GPAs for their first, second, and third years of college (the dependent variable), and a regression analysis was run with the significant factors: years of schooling in the home country, years of schooling in the U.S., length of residence in the U.S., and objective score on the MELAB. The results showed years of schooling in the home country to have the highest positive correlation with first-year GPA, with objective score on the MELAB the next significant factor. These same factors correlated positively with second- and third-year GPAs, with objective MELAB scores a better predictor than years of schooling for these future GPAs. Conversely, years of schooling and length of residence in the U.S. had significant negative correlations with first-, second-, and third-year college GPAs. Bosher and Rowekamp conclude that years of schooling in the home country and objective score on the MELAB are good predictors of academic success in U.S. higher education. Several important implications of these results are relevant for those who make placement decisions for L2 students in higher education: oral L2 proficiency is insufficient for determining if students need further ESL support; years of schooling in students' home countries could serve as a useful indicator of potential success for L2 students; years of schooling in the 
U.S. may actually put Generation I. 5 students at a disadvantage; and despite obvious differences in other skills, composition scores may not be detailed enough to reveal students' specific strengths and weaknesses.

In a similar study, motivated by their observations of changing score patterns among L2 students entering a college intensive English program, Dennis Muchinsky and Nancy Tangren collected data including students' scores on the Michigan Test of English Language Proficiency (MTELP), the Michigan Test of Aural Comprehension (MTAC), and a 30-minute holistically scored composition, as well as passing rates upon completion of the program. Results showed that the thirteen students who had completed high school in the U.S. scored significantly higher on the MTAC, or aural component, than the other sections of the exam, while the nine students who had completed high school in their home countries scored similarly on both the MTAC and the MTELP, and scored significantly better on the MTELP section than the U.S.-educated cohort. The U.S.-educated students appeared to score higher on the MTAC than the international students, but the difference was not significant. Upon completion of the ESL program, the students who had completed high school in their home countries still scored significantly better on the MTELP than the U.S. high school graduates, and also better on the MTAC section, though not significantly so. In other words, the home country graduates maintained a lead over the U.S. graduates in the MTELP portion of the test, and may even have surpassed them for the MTAC section. Though the number of participants was small, which probably contributed to the lack of significance in score differences, Muchinsky and Tangren believe these results provide evidence that the MTELP is a better predictor of academic success than the MTAC, and that U.S.-educated students who perform well on the MTAC have inflated overall placement scores not representative of their actual academic proficiency. Specifically, students who have completed their education in their Lis are at an advantage in college classes, even with noticeably weaker L2 skills in certain areas, because their familiarity with context-reduced academic language is greater than that of Generation I.5 students, whose skills are stronger with context-embedded language.

In their analysis of the composition component, Muchinsky and Tangren found that the essays by U.S.-educated students were the longest, but the international students had the highest scores. These results support the claim that Generation I.5 students are more fluent language users, yet not necessarily well prepared in the language of academic writing. Such observations bring into question the role of fluency, or length, in measures 
of writing ability, as this feature may not correspond with strong academic language proficiency.

\section{Implications for Placement Testing}

The studies described above provide evidence that Generation I. 5 students may be at a disadvantage if placed into programs designed to address international L2 students' needs, and vice versa. The qualitative studies reveal that ESL courses designed to assist L2 learners may actually marginalize certain learners already familiar with U.S. culture. One study also provides limited, but empirical evidence as to noticeable patterns found in students' writing performance. The quantitative studies emphasize that, despite their fluency, advanced oral/aural skills, and overall familiarity with English in many situations, Generation I.5 students tend to lack the academic language skills that their international peers have acquired in their LIs.

Several implications for the assessment of students' writing ability for placement purposes can be drawn from these studies:

- Academic writing proficiency is a specific type of language ability not necessarily acquired through immersion in an L2 culture.

- A U.S. high school diploma does not automatically exclude Generation I.5 learners from potentially needing English language support in college writing courses.

- The needs of Generation I.5 students differ from those of international L2 students.

- $\quad$ The writing of Generation I.5 and international L2 students may exhibit different types of errors.

- $\quad$ Fluency, as measured by length in timed writing tests, is not necessarily a useful indicator of academic writing ability.

- Exams that include an oral/aural component may mislead test users concerning students' academic writing ability.

- Information about length of residence in the U.S. and years of schooling in the LI may be helpful for placement readers and instructors to identify the types of strengths and weaknesses L2 students are likely to exhibit.

Those who make decisions concerning L2 students' placement should know that certain types of assessments or scoring criteria may favor either 
international or Generation I.5 students and may not be useful indicators of students' strengths and weaknesses in college writing courses. Since Generation I. 5 students often do not self-identify with the ESL label-indeed, they may even resent such labeling, as Christina Ortmeier-Hooper discovered during her case studies of three Generation I.5 students-it is necessary to examine students' writing in order to make accurate placement decisions. At the same time, results from writing samples alone may not provide test users with certain critical information about L2 learners, such as length of residence in the U.S. and years of schooling in the LI, in order to offer them the most appropriate placement options. Until future empirical studies can identify more precisely the types of differences typical of each population's writing performance (if such reliable indicators indeed exist), test users may need to rely on questionnaire data, in addition to writing samples, to assist them in making appropriate course placement decisions. To clarify, I am not suggesting that programs offer separate tests to different groups of students, as this is neither practical nor necessary. I am, however, suggesting that it is reasonable for program coordinators to ensure that students' writing is evaluated by readers who are aware of and sensitive to the types of strengths and weaknesses that likely correspond with students' diverse backgrounds. An additional suggestion is that programs consider adopting a term other than "ESL" for L2 learners in college writing courses, as this term tends to exclude U.S.-educated L2 students. Perhaps a course label emphasizing writing in a second language would be more appealing to all L2 students (Costino and Hyon).

I believe the findings cited here offer an initial framework for placement test designers to consider and build on when selecting and creating instruments for placing different types of L2 learners in college writing courses. I recognize, however, that not all programs offer students a wide range of placement options, including sections taught by ESL-trained professionals. In cases where placement options are limited, first-day in-class diagnostic writing assignments can be especially useful. Instructors can use this occasion not only to examine students' writing abilities, but also to determine if students are more similar to international $\mathrm{L} 2$ or Generation I.5 students in order to develop realistic expectations and select appropriate teaching materials. Such information can even be part of the writing prompt. For example, after reading "Second Language Writing Up Close and Personal: Some Success Stories" (Silva et al.), which includes contributions by five L2 writers on their experiences writing in a second language, I developed a writing topic I often use on the first day of class, which asks 
students to write about their own writing experiences in a type of writing autobiography (see Appendix). Not only do students' responses reveal useful information about their backgrounds, the topic also lends itself well to both LI and L2 writers, and thus can work in classes including all types of learners. Furthermore, since students' experiences with writing will continue to develop during the course, this topic can also be adapted for repeated use throughout the term, resulting in a self-revised multi-drafted essay useful for different assessment purposes later in the course, as described by Janine Graziano-King in "Assessing Student Writing: The Self-Revised Essay."

\section{Directions for Future Research: A Closer Look at Performance Data and Student Preferences}

While several studies support claims of the existence of two distinct types of L2 writers in U.S. higher education, what is currently lacking is a more precise description of each group's writing performance. For example, Generation I.5 students' writing appears to be more fluent and exhibit grammatical and lexical errors based on their having acquired English primarily through spoken input, yet the research confirming these linguistic analyses is scant. If writing program administrators are to identify learners based on developmental patterns in their writing, they need more specific information concerning students' linguistic performance.

The research described here also suggests it is important to collect background data in order to distinguish types of L2 learners. In an ideal situation, placement assessments would include several types of information in addition to writing performance data. In reality, however, such additional information may be unavailable, misleading, or merely insufficient. For example, in programs where large numbers of students are tested at the same time, and where test administrators require immediate results, it is not possible to include interviews or other types of oral components in order to determine course placement. And while short questionnaires may provide useful information, self-reported answers are not always reliable. Moreover, if learners react as one of the students in Ortmeier-Hooper's study, they may even conceal their L2 status as a way of rejecting the ESL label and its connotations. Finally, in many cases, those who evaluate writing exams and make placement decisions may not have access to questionnaire data.

For these reasons, future investigations of L2 learners' writing need to provide more complete descriptions of each group's writing performance in addition to their personal and academic profiles. Specifically, research com- 
paring writing performance with other sociolinguistic and background data, to see if specific patterns in writing performance exist for each group, would be particularly useful. If such patterns are discernable, the results could greatly affect writing placement procedures, potentially making it possible for those who only have access to students' writing performance without background data to make more accurate recommendations. On the other hand, if future research concludes that differences observable only in writing performance data are not as consistent or accurate as many believe, this would confirm the need for writing placement exams to include additional instruments inquiring about learners' background information, such as their academic and life experiences in addition to their writing performance, in order to distinguish between these two types of learners (Harklau).

Finally, given the negative connotations that college courses labeled "ESL" have unfortunately acquired, it would also be useful to conduct more research concerning students' preferences, if not for placement decisions, then for the types of practice they see themselves as needing, along with their opinions about what to call courses created for college L2 writers. For the many programs able to offer separate credit-bearing "ESL" sections to L2 writers, finding a label inclusive of all types of L2 learners, especially U.S.-educated students, is a real problem. For those programs whose enrollments or student populations do not warrant creating separate ESL sections, the most pressing need may be to increase awareness among instructors about the distinctive nature of L2 writing (see Silva) and the characteristics of Generation I.5 learners (see Harklau, Losey, and Siegal) to assist instructors in establishing realistic expectations for these learners' writing ability, especially in testing situations.

\section{Conclusion}

In this article, I have highlighted what I consider to be principal implications to be drawn from the existing research on Generation I.5 learners with regard to writing assessment and placement in college writing courses. It is not enough for writing program administrators to recognize the existence of different types of L2 learners. We must also adopt or design assessment procedures to help us identify these different groups of learners if we are to provide them with the most appropriate placement options, ensuring that our tests serve as door-openers rather than gate-keepers. Additionally, I emphasized the need for more empirical research based on analyses of students' writing performance, such as that by Frodesen and 
Starna, which could confirm or refute claims regarding the strengths and weaknesses typical of Generation I.5 learners based on their writing alone. Such research could also contribute to our understanding of how writing ability develops in different types of L2 learners. Greater knowledge of the developmental nature of writing ability across different learners could assist writing program administrators in identifying students' needs based on where they may fall along a learning continuum, and also assist writing instructors in selecting assessment and instructional activities for the range of students in their classes.

\section{Acknowledgment}

I would like to thank Monika Ekiert, Tom Henthorne, and Jim Purpura for their comments and suggestions on early drafts, and the $J B W$ reviewers and editors for their valuable feedback and assistance in bringing this article to publication.

\section{Works Cited}

Bachman, Lyle F., and Adrian S. Palmer. Fundamental Considerations in Language Testing. Oxford: Oxford UP, 1996.

Bachman, Lyle F., and James E. Purpura. "Language Assessments: Gatekeepers or Door openers?” Ed. B. M. Spolsky and F. M. Hult. Blackwell Handbook of Educational Linguistics. Malden, MA: Blackwell, 2007.

Bosher, Susan. "The Composing Processes of Three Southeast Asian Writers at the Post-Secondary Level: An Exploratory Study." Journal of Second Language Writing 7.2 (1998): 205-4I.

Bosher, Susan, and Jenise Rowekamp. "The Refugee/Immigrant in Higher Education: The Role of Educational Background." College ESL 8.I (1998): 23-42.

Braine, George. "ESL Students in First-Year Writing Courses: ESL versus Mainstream Classes." Journal of Second Language Writing 5.2 (I996): 9I-IO7.

Canagarajah, A. Suresh. "Understanding Critical Writing." Matsuda, et al. $210-24$.

CCCC Committee on Second Language Writing. "CCCC Statement on Second Language Writing and Writers." College Composition and Communication 52.4 (200I): 669-74.

Costino, Kimberly A., and Sunny Hyon. "A Class for Students Like Me: Re- 
considering Relationships Among Identity Labels, Residency Status, and Students' Perceptions for Mainstream or Multilingual Composition." Journal of Second Language Writing, I6.2 (2007): 63-8I.

Fox, Janna. "Rethinking Second Language Admission Requirements: Problems with Language-Residency Criteria and the Need for Language Assessment and Support." Language Assessment Quarterly 2.2 (2005): 85-II5.

Frodesen, Jan, and Nancy Starna. "Distinguishing Incipient and Functional Bilingual Writers: Assessment and Instructional Insights Gained Through Second-Language Writer Profiles." Harklau, Losey, and Siegal 6I-80.

Graziano-King, Janine. “Assessing Student Writing: The Self-Revised Essay.” Journal of Basic Writing 26.2 (2007): 73-92.

Harklau, Linda. "From the 'Good Kids' to the 'Worst': Representations of English Language Learners Across Educational Settings. TESOL Quarterly 34.I (2000): 35-67.

Harklau, Linda, Kay M. Losey, and Meryl Siegal, eds. Generation I.5 Meets College Composition: Issues in the Teaching of Writing to U.S.-Educated Learners of ESL. Mahwah, NJ: Lawrence Erlbaum, I999.

Kroll, Barbara, ed. Exploring the Dynamics of Second Language Writing. Cambridge, UK: Cambridge UP, 2003.

Matsuda, Paul Kei. "Second Language Writing in the Twentieth Century: A Situated Historical Perspective.” Kroll I5-34.

Matsuda, Paul Kei, et al., eds. Second Language Writing in the Composition Classroom. Boston: Bedford/St. Martin's, 2006.

Muchinsky, Dennis, and Nancy Tangren. "Immigrant Student Performance in an Academic Intensive English Program.” Harklau, Losey, and Siegal 2II-34.

Ortmeier-Hooper, Christina. “English May Be My Second Language But I'm Not 'ESL.'” College Composition and Communication 59.3 (2008): 389-4I9.

Purves, Alan C. "Clothing the Emperor: Towards a Framework Relating Function and Form in Literacy." Journal of Basic Writing IO.2 (I99I): 33-53.

Reid, Joy. “'Eye’ Learners and 'Ear' Learners: Identifying the Language Needs of International Students and U.S. Resident Writers." Matsuda, et al. 76-88.

Rumbaut, Rubèn G., and Kenji Ima. "The Adaptation of Southeast Asian Refugee Youth: A Comparative Study." San Diego, CA: San Diego State University (ED 299 372), I988. 
Silva, Tony. "Toward an Understanding of the Distinct Nature of L2 Writing: The ESL Research and Its Implications." TESOL Quarterly 27.4 (I993): 657-75.

Silva, Tony, et al. "Second Language Writing Up Close and Personal: Some Success Stories." Kroll 93-II4.

Slager, William. "The Foreign Student and the Immigrant-Their Different Problems as Students of English." Language Learning, 6.3/4 (1956): 24-29.

Valdés, Guadalupe. "Bilingual Minorities and Language Issues in Writing: Toward Professionwide Responses to a New Challenge." Written Communication 9.I (I992): 85-I36. 


\section{APPENDIX}

\section{First-Day Diagnostic Writing Assignment}

Write an essay about your writing experience. Below are some questions I'd like you to think about in composing your response. Try to organize your answers into an essay-do not write just a list of answers to the questions.

- What types of writing do you have to do? What types of writing do you do for pleasure?

- What type of writing do you expect to do in the future?

- Is most of your writing experience in English or in another language?

- Has your experience with writing been mostly positive, negative, or neutral? Explain.

- What is your opinion of your current writing ability?

- How important (or not) do you think it is for you to be able to write well?

- Feel free to discuss other information about your writing experience in addition to these questions. 


\section{Material Realities in the Basic}

\section{Writing Classroom: Intersections of Discovery for Young Women Reading Persepolis 2}

\section{Susan Naomi Bernstein}

ABSTRACT: This essay focuses on how young women students in a first-year, firstquarter basic reading and writing course wrote about their connections to the process of identity development as portrayed in the graphic novel Persepolis 2: The Story of a Return by Marjane Satrapi. While the circumstances of becoming a student in a required university-sanctioned remedial course in an urban Midwestern university differed greatly from Marjane's privileged education at a French lycée in Vienna, these women, not unlike Marjane, dealt with struggles against marginality and invisibility in a bureaucratic and unfamiliar environment. Exploring the correspondences of coming-of-age for both my students and the novel's main character, Marjane, I demonstrate the use of the graphic novel as a means for renegotiating students' agency and identity beyond fixed categories of gender, race, and class, as well as institutional definitions of the basic writer.

KEYWORDS: intersectionality; young women; basic writing; feminist pedagogical practices; graphic novels

The students in my first-year, first-quarter, basic reading and writing course lived and worked in Cincinnati, Ohio, and its suburbs. We began in late September 2005 , four years after civil unrest in this city and three weeks after Hurricane Katrina. Both disasters were very much on the minds of students at this time as each still reflected the consequences of years of neglect of poverty-stricken urban spaces. The civil unrest of 2001 , generated by the shooting death of an unarmed nineteen-year-old African-American man by a white police officer, exacerbated white flight from the city center begun years earlier. And as we were now experiencing the aftershock of Hurricane Katrina and the New Orleans flood, our moment seemed to further reveal the perils of pretending that racial polarization did not exist in the United

Susan Naomi Bernstein has published the third edition of Teaching Developmental Writing: Background Readings (Bedford/St. Martin's, 2007), as well as two previous editions (2004, 200I), two shorter ancillary versions (2000, 1998), and the textbook A Brief Guide to the Novel (Longman, 2002). Her articles on teaching writing have appeared in the Chronicle of Higher Education, Journal of Basic Writing, Modern Language Studies, English in Texas, and elsewhere. She teaches at LaGuardia Community College, City University of New York, and is a past co-chair of the Conference on Basic Writing.

(c) Journal of Basic Writing, Vol. 27, No. I, 2008 
States. My students, most of whom identified as African-American, were not unfamiliar with such intolerance, and our heated discussions pointed to both their empathy for Katrina's victims as well as their frustration with civic inaction and irresponsibility.

Beyond noting the complexity of race as my students lived it locally, I saw the young, working-class and poor women enrolled in my developmental English course as important to study because, in this city and in this university, they faced particular risks of erasure. In this region of the Midwest, the mix of Appalachian, African-American, and immigrant communities provided a rich confluence of cultures that often converged in classroom spaces where the significance of education for upward class mobility was clearly understood. Local traditions, rooted in resistance to outsiders and competition for increasingly scarce economic resources, not only polarized race, but also reinforced traditional gender roles. The city and the region suffered from the limited employment opportunities found in post-industrial rust-belt areas across the Midwest that had never recovered from the factory closures of the previous decades. Work was not an option for women, yet they also dealt with a background of questions and shifting expectations around women's and men's roles.

For these reasons, I was drawn to the work of literacy educator Deborah Hicks who has written perceptively about the lives of white pre-teen girls in this same city, focusing on literacy development and identity formation. Hicks discovered that the girls in her study, rather than wanting to read novels about the lives of working-class girls, instead were compelled by horror fictions by R. L. Stine. The girls were able to draw connections between the horrific details of these fantasy fictions and their own lives. By contrast, the girls found the seemingly familiar struggles of working-class girls "boring, “ which Hicks perceives as "perhaps a code word for. . . unfamiliar or difficult language" (8o). Probing the disconnect, Hicks took seriously the girls' reading interests and practices, working to build bridges from community-based literacies to academic ones. "Most important," Hicks reflects, "was the possibility that girls could see a legitimate place for their storied lives and their voices in a reading practice that, initially, could feel dislocating" (78; See also Hicks and Dolan; Shannon Carter).

In much the same vein, I needed to examine my own evolving relationship to race, class, and gender in a culturally honest way. Like many of the students in my Fall 2005 class, I grew up and was educated in the Midwest. However, as a white, middle-class, Jewish woman, and native speaker of English with educational privilege, I had chosen for many years to live and 
work outside of the Midwest. I had returned to teach in the region and was beginning my second year at the university when this basic writing class began. In the years that I had been away, a severe economic downturn had devastated the region's smaller urban areas, leaving inner-city workers in our community without sustainable means of employment. University employment offered a sense of stability and connection that contrasted sharply with the distressed economic circumstances that faced most of the region. In this context, my white privilege remained problematic, at the same time it encouraged me to optimize students', and my own, outsider status (see Asher, Center, Green). I saw that both my students and I sought academia in a shared, Midwestern-city, cultural context. The University of Cincinnati remained the city's largest employer, and a degree (in my case, a teaching position) from the university literally and figuratively signified upward mobility for many people in the community. However, for several years the university had been in the process of downsizing its open admissions programs, effectively locking out those residents whom it might have best served. The university agreed to create our program, the Center for Access and Transition, in order to retain open admissions in a very limited form, an attempt that lasted only two years before a selective admissions policy was enacted. The Fall 2005 class would be the last cohort of students who would be admitted through open admissions, closing a door that had been open to inner-city students since the I96os (Gibson and Meem). The fact of this door closing on my current and future students greatly bore upon our similarities and differences.

Fortunately, I chose Persepolis 2: The Story of a Return by Marjane Satrapi for our first text. This graphic novel presented unique opportunities for this first-time, mostly traditional-aged, college audience, as these students proved to be particularly sensitive to the challenges of transitioning to new and potentially alienating environments. With its interplay of visuality and text, and the reorientation toward reading it inspires, the graphic novel offered an invaluable opportunity for interpreting experience as presented in the text and students' lives. Young women, the gendered minority in the course, found the graphic novel particularly engaging as a subject for writing, and their connections to processes of identity development were especially eloquent. I was moved by their reflections on coming of age as young women in the twenty-first century. The profound dislocation experienced by the main character, Marjane, bore upon students' own movement toward new awarenesses of gender, race, and class in our society, and within academia. As readers, students moved through unfamiliar settings, 
as Marjane experienced them, including French language schools, Viennese pubs, and post-war Iranian nightlife, then back to the terrain of the more familiar struggles of their own young womanhood. These more familiar struggles-the often contradictory experiences of region, home, school, and romantic lives-proved to be an important link to Marjane's story. Like the connection to horror experienced by Hicks' students, the young women enrolled in this basic writing course understood the potential for embodied horror in the material realities of late adolescence. That Marjane shared similar struggles, including experiences of drug use, intolerant communities, and unmitigated peer pressure, proved to be a significant catalyst for students to study identity formation and the intersections of gender, race, and class.

\section{Intersectionality and Basic Writing}

In undertaking this article, I wanted to investigate the formative attempts of young women to identify personal and intellectual connections to text, coincident with the added challenges of becoming readers and writers in a university setting. Taking an "emic" or insider perspective, as a participant/observer in my own classroom (Cochran-Smith and Lytle 36), I began with the question of "what happens when" students and teacher, each with unique and shared aspects of background, meet together in a six-hour, tenweek course called "Preparatory Composition I/Fundamentals of Reading I." My perspective required that I not only examine student artifacts, but also interrogate the traditional top-down structure of "remedial" basic skills education, inviting students to take part in this process.

As Cochran-Smith and Lytle suggest, I wanted students to become researching subjects with me, the teacher-researcher, rather than the objects of research-in other words, and in Freire's terms, problem-posers, rather than passive receptacles of "basic skills." Research evolved as the course unfolded with students and teacher working together to shape-and often shake-the agenda (Cochran-Smith and Lytle I2O). Like Nina Asher, who worked primarily with white teacher-education students in Louisiana, I focused on a specific assignment sequence and how such might be informed by the cultural and material contexts of the classroom. My assignment sequence included a summary and full-length essay based on Persepolis 2 , and addressed the material realities of coming of age as basic writing students at a specific time and place. With Asher, I contend that such work of contextualizing is necessary for “. . . a decolonizing multicultural education pedagogy, which 
engages the interstices-in-between, hybrid spaces-that emerge at the intersections of different cultures, histories and locations" (IO79).

The awareness of material realities in the classroom accounted for both cultural and textual "intersectionality" in our everyday practice. Critical race theorist Kimberle Williams Crenshaw describes "intersectionality" as "the need to account for multiple grounds of identity when considering how the social world is constructed" (358). Crenshaw argues that identity markers, especially race/class/gender, are interconnected, rather than distinct from each other. Intersectionality precludes essentialism by suggesting that subjects are not merely gendered, raced, or classed-but constructed by multiple social forces (see also Hourigan, Gray-Rosendale, and Birnley). It deconstructs binaries imposed by categories of preconceived oppositions such as woman/man, black/white, middle-class/poor (Cixous and Clément). Through its lens the complications and contradictions of such categories in a post-modern, post-millennial world, are acknowledged; race, class, and gender become interdependent and inextricably linked. Sengupta explains the power of intersectionality across international borders and apparent cultural differences:

Just as parallel lines meet and intersect when one moves from Euclidean two-dimensional geometry to non-Euclidean threedimensional geometry, so too an entirely different vision of the same realities becomes contingent in how one chooses to see... in a networked world, each of our individual circumstances connects to inform larger patterns of oppression and liberty. (637)

The circumstances of becoming a student in a required university-sanctioned remedial course in an urban Midwestern university differed greatly from Marjane's privileged education at a French lycée in Vienna. However, these women, not unlike Marjane, dealt with struggles against marginality and invisibility in a bureaucratic and unfamiliar environment. At the same time, Marjane's resilience and resistance proved to be a critical point of intersection for these women writers/readers, charting a pattern of liberty noted by Sengupta as vital in the process of negotiating the "minefield" of intersectionality and identity (637).

Our class would offer the opportunity for students to engage in a sixhour writing/reading seminar experience "modeled after a course for advanced graduate students" on coming of age (Bartholomae and Petrosky 47). In addition, we were joined by two white women graduate students engaged 
in observations for their doctoral program as well as two senior English education majors who served as teaching assistants as part of a required practicum. Our course theme was "Coming of Age in the Twenty-First Century." Beginning with this general theme, the students would facilitate opportunities to generate more specific topics for writing, as described in the classroom scenes that I present. Although I focus primarily on the writing of five women, the interactions with the entire class also are represented, as these discussions helped to create the communal context in which students grappled with constructing a response to a writing assignment for Persepolis 2.

\section{The Graphic Novel: More Intersections}

Because graphic novels hold interpretive potential for disruption and generation of meaning, students may find that these hybrid texts present opportunities for renegotiating agency and identity beyond the seemingly fixed institutional category of "basic writer." As a graphic novel, Persepolis 2 presents innovative "word/picture combinations" (McCloud, Making Comics I30) that invite readers to engage and resist the text in unexpected ways. In Making Comics, McCloud uses the term "intersecting" as a key word for creating and interpreting comics. He defines "intersecting" as "words and pictures working together while contributing information independently" (I30). The late comics artist Will Eisner offered an additional point of view:

the reader [of comics] is thus required to exercise both visual and verbal interpretive skills. The regimens of art (e.g. perspective, symmetry, brush stroke) and the regimens of literature (e.g. grammar, plot, syntax) become superimposed upon each other. The reading of the comic book is an act of both perception and intellectual pursuit. (8)

This unfamiliar way of seeing/reading/interpreting would mean that no two pages of Persepolis 2 would be organized in precisely the same way. The order of panels might shift, panels might be wordless, requiring readers to interpret images alone-and sometimes words would overwhelm the page. Even the thought balloons that held the words over the characters' heads could shift in both shape and meaning. The students generally had more experience reading texts that McCloud, as comics artist, describes as “... [moving through] a very linear progress. Just a straight line from point A to point B" (Understanding IO6). Persepolis 2 would thus require of the student 
more "viewer participation" (McCloud, Understanding Io6) than either informational or pleasure reading encountered in school-based settings. "Reading" in this sense would become an unstable process as continual transitions would require readers to constantly shift perspective. In other words, the new experience of reading and interpreting a graphic novel would require the "different vision" Sengupta describes in negotiating intersections of identity.

Initially students questioned the inclusion of a graphic novel, resisting a "picture book" as appropriate for college reading. Students also encountered difficulties as they had to widen their range of practiced literacy, synthesizing word and image. Yet as Jacobs suggests, "If we think about comics as multimodal texts that involve multiple kinds of making meaning, we do not give up the benefits of word-based literacy construction but strengthen it through the inclusion of visual and other literacies (2 I; see also James Bucky Carter). Eisner's description of reading comics as "an act of both perception and intellectual pursuit" provides the essential point of connection with Persepolis 2. As students discovered the promise of the verbal/visual intersections of the text, they also found ways of relating across the difficult cultural divides between Marjane and themselves. The graphic novel presented an opportunity for students to variously observe, and construct, Marjane's responses to her own multiply-determined, multiply-contextualized and recontextualized experiences. The visual/textual hybridity of Persepolis 2 was itself a generator of intersections, offering the reader constant opportunity for making meaning from unfamiliar circumstances, and casting many of Marjane's experiences as analogous to the unfamiliar and material struggles of the young women in my class.

\section{“Blossoming into a Young Woman"}

In Persepolis 2: The Story of a Return, the second of her two autobiographical graphic novels about coming of age in the late twentieth century, Marjane Satrapi presents a compelling narrative of an independent adolescent growing into young womanhood. Marjane, the central character, experiences her identity in a variety of intersecting and overlapping categories (Satrapi “How Can One Be Persian?"; Zanganeh). A young female upper-middle-class, Generation X, Iranian punk rocker, Marjane resides in Vienna, Austria, where her parents have sent her to escape the ravages of war in Iran in the I980s. Because Marjane is living on her own for the first time, she faces challenges of loneliness, cultural and racial difference, peer 
pressure, sex, sexuality, drug abuse, displacement, homelessness, and illness-all without the support of her family or home community.

Like Hicks' students, the young women in this basic writing course gravitated toward the "horrifying" elements of Marjane's story, set in the unfamiliar locations of Austria and Iran, relative to their own transitions from familiar, if often difficult, high school experiences to the unknown and often confusing setting of an urban public university. Women were the gendered minority, their multiple identities variously intersecting with the men in the class, including but not limited to, their university-assigned identity of "at risk" for successful matriculation. Yet such a designation did not recognize students' strengths, nor account for the ways in which it negatively inflected local culture, in which women of color, and poor and working-class women did not hold sustainable positions of authority. Given the tenuous status of "remedial" in the university that semester, the designation of being at-risk certainly did not indicate to students their strengths, nor their ability to define success on their own terms (Ladson-Billings 36). Much less could it ever address the full range of their gender-, class-, and race-related, intersecting concerns. At the same time, the expectations of families and communities for their success were often inexorable for students as concerned full-time work schedules, financial challenges, and "remedial" courses in additional subjects, especially mathematics (Mutnick 99-IOo).

Margaret, Angela, Isobel, Wendy, and Katharine (all names are pseudonyms) came to the course with varying levels of experience with reading and writing. (Only Angela felt that she had been misplaced in the course.) These young working-class women envisioned education as a means of improving difficult life circumstances; and thus a significant challenge for these young women would be to reconceive their own contributions as central rather than marginal to the work of the course (hooks I8I-83; Mutnick 46). As the women struggled with their own transitions, they found themselves able to identify with Marjane-and were inspired by her ability to take action on her own behalf.

\section{Critical Beginnings in Reading and Writing: Margaret and Angela}

Margaret had learned English as a second language and had emigrated from West Africa, completing high school in the U.S. in our state's capital city. In class, Margaret often sat apart from the other students. Her oftendifficult experiences transitioning between her country of origin and the U.S., she offered, had influenced her caution and reticence in interacting 
with peers. And yet her position as an outsider gave her a unique vantage point for observation and critical thinking, by which she strongly engaged her classmates.

On our first day, I invited students to respond in writing to five questions:

-What do you already know about literacy (reading and writing)? What do you hope to learn about literacy in this course?

-What do you already know about our course theme: "What does it mean to come of age in the $2 \mathrm{I}^{\text {st }}$ century?"

-What do you hope to learn about our course theme?

- What special strengths, talents, and insights do you bring to the course?

-What do you need to know in order to succeed in the course and in academic literacy?

Margaret's response was especially helpful in considering this new quarter:

My knowledge on reading and writing is the more you read and write, the more you discover and learn alot of thing. It makes your writing skills improve, you ask alot of question on things you do not understand and very careful on things you see.

I hope to learn, discovery and improve my writing skills to the next level of my college year and also reading to be able to create thing on my own words.

The course theme is creating, improving and discovering writing and reading skills to the next level.

My special strengths, talents, and insights to this course will be contributing, asking questions, doing my homework, and obey instructions when is given. Ineed understanding, practicing more and reading and writing more outside class.

I hope you are going to consider my few words and help me achieve my goals in the university and my future.

Although Margaret expresses her ability to obey instructions, she also highlights the importance of discovery as a critical part of the learning process. "Discover, discovery, and discovering" are her critical goals for the course, part of "improving reading and writing skills to the next level" with a focus 
on "skills" as mirrored in the university requirements for students entering the one-year transitional program. Through two summaries, three essays, as well as portfolio revisions of these assignments, she would explore the contradictions of academic literacy that her first-day writing implies: the imperative to "obey instruction" and the need to find possibilities for "discovery" (Belenky, Clinchy, Goldberger, and Tarule 209).

Angela, identifying as African-American and one of the strongest writers in the class, came from a small rust-belt town in the northeast corner of our state and lived in the residence halls. From the beginning, Angela was articulate in her writing, as well as fluent in reading, often offering her drafts for whole-class revision workshops. Her classmates were inspired by her writing's fluidity and her thorough attention to the course readings. Angela's first summary of Persepolis 2 picks up on the possibilities for discovery at the crossroads of young womanhood:

In the novel Persepolis 2: The Story of a Return, Marjane Satrapi write an engaging story about a Middle Eastern teenage girl from Iran blossoming into a woman. Throughout the book she talks about the dilemmas and hardships Marjane had to encounter with family, adjusting to new environments, boys, and finding herself. Being that she was from a Middle Eastern country, constantly at war, communication amongst Marjane and her parents wasn't easy. "Sigh! Still the same bombings, arrests, we're so used to that the calm here [in Vienna] makes me a little nervous" (Persepolis 2 49). Dealing with life's obstacles that life was throwing at them wasn't easy, let alone dealing with roommates, moving to new places, and living with other people's life styles and continuously changing hers. But in the end Marjane had grown into a smart, sophisticated woman, with the knowledge of life.

"So I pretended to participate, but I never inhaled the smoke" (Persepolis 2 38). In this book, Marjane struggled to fit in, and sometimes did dangerous things to fit in. This was all a part of her growing up and transitioning in to the successful woman she became. By reading this book it will guide young audiences on how to deal with adjusting to new things. In Persepolis 2 Satrapi really develops a great story to explain the dilemmas and battles that life puts you through.

Angela emphasizes Marjane's "blossoming into a young woman" 
both in spite of and because of "life's obstacles." As her summary presents Marjane's processes of "growing up and transitioning in to the successful woman she became," Angela reads the text as a "guide [for] young audiences on how to deal with adjusting to "new things," including the many demands of college life. The point was made frequently in class, as students cross-referenced their dislocations, isolation, and adjustments to unfamiliar circumstances. Angela's essay on Persepolis 2 addresses such transitions, comparing her adjustments to living in the residence hall to Marjane's first experiences in Austria living with a roommate:

You will come face to face with a lot of problems when you first get to college, some you may be able to cope with some you may not. But for me my first dilemma was coming to the realization that I had to adjust to this new way of living even though I wasn't comfortable with it. I have to live in this little room with one other person, I have to use a shower that is used by thirty to forty other females. And I have to adjust to their schedules even if it involves them getting up at seven in the morning making noise while I am sleeping. One of the most important issues while living on campus is your relationship status with your roommate. You are going to be living with the person or persons for a long time, so you can either love them or hate them. In the book Marjane first roommate Lucia was a very nice person, but Marjane had one problem, Lucia like to blow dry her hair every morning. "Every morning I was rudely awakened by the sound of Lucia's hair dryer" (Persepolis 2). Compromising is something that is very much needed to have a good relationship with you roommate. You must agree specific times that you are going to do certain things so that it will not come into conflict with each others activities.

Angela continues to foreground gender as she addresses the need to compromise so as to "not come into conflict" with the other young women who share her space. Much as Marjane and Lucia face differences of race and ethnicity, women of color were in the minority at our university and in the residence halls. As Angela comments, "Just like me, before [Marjane] knew she was in this strange new place where she had to struggle to fit in." At this juncture, Marjane's life intersects the lives of the women enrolled in English 095, most of whose struggles, if not successfully resolved, would impede matriculation and fulfill the warning of the designation "at risk." 


\section{“Becoming a vegetable was out of the question": Margaret and Isobel}

The students collectively posed problems and questions about the text specifically highlighting the triangle of visuals, text, and meaning. Marjane's metaphorical drawing of herself as an eggplant fell into this category, with several students stating that they had never seen an eggplant and so did not know how to read the image. Although eggplant is a staple of Middle Eastern cuisine and therefore connotes meaning for many readers, none of the students in my class claimed that heritage. Most lived in inner-city communities with limited access to grocery stores well-stocked with fresh produce. Gourmet shops and supermarkets, popular among the middle-class, such as Trader Joe's and Whole Foods, were located in outlying suburbs. Again, access-in terms of public transportation to these suburbs-was limited. Without financial resources to drive out of the city to obtain such foods, students faced a barrier to understanding a literal image, absent within their material realm, on an interpretative level. This unfamiliarity proved to be another sort of dislocation, as students realized that they were missing a significant metaphor.

To remedy the situation, I brought in a slightly overripe eggplant and passed it around so that the students could touch, smell, and see the material object, a kinesthetic, tactile, olfactory, and visual that would serve as an embodied experience (Fleckenstein, Embodied Literacies I5I). After we passed the eggplant around the room, we reexamined the text. In particular, we looked at how Marjane's resolution does not keep her from struggling with displacement and alienation. She writes:

If only they [my parents] knew . . . if they only knew that their daughter was made up like a punk, that she smoked joints to make a good impression, that she had seen men in their underwear while they were being bombed every day, they wouldn't call me their dream child. (39)

Afterwards, we created separate lists of words on the board to describe both the eggplant as material object and Marjane's metaphor of herself turning into one. We divided the lists into two categories, sensation and emotion: 


$\begin{array}{cc}\text { Sensation } & \text { Emotion } \\ \text { Rubbery } & \text { Loneliness } \\ \text { Ugly } & \text { Depression } \\ \text { Bruises on one side } & \text { Confused } \\ \text { Has a stench } & \text { Anger } \\ \text { Smooth } & \text { Sadness } \\ \text { Funny shape } & \text { Love } \\ \text { It's old } & \text { Used } \\ \text { Stem on top } & \text { Disappointment } \\ \text { Shiny } & \text { Desire } \\ \text { Purple/black } & \text { Hate } \\ \text { Has a pushing feel } & \text { Content } \\ \text { Dry } & \text { Ok happy } \\ \text { Dense } & \text { Betrayed } \\ \text { Sounds hollow } & \end{array}$

These lists, with interpretive commentary alongside sensory observation, later helped students to revise their first essays. In later reflection, students noted that they had: "added more details," "added more description and metaphors," "added more examples to make it more interesting," "changed word choice and added more verbs and emotions," and "added something to make it look juicy." Margaret reflected on this revision process in a subsequent conference, noting a connection with the eggplant activity and its relationship to students' suggestions for revision, especially as she learned to break down the different parts of her essay draft to discover what might be changed or added, and how experience must also be interpreted. Indeed, in Margaret's final in-class self-assessment essay, she indicated the need to make use of details that could serve as a catalyst for revision. She also discussed her process of making sense of the text in light of her own struggles:

What I learn writing the essay and after writing the essay is being able to express my self, giving details and examples for readers to know what I'm talking about. Also I need to work on supporting my essays with a lot of details and quotes. Persepolis 2 talks about self confidence, believing in your self, and fighting for what you believe in. I picture the character in my head like I'm watching a movie which makes it understanding and interesting and I will 
recommend it to everybody to read it to always fight for their equal rights.

For Margaret, learning to make sense of the details seemed to be a means toward gaining agency, for "fighting for what you believe in." As a graphic novel, Persepolis 2 suggested multiple means of making sense of a text such as "watching a movie." As Kristie S. Fleckenstein suggests, "by adding an imagistic layer to their writing, [students] can weave self and other, self and environment, self and self into their evolving essays," wherein "writing and reading (become) intertwined." Fleckenstein argues, "Although an image is not reality-it is a way of punctuating reality-it anchors us to our identity and our being in reality" ("Inviting Imagery" I8, 6, I5). As a concurrent step toward exploring this intertwining, students learn to read beyond the limits of word and text, analyzing the verbal/visual metaphor of vegetable/eggplant, and in the process, find their way back to language as a way to experience writing and reading for symbolic detail and imagery.

The strangeness of this new tactile/visual/auditory/olfactory encounter with a material object intersected with the alienation described by Marjane and the dislocations of students' experience. For Isobel, the anchoring Fleckenstein speaks of seemed especially important. Isobel identified as an African-Caribbean student; she had immigrated with her family as a child and had attended a re-segregated high school across the street from the university. As part of an extra-credit service-learning project, she wrote poetry with students from this high school. She chose to revise one of her poems to supplement her extra credit project-and the poem became a kind of metacommentary on Marjane's experience. At one transitional juncture, Marjane speaks of "my nostalgia for the Caspian Sea" (Satrapi, Persepolis 2 27), linked to the drawing of a flashback of her sitting at the seaside with her parents around a samovar brewing tea. Marjane explains to the mother of the friend with whom she is staying, "at home we drink tea all day long" (27) and finds an ally in her friend's mother as someone who understands Iran and her longing for the Caspian Sea. Marjane adds, "She was also the only one to have seen a samovar" (27). Isobel remembers her own moment of sustenance, similarly conjuring nostalgia of a motherland. Aptly optimizing the critical potential within the visual, as encouraged by the graphic novel, Isobel reflects: 
It was the summer of 1990.

Mama cooking in the kitchen my

favorite Mac and cheeses.

We could hear the birds singing

in the trees and Ms. Jackson

yelling out loud for us to get off

her grass.

My friends outside playing the best game ever hide and seek.

The grass is so dark that it's hard to find them.

It's summer every day for us because we live on an Island, for us it's the best place on earth and you couldn't tell us any different. It was even better than Christmas.

The visual dimension of language, the "imagistic layer" now superimposed upon analysis, reflects for Isobel the process Fleckenstein describes wherein students "weave self and other, self and environment, self and self" within their work as integrated writers and readers ("Inviting Imagery" I9). Just as the eggplant could be examined in terms of its different but intersecting aspects, so too could Isobel's writing be analyzed for overlapping components of a finished essay, as it concerned detail and development, even organization and support (Elbow 50).

\section{Co-Creatinga Writing/Reading/Essay Assignment: Wendy and Katharine}

As the class collaborated on creating the essay assignment, we reflected on the many connections that students were finding between Marjane's story and their own stories. Marjane eventually returns to Iran, begins university art classes, marries, divorces, and decides to return to Europe to further her art education. What resonated for students most strongly was Marjane's dilemma with acculturating to an alien environment while still attempting to remain loyal to her home training and values. Students wanted to write about their own transitions, their own experiences with crossing borders. I invited them to consider specific examples from Persepolis 2 that connected to their own stories. Students were asked to imagine their essays as a letter to one of the following audiences: adults of an older generation; high school students; or college students, their same-age peers (see Appendix). Why, I asked, would any of these readers care about connections that first-quarter writers would make between a book and their own experiences? What needs would the students' essays serve? What would be their reasons for writing? 
In my teaching journal, I wrote down the results of the list of possible topics that we constructed on the board.

\#I LETTER TO ADULTS:

- Learning how to grow yourself up mentally to make a change for your future.

- Being open to sacrifices that you don't want to make-but have to make-examples:

o Becoming a young mother

o Learning how to deal with relationships

o Learning how to deal with people who bring you down

\section{\#2 LETTER TO HIGH SCHOOL STUDENTS}

- Freshmen [sic] coming to high school from middle school

- A traveling family: how did you adjust to making new friends, living in new neighborhoods, attending new schools

- High school to college

- Moving to a new country

- Moving state to state

\section{\#3 LETTER TO COLLEGE STUDENTS}

- Choosing between education and friends

- Changing the way you talk to people

- Learning how to cope with change of a social environment

Intersections, crossroads, and border crossings stand out as major themes, including the figurative crossings involved in coming of age at the literal crossroads of material reality: becoming a young mother, moving to a new country, choosing between education and friends.

Wendy, who had two small children, commuted from her home in the city. She would often struggle with attendance, but would use her time in class to work toward becoming a careful reader and a more confident writer. Initially, she kept very quiet in class. However, when the topic turned to feeling out of place in a new environment, she contributed powerfully. Her feelings of marginality were based in part on her status as a young working mother, and a woman of color, on a historically white campus of traditional-aged students. No matter, she became an articulate presence in the classroom. She was particularly interested, she said, in "decoding" the 
deeper meanings of our course texts. For her essay, Wendy wrote a letter to her peers on learning how to cope with a change of social environment:

Loneliness is also a topic that I wanted to touch base on, because sometimes when someone is new to an environment, such as college it's easy to get lost in the crowd, and become invisible. When I fell a lone I just try to be myself, and do things I'm comfortable with doing until I open up on my own, I can really relate to this subject, because when I first came to my new school. I felt extremely lonely, I didn't know anyone at my school but as time went by I began to see myself open up more, and every day I still felt invisible, but at least I knew a few names, and faces. Even though Marjane Satrapi didn't really know anyone in her school she became friends with a older girl in her class who introduced her to more people.

Even farther from home, Katharine commuted from a neighboring state on the interstate loop each day through crowded rush hour traffic and, like many of the students, worked long hours to help pay expenses. Moving from an isolated experience as one of the only students in her high school class who believed in evolution and who openly stated her disenchantment with religion, Katharine longed to make tangible changes in her life as she began college. She signified this desire by changing her childhood nickname "Kathy," back to the longer, and for her more elegant, Katharine. Although generally reticent in class and often ill, she soon revealed that she had a strong interest in performance, especially dance and music. Katharine wrote to older adults on learning how to deal with people who bring you down, which she identified as "peer pressure":

I am writing you to tell you (adults) about what teenagers go through that you may not understand, or have not dealt with. Peer pressure, depression, and abuse are just to name a few. Peer pressure is probably the most popular throughout teenager. I will be giving examples of my life and also from the book Persepolis 2 about a girl named Marjane Satrapi coming of age. She dealt with most of the things that teenagers go through. I think that Marjane responded the way that she did because she was going through peer pressure and maybe she didn't really know how to act. She tried to do what was right at the time. I know that a long time ago I wouldn't know what to do about peer pressure because I just wanted to fit in, but 
now I know that it will only make things worse and people are not going to be your true friends if they pressure you into things.

In identifying "invisibility" and "want[ing] to fit in," Wendy and Katharine address critical issues of adolescence for young women-and of life on the crossroads of institutionalized remediation.

\section{Conclusions and Connections: A Collage of Young Women's Voices}

Margaret, Angela, Isobel, Wendy, and Katharine all describe the contradictions encountered by young women in patriarchal culture, especially the desire to "fit in" and the loneliness that comes with discovering that home culture often conflicts radically with the cultures encountered in new environments (Collins 237). In her letter written to high school students, Margaret continued "asking questions" to comprehend connections and contradictions within her experience of transitioning, from West Africa, as compared to Marjane's transitions. As she concludes:

Moving from a country to another country is like being adopted from a foster home. Every thing about you has to change because you are in a different environment which is different from where you come from. So you have to learn and adjust their culture to your own in order for both parties to live peacefully by trying to be friends with them, do what they say, applied the training you had back home including culture and religion. We should also try not to be pressured by friends all because we want to fit in.

Such conflicts of adjustment and assimilation come to no easy or comfortable resolutions for these young women. Isobel reflected at the end of the course:

The writing I did for Marjane Satrapi wasn't that hard because I could compare it to my life, and that's always easier to do. It was fun to compare it because she leaving her country that she known for so long and leaving family and friends behind was hard for her. And that was the same thing, but different, my parent came with me so I was not so alone too much. But I miss my friends and family that I left behind and I did wish that they could come with us. 
Katharine in fact saw Persepolis 2 as a turning point:

One of the books called Persepolis 2, I could not put it down. I would read at work, at school, and before I went to bed. A long time ago I never wanted to read. I hated reading for school. I would get so bored with the books. When I was in third grade I had a problem with reading. I would have to go to a special reading class. It helped a lot but I didn't feel smart when I was in it. I was always afraid someone was going to make fun of me because I couldn't read very well. I think it was because I was to slow and had a hard time pronouncing the words.

I never wanted to go to college when I was in high school. I just wanted to be [a dancer]. My parents sort of made me apply and I'm glad they did because I never saw myself as being smart enough to go to college. I have learned so much by being in college and it has been only eleven weeks.

Young women who arrive at college with the added institutional requirement of remediation may learn to benefit from understanding such "conflict and struggle" as they begin their journey through higher education (Lu 55; Armstrong). As Wendy often reminded me, our autumn quarter class felt strongly inclined to relate to Marjane Satrapi's autobiographical representation of herself in Persepolis 2, even though her racial, ethnic, class, and cultural circumstances differed so significantly from their own.

For what the students admired in the character of Marjane was not her ability to pull herself up by her bootstraps (Villanueva I2O-2I) because, of course, Marjane grew up with upper middle-class privilege and education; her parents could use their connections to send Marjane to Vienna when the Iran-Iraq war escalated, and Marjane was endangered herself by the repression she faced as an outspoken adolescent girl in the midst of the Islamic Revolution. (Satrapi had candidly presented these dangers in her first autobiographical graphic novel, Persepolis: The Story of a Childhood, and several of the scenes from this early text were incorporated as flashbacks in Persepolis 2.) Rather Satrapi, in commenting on the Academy Awardnominated animated film version based on both volumes, has addressed the response that students articulated over and over again, that their own struggles and triumphs intersected with the events experienced by the character of Marjane: "Little by little, as my first book got translated into other languages, people were saying, ‘That's my story too!” (Hohenadel). Marjane’s 
recovery and survival from drug addiction, depression, and homelessness; her strongly expressed opposition to systemic racism and sexist oppression in Vienna and Iran-all provided intersectional connections for young women who came to identify their own struggles with social constraints through the lens of Marjane's activism. Students referenced Marjane's strength and courage in leaving her beloved homeland, family, and failed marriage to emigrate from Iran to Europe, not once but twice, to further her education and to pursue her career as an artist.

As Hicks and Dolan suggest about the girls they studied in "a high poverty, predominantly white community" little more than five miles from the university:

Close rendering of language, identities and individual histories revealed important moments of agency and discursive hybridity, amid seemingly transgressive acts of reading. Practices that did not on the surface appear to be generative of educational change became in fact possibilities for dialogic contact between girls' community voices and school-situated discourses of reading. It is through concretely situated readings like these that critical educators and theorists can hope to unravel the deeper and most meaningful relations between language, identity, and pedagogical practice. (56)

Like Hicks and Dolan's middle-school students, the young women in this basic writing course learned strategies for creating connections from their own lives to the world-and work-of the university. As participant/observer, I learned how the process of discovery might further evolve engagement with text. The intersections of personal, social, and systemic change seemed especially acute in the lives of these first-year women students who claimed a multiplicity of identities that did not seem discrete or easily separated.

And yet such intersections of impossibility remain a recognizable juncture of growing from late adolescence into young womanhood. At this juncture, women find opportunities to redefine their own experiences as central rather than marginal (hooks). "My mental transformation," Marjane says, "was followed by my physical metamorphosis. . . In short, I was in an ugly stage seemingly without end" (35). Considering the eggplant as metaphor and material reality, these intersections appear ugly and smooth at once and are filled with both disappointment and desire. The contradictions hold open a moment wherein one may recognize, as did Marjane and 
my students, that "Becoming a vegetable was out of the question."

For students in first-year basic writing open admission programs, the need to interrogate texts and material conditions-and to co-create curricula-remains particularly acute. Indeed by Fall 2006, our program, following university mandate, had eliminated open access admissions and was looking ahead to the implementation of a new state law that would no longer fund what it called "remedial" education at its four-year public universities, most of which were located in equally depressed, rust-belt cities. Yet as my experience with ENG 095 demonstrates, young women with opportunities for equal access to higher education may use their personal discoveries of the possibilities of academic literacy to define the material culture and context of their education, as they work to transform their responses from acceptance to passionate resistance.

\section{Acknowledgment}

Thanks to my Fall 2005 students for their generosity in sharing their work and reading and commenting on sections of this essay. I would also like to thank graduate assistants Terry Peters and Mary Pat Raupach for their support of and dedication to the mission of the beginning basic reading and writing course. Thanks as well to colleagues who read and commented on multiple drafts of this essay, especially Jonathan Alexander, Stephen Cormany, Ann E. Green, Eric Paulson, Deborah Sanchez, Adam Vine, Amy E. Winans, and the reviewers for $J B W$.

\section{Works Cited}

Armstrong, Sonya. "Beginning the Literacy Transition: Postsecondary Students' Conceptualizations of Academic Writing in Developmental Environments." Diss. University of Cincinnati, 2007.

Asher, Nina. "At the Interstices: Engaging Postcolonial and Feminist Perspectives for a Multicultural Education Pedagogy in the South." Teachers College Record I07.5 (2005): IO79-IIO6.

Bartholomae, David, and Anthony R. Petrosky. Facts, Artifacts, and Counterfacts: Theory and Method for a Reading and Writing Course. Portsmouth, NH: Boynton/Cook, I986.

Belenky, Mary Field, Blythe McVicker Clinchy, Nancy Rule Goldberger, and 
Jill Mattuck Tarule. Women's Ways of Knowing: The Development of Self, Voice, and Mind. New York: Basic Books, 1986 (reissued 1997).

Birnley, Kendra. "Embodiment, Emotion, and Gender in the Developmental Writing Classroom." Teaching Basic Writing May 2005. <http://www. mhhe.com/socscience/english/tbw/birnleys/birnleymodule.html >.

Accessed 30 January 2007.

Carter, James Bucky. Building Literacy Connections with Graphic Novels: Page by Page, Panel by Panel. Urbana, IL: National Council of Teachers of English, 2007.

Carter, Shannon. The Way Literacy Lives: Rhetorical Dexterity and the "Basic Writer." Albany, NY: State University of New York P, 2008.

Center, Carole. "Representing Race in Basic Writing Scholarship." Journal of Basic Writing 26.I (2007): 20-42.

Cixous, Hélène, and Catherine Clément. The Newly Born Woman. Trans. Betsy Wing. Minneapolis: University of Minnesota P, 1986.

Cochran-Smith, Marilyn, and Susan Lytle. Inside/Outside: Teacher Research and Knowledge. New York/London: Teachers College P, 1993.

Collins, Patricia Hill. Black Feminist Thought: Knowledge, Consciousness, and the Politics of Empowerment. New York/London: Routledge, I99I.

Crenshaw, Kimberle Williams. "Mapping the Margins: Intersectionality, Identity Politics, and Violence Against Women of Color." Critical Race Theory: The Key Writings that Formed the Movement. Ed. Kimberle Williams Crenshaw, Neil Gotanda, Gary Peller, and Kendall Thomas. New York: New Press, 2005. 357-83.

Eisner, Will. Comics and Sequential Art. Tamarac, FL: Poorhouse Press, I994.

Elbow, Peter. Writing with Power: Techniques for Mastering the Writing Process. $2^{\text {nd }}$ edition. New York, Oxford: Oxford UP, 1998.

Fleckenstein, Kristie S. Embodied Literacies: Imageword and a Poetics of Teaching. Carbondale, IL: Southern Illinois UP, 2003.

. "Inviting Imagery Into Our Classrooms." Language and Image in the Reading-Writing Classroom: Teaching Vision. Ed. Kristie S. Fleckenstein, Linda T. Callendrillo, and Demetrice A. Worley. Mahwah, NJ, London: Lawrence Erlbaum, 2002. 3-24.

Gibson, Michelle, and Deborah T. Meem. "The Life and Death of a College, a Department, and a Basic Writing Program." Basic Writing in America: The History of Nine College Programs. Ed. Nicole Pepinster Greene and Patricia J. McAlexander. Creskill, New Jersey: Hampton Press, 2008. 49-70. Gray-Rosendale, Laura. Rethinking Basic Writing: Exploring Identity, Politics 
and Community in Interaction. Mahwah, NJ: Lawrence Erlbaum, I999. Green, Ann E. "Difficult Stories: Service-Learning, Race, Class, and Whiteness." College Composition and Communication 55.2 (2003): 276-30I.

Hicks, Deborah. "Back to Oz? Rethinking the Literary in a Critical Study of Reading." Research in the Teaching of English 39.I (2004): 63-84.

Hicks, Deborah, and Tami K. Dolan. "Haunted Landscapes and Girlhood Imaginations: The Power of Horror Fictions for Marginalised Readers." Changing English IO.I (2003): 44-57.

Hohenadel, Kristin. "An Animated Adventure, Drawn from Life." New York Times Online Edition. 2I January 2007. <http://www.nytimes. com/2007/or/2I/movies/2 Ihohe.html?_r=I\&oref=slogin $>$. Accessed 25 January 2007.

hooks, bell. Teaching to Transgress: Education as the Practice of Freedom. New York: Routledge, I994.

Hourigan, Maureen M. Literacy as Social Exchange: Intersections of Class, Gender, and Culture. Albany, NY: State University of New York P, I994.

Jacobs, Dale. "More Than Words: Comics as a Means of Teaching Multiple Literacies." English Journal 96. 3 (2007): 19-25.

Ladson-Billings, Gloria. "Yes, But How Do We Do It? Practicing Culturally Relevant Pedagogy." White Teachers/Diverse Classrooms: A Guide to Building Inclusive Schools, Promoting High Expectations, and Eliminating Racism. Ed. Julie Landsman and Chance W. Lewis. Sterling, VA: Stylus, 2006. 29-42.

Lu, Min-Zhan. "Conflict and Struggle: The Enemies or Preconditions of Basic Writing?" Representing the "Other": Basic Writing and the Teaching of Basic Writing. Bruce Horner and Min-Zhan Lu. Urbana, IL: National Council of Teachers of English, 1999. 30-55.

McCloud, Scott. Making Comics: Storytelling Secrets of Comics, Manga, and Graphic Novels. New York: HarperCollins, 2006.

. Understanding Comics. New York: HarperCollins, I994.

Mutnick, Deborah. Writing in an Alien World: Basic Writing and the Struggle for Equality in Higher Education. Portsmouth, NH: Boynton, 1996.

Satrapi, Marjane. "How Can One Be Persian?" My Sister Guard Your Veil; My Brother Guard Your Eyes: Uncensored Iranian Voices. Ed. Lila Azam Zanganeh. Boston: Beacon, 2006. 20-23. . Persepolis: The Story of a Childhood. New York: Pantheon, 2003. . Persepolis 2: The Story of a Return. New York: Pantheon, 2004.

Sengupta, Shuddhabrata. "I/Me/Mine-Intersectional Identities as Negotiated Minefields." Signs: Journal of Women, Culture, and Society 31.3 (2006): 629-40. 
Material Realities in the Basic Writing Classroom

Villanueva, Victor. Bootstraps: From an American Academic of Color. Urbana, IL: National Council of Teachers of English, I993.

Zanganeh, Lila Azam, ed. My Sister Guard Your Veil; My Brother Guard Your Eyes: Uncensored Iranian Voices. Boston: Beacon, 2006. 


\section{APPENDIX \\ Coming-of-Age Narrative}

Consider Satrapi's coming-of-age narrative as you write your own coming-of-age narrative for Essay I. Choose one of the prompts below as you write your narrative:

I. LETTER TO OLDER ADULTS: Tell a story about your own life and compare it to one of Marjane's stories in Persepolis 2. How and why do you think she responded to the problems that she faced in the story? Would you respond in the same way? How and why are you similar to and/or different from Marjane? You may write a fictional story related to a current event if you choose. Write your essay as a letter to older adults who have a difficult time understanding the problems faced by teenagers and young adults.

2. LETTER TO HIGH SCHOOL STUDENTS: Tell a story about adjusting to a new environment and compare your story to one of Marjane's stories. How did Marjane deal with adjusting to her new environments? How do you deal with adjusting to new environments? What similarities do you see? What differences? You may write a fictional story if you choose. Write your essay as a letter to high school students who are considering applying to college and are interested in learning about adjusting to a new environment.

3. LETTER TO COLLEGE STUDENTS: Tell a story about a time when you experienced "double consciousness" (double identity) and compare it to one of Marjane's stories about experiencing double consciousness. Why do you think Marjane portrayed herself with different identities? How do you deal with situations that call for you to present an identity that seems alien to you? You may write a fictional story if you choose. Write your letter as an essay to college students who are dealing with the same kinds of struggles with identity as you and Marjane are facing. 


\title{
Feedback on Feedback: Exploring Student Responses to Teachers' Written Commentary
}

\author{
Maria Ornella Treglia
}

\begin{abstract}
How students respond to teacher-written commentary has been an underresearched topic, and the existing literature in L2 studies is contradictory. The present study analyzes the critical and positive commentary, mitigated and unmitigated, written by two community-college, first-year composition teachers on two drafts of two writing assignments done by $I_{4} L_{1}$ and L2 students and addresses the students' reactions to these comments. Qualitative data was collected through interviews with the two teachers and their I4 student participants. Students indicated that they equally understand and revise following mitigated and directive comments. However, they found most helpful the commentary that provided some acknowledgment of their writing, offered specific suggestions, and gave them choices. In addition, many of the students felt discouraged by directives that didn't convey trust in their abilities to revise. The findings are compared with those of similar studies, and conclusions are drawn about implications for instructors of first-year composition classes.
\end{abstract}

KEYWORDS: teacher-written commentary; feedback; student response; mitigated and directive comments

Writing is an act of confidence, as Mina Shaughnessy has reminded us in Errors and Expectations. LI and L2 theories related to learning to write thus suggest that feedback be supportive to facilitate that confidence. ${ }^{\mathrm{I}} \mathrm{Al}-$ though most educators agree-at least in theory-that a positive, dynamic interaction is necessary to give students the confidence to take charge of their writing (Brannon and Knoblauch; Elbow; Ferris, "Response;" Lea and Street; Straub, "The Student"), research shows that commentary practices don't always reflect that premise. As Stern and Solomon put it, overwhelmed with the number of papers to respond to and unsure of how to provide effective commentary, instructors often "scribble a few arbitrary comments and assign an obligatory grade" (24). Such comments are more likely to

Maria O. Treglia is an Assistant Professor in the English Department at Bronx Community College of the City University of New York, where she serves as coordinator of the ESL program. Her current research focuses on feedback to student writing and the use of literature in L2 and developmental college writing courses. She is also interested in ethnographic studies and is presently collaborating on a research project to collect oral histories of African college students and analyze the effects of immigration on their identities.

(C) Journal of Basic Writing, Vol. 27, No. I, 2008 
lead students to become defensive and to lose confidence rather than to encourage them to revise productively (Daiker; Ferris, "Response"; Straub, "Students' Reactions"; Weaver).

The language in which commentary is written affects the way students receive it (Hyland and Hyland; Lea and Street; Ivanic et al.; Weaver). For instance, the comment, "This is not clear, reword it" does not convey the same cognitive and affective impact as "I get a sense of what you want to say, yet the language could be made clearer," or "I'm confused at this point. Do you mean that ... [comment makes reference to the text and offers an interpretation]?" Pressured by their heavy workload and limited time, and, perhaps, overstressing the principle that directness under all circumstances prevents miscommunication, writing instructors may resort to directives. Many writing educators have noted that directive commentary can potentially thwart a student writer's decision-making abilities and co-opt ownership of her or his work, and thus negatively affect the writer's confidence (Ferris, "The Influence"; Lea and Street; Probst; Sommers, "Across"; Straub, "The Student"). Hyland and Hyland conducted a case study on the use of mitigation techniques (operationally defined in Appendix A) and their effect on six L2 students and found that it's not directive but indirect or mitigated commentary that leads to miscommunication. The students in this study indicated that the mitigating technique of preceding a critical statement with a positive one was too obvious to them, and as a consequence, they didn't feel the positive part of the comment was sincere. The results of the Hyland and Hyland study, although pertaining to a small group of students, open the door to the possibility that some forms of mitigation may not only be ineffective in prompting students to revise their writing but may also cause negative affective repercussions. Investigating how LI and L2 first-year students perceive their teachers' feedback will shed some light on this area of commentary that has scarcely been researched (Goldstein; Mutch; Perpignan; Weaver). In the study on which this article is based I looked into the impact of two first-year composition teachers' commentary on fourteen of their students' essays (Treglia). Adopting a case study approach, I categorized the comments written by the two teachers, interviewed both teachers, and interviewed the students to gain a better insight into how they perceived and felt about their teachers' mitigated and directive comments. The research focused on the following questions:

I. What is the ratio between critical and positive comments, mitigated and unmitigated ones? 
2. What are students' affective responses to their teachers' directive and mitigated comments?

3. What do students perceive as helpful commentary?

\section{PREVIOUS RESEARCH ON TEACHER COMMENTARY}

\section{The Role of the Teacher}

Certain trends in composition studies and second-language pedagogy (notably the process approach and English for academic purposes) have made teachers more aware of the complex role they play as readers of their students' papers. Research indicates, however, that to provide effective feedback, teachers may need to change both their traditional teaching approaches and their attitudes (Brannon and Knoblauch; Onore). Recognizing that a teacher's written commentary is influenced by her or his personality and background, Purves distinguishes eight major roles of the teacher as reader: the common reader, the copy editor, the proofreader, the reviewer, the gatekeeper, the critic, the linguist, and the diagnostician. A conscientious teacher will adopt each of these roles-or a combination of them-depending on the nature and situation of the writing assignment, the needs of the writer, and the stage of the writing process. Purves further suggests that teachers should discuss with their students the functions of the reader and make their students aware that not only will different readers interpret their writing differently, but also the same reader may interpret their writing differently in different situations.

Anson found that teachers' belief systems inform the way they comment on student essays. He discovered that teachers typically provide feedback to student writing in one of three ways. Dualistic responders (about 3/4 of the teachers who participated in Anson's study) are often guided by a clear-cut concept of right and wrong, focus mostly on surface features, and assume the tone of critical judges or evaluators. Relativistic responders provide feedback almost exclusively to the ideas expressed in the writing, often ignoring significant linguistic and rhetorical aspects. And reflective responders attend to both ideas and stylistic devices while attempting to offer options for revision without being controlling.

In addition to considering what to respond to, teachers must examine their roles as writing evaluators. Recent research on feedback in composition 
classes has consistently urged teachers to abandon styles that take control of student texts, and to adopt ways of responding that allow students to retain autonomy over their writing. Over the last twenty years, a number of social-epistemic rhetoricians have advocated that knowledge is constructed by the interaction between one's "material conditions of existence" and the discourse community in which one is functioning (Berlin I9). Language is the means by which this dialectical interaction is made possible; thus it constitutes the main medium in which knowledge is generated and negotiated (Berlin). In the collaborative classroom, the teacher is expected to facilitate this same dialectic by adopting the role of leader of the class as a community that, in turn, represents a larger community, the academic discipline. The teacher initiates students into the academic world and engages them in meaning-making dialogues by negotiating with them on what they want to say and how they want to say it. Most writing experts suggest that for this to happen teachers should abandon authoritarian views (Giberson; Lea and Street; Onore; Probst) and adopt feedback styles that involve students in making their own decisions. Successful collaborative interaction is hindered if teachers authoritatively tell students what to do because students then have no or little chance to explore their own opinions or inquiries.

When Brannon and Knoblauch asked 40 teachers to assess the quality of one student's essay, none recognized "the writer's control over choices" (I20). The researchers concluded that the teacher participants read the student's text from "the perspective of their own shared Ideal Text" (I2I). Brannon and Knoblauch acknowledge that teachers often correctly assume that their students "have not yet earned the authority" that makes readers pay serious attention to what they have to say. Yet, they argue that teachers provide little help to their students if they take on "primary control" of the choices that should be made by the writer, and if they "correct" those choices that deviate from the "Ideal Text" (II8-I9). Brannon and Knoblauch also observed that teachers who make extensive directive corrections tend to send a message that "the teacher's agenda is more important" (II8) than what the writer is trying to say. As a consequence, students may shift their motives and try to match their writing to "expectations that lie beyond their own sense of their intention and method" (II9). This may cause students to lose the incentive to communicate their ideas and, perhaps, to become disinterested in writing. 


\section{Tenets to Guide Responders}

Educators generally agree that to become successful in an academic environment students must ultimately become their own evaluators. This means that students need to acquire the skills to read analytically and, above all, to evaluate whether their writing expresses what they intend in a fluent, logical, and accurate manner (Ferris, "Response"; Probst). What, then, can and should teachers do to begin to encourage students' independence as writers? Brannon and Knoblauch (see also Goldstein; Elbow; Onore; Probst) suggest the following tenets to guide teachers as responders:

- Focus on what the writer wants to say as if the text actually reflects the writer's intention.

- Recognize that even inexperienced writers possess a sense of logic and purpose that guides their choices although it may not appear in the text.

- See feedback as a process of negotiation where writer and teacher cooperate to consider and improve, whenever possible, the relationship between intention and effect.

- Make the writer think about what he or she has said rather than tell him or her what to do.

- Acknowledge the writer's authority, that is, give the student the right to make choices.

To abide by these tenets, teachers may need to reconceptualize their roles as responders, reassess their sense of authority, and focus on the process of negotiation of meaning. Perhaps they should also consider their audience when writing comments, just as they ask students to do when writing essays. Straub notes that directive commentary such as "rephrase," "avoid repetition," or "elaborate" do not engage the students in meaning negotiation but leave them wondering, what did I do wrong? These types of phrases, he states, fail to consider how comments might affect the students' composing processes, their attitudes toward writing, and their awareness of writing as a social action (Straub, "The Concept"). Knoblauch and Brannon define directive comments as designed "either simply to label the errors in 
writing or to define restrictively what a student would (or will) have to do in order to perfect it in the teacher's eyes" (I25). In contrast, by providing facilitative comments, a teacher tries "to create motivation for immediate and substantive revision by describing a careful reader's uncertainties about what a writer intends to say" (I26). Straub advises teachers to "resist taking over student texts" and to offer comments that "share responsibility with the writer" (I30).

The reflective respondents in the Anson study mentioned earlier exemplify facilitative teachers. Their comments focus on diverse issues such as "ideas, textual decisions, personal reactions" and offer ways to improve the essay without being dictatorial or appropriative (Anson 35I). Their comments also indicate that they are given between drafts or, if on final drafts, would serve as vehicles for further learning. Anson found that reflective respondents most frequently use some form of mitigation such as: "maybe you could think about . . .," "what if you . . .," and "how about seeing if there's a way to..." (35I). These are semantic phrases that serve at least three functions: (I) expressing the teacher's tentative suggestions in revising the paper, (2) indicating that the final decisions are the student's responsibility, and (3) mitigating the potential damage of comments that may be perceived as irreversible criticism. However, the impact of such phrases on students' affective and cognitive needs has scarcely been researched. Are LI and L2 students put off and confused by mitigated commentary as Hyland and Hyland suggest? Or do they benefit from mitigated commentary as Ferris ("Student Reactions," "The Influence") and Lea and Street have found? Which one of the two forms-directive or mitigated commentary-do students find most helpful?

\section{PARTICIPANTS AND DATA COLLECTION}

The site selected for the study on which this article is based is a community college that is part of a large urban university in the northeast United States. I selected two I5-week first-year English composition classes because they represented a typical classroom environment with students from a variety of cultural, linguistic, and academic backgrounds. Fourteen students (seven from each class) agreed to participate. The instructors, Jane and Adam (pseudonyms) had excellent reputations as dedicated teachers and several years of experience in teaching first year composition classes 
with mixed LI and L2 students. They agreed to be interviewed two times, at the beginning and end of the semester, and to have their feedback on two agreed-upon assignments collected. Interviews with the instructors provided background information on their teaching methods and their commentary practices. Both Jane and Adam said that they adopted a combination of the process approach and the English for academic purposes approach. They individually indicated that they responded to student essays with the intent of assisting students to think through their ideas and express them as clearly as possible, and that one of their priorities was to foster students' ownership of their writing. Jane and Adam also said that they provided comments as they thought necessary without feeling locked in by a particular prescription or methodology.

The sample of students selected for the interview was purposive rather than randomized in order to increase the scope and range of the data collected (Guba and Lincoln). Two students in each class had an A average, two students had F, D, or C- averages, and three students in each class had an average that fluctuated from $\mathrm{C}$ to $\mathrm{B}+$. The semi-structured, open-ended questions I used as a guideline are listed in Appendix B. In addition, I asked students questions related to comments they received on the two assignments under study. They had the original assignments with them while I had photocopies of the same. This facilitated addressing specific comments and cross-referencing student revisions. I conducted the interviews, which lasted one hour on average, before or after class in an empty room next to or in the vicinity of the classroom. The names of student participants are pseudonyms.

Following Creswell's suggestion, I gathered information through different methods; made a taxonomy of positive, mitigated, and directive comments; evaluated the student revisions; and conducted interviews with the instructors and the students. To control for variables related to the rhetorical structure and focus of the two assignments under study, the instructors gave the same two expository topics (Appendix C). The assignment on technology is referred to as Assignment A and the one on boys' toys as Assignment B. Also, to make sure that the commentary for both classes was given at the same time during the semester, Jane and Adam gave the two assignments one after the other in the middle of the semester.

I interviewed eight women and six men, from 22 to 55 years in age. For four of them English is their first language; for four of them - three West Africans and one Dominican-English is the language they received all their schooling in, and it is the language they feel most comfortable writing in if 
not conversing in as well. The six remaining students represent more typical L2 students in that they may still have some problems with fluency in English even though, except for Kim, they have passed the English writing proficiency exam required by the university to register for this freshman composition class. Four of the L2 students are from the Dominican Republic, one is from Haiti, and one is from South Korea. In the transcription of the interviews, quotations within quotations are italicized to better indicate that the student or I, the interviewer, were quoting someone else.

\section{QUANTITATIVE FINDINGS}

The number of comments the fourteen students received on their first, second, and (in three cases) third drafts, on the two assignments was 385 . Jane wrote more comments (243) than Adam (I42), and she had three of her students, Yvette, Kim, and Nancy, rewrite the assignment on boys' toys a third time (see Table I).

Table I

Number of Comments Written by the Two Instructors

\begin{tabular}{|l|l|l|l|l|}
\hline & $\mathbf{I}^{\text {st }}$ drafts & $2^{\text {nd }}$ drafts & $3^{\text {rd }}$ drafts & Total \\
\hline Jane & I 37 & 87 & I 9 & 243 \\
\hline Adam & 82 & 60 & O & I 42 \\
\hline Total & 2 I 9 & I 47 & I & 385 \\
\hline
\end{tabular}

Not surprisingly, the two teachers wrote more comments on first drafts (2I9), which students were going to revise, than on second drafts (I47). Table 2 shows the frequencies and percentages of the commentary categorized as praise, mitigated comments, directives, and other. 
Table 2

Types of Comments Written by the Two Instructors

\begin{tabular}{|c|c|c|c|}
\hline & Jane & Adam & Total \\
\hline $\begin{array}{l}\text { Praise } \\
\qquad \begin{array}{l}I^{\text {st }} \text { drafts } \\
2^{\text {nd }} \text { drafts } \\
3^{\text {rd }} \text { drafts }\end{array}\end{array}$ & $\begin{array}{l}55(22.6 \%) \\
28 \\
2 \mathrm{I} \\
6\end{array}$ & $\begin{array}{l}29(20 \%) \\
\text { I3 } \\
\text { I6 }\end{array}$ & $84(2 \mathrm{I} .8 \%)$ \\
\hline $\begin{array}{l}\text { Mitigated Commentary } \\
\text { I }^{\text {st }} \text { drafts } \\
2^{\text {nd }} \text { drafts } \\
3^{\text {rd }} \text { drafts } \\
\text { - lexical hedges } \\
\text { - syntactic hedges } \\
\text { - paired act pattern } \\
\text { - personal attribution }\end{array}$ & $\begin{array}{l}43(\mathrm{I} 7.6 \%) \\
30 \\
\text { IO } \\
3 \\
\\
\text { II } \\
\text { I7 } \\
7 \\
8\end{array}$ & $\begin{array}{l}\text { I5 (IO \%) } \\
\text { II } \\
4 \\
\text { IO } \\
\text { O } \\
5 \\
\text { O }\end{array}$ & $\begin{array}{l}58(\mathrm{I} 5 \%) \\
\\
2 \mathrm{I} \\
\text { I7 } \\
\text { I2 } \\
8\end{array}$ \\
\hline $\begin{array}{l}\text { Directives } \\
I^{\text {st }} \text { drafts } \\
2^{\text {nd }} \text { drafts } \\
3^{\text {rd }} \text { drafts }\end{array}$ & $\begin{array}{l}\text { IO7 }(44 \%) \\
60 \\
40 \\
7\end{array}$ & $\begin{array}{l}96(67.6 \%) \\
57 \\
39\end{array}$ & $203(52.7 \%)$ \\
\hline $\begin{array}{l}\text { Other (e.g., clarifica- } \\
\text { tion, personal note, funny } \\
\text { remark) } \\
\quad I^{\text {st }} \text { drafts } \\
\quad 2^{\text {nd }} \text { drafts }\end{array}$ & $\begin{array}{l}38(\mathrm{I} 5.6 \%) \\
\text { I9 } \\
\text { I9 }\end{array}$ & $\begin{array}{l}2(.0 \mathrm{O} \%) \\
\mathrm{I} \\
\mathrm{I}\end{array}$ & 40 (IO\%) \\
\hline
\end{tabular}

Almost $22 \%$ of Jane and Adam's commentary consisted of praise, a middle range when compared to similar studies (see Appendix A for definitions and examples of the different types of comments). In Dragga's Li study merely $6 \%$ of the commentary was positive and in Daiker's Li study praise comprised I0.6\% of the comments. Studies conducted in L2 classes indicate higher praise percentages: Ferris ("The Influence") and Ferris et al. found that the average for praise was $24.6 \%$, and Hyland and Hyland found that out of 495 comments $44 \%$ were positive. Hyland and Hyland's one-to-one ratio of positive and critical comments stands out among these studies, raising the following question: Could receiving as much praise as constructive criticism lead students to doubt the sincerity of the positive comments? Is there a limit to how much praise a teacher should provide before it defeats the purpose? These two questions suggest the need for further research. 
Jane and Adam mitigated $15 \%$ of their commentary and wrote $52.7 \%$ directives. These data corroborate the Ferris L2 study ("The Influence"), which analyzed the commentary of one experienced teacher and revealed that mitigated commentary comprised $15 \%$ of all the comments. It also corroborates the results of the L2 study by Ferris et al., where the percentage of hedged comments among marginal notes was $16.7 \%$ and among end notes was $20.4 \%$. In Hyland and Hyland's L2 study, however, the two teacher participants mitigated $68 \%$ of their commentary while approximately $30 \%$ were categorized as "unmitigated." It's possible that the very high percentage of praise and mitigated commentary may have led the students in Hyland's and Hyland's study to believe that their teachers' paired-act pattern of preceding a critical comment with a positive one was too obvious and, therefore, insincere. Perhaps the two teachers in Hyland and Hyland's study gave praise too freely. In that case, as Sommers ("Across") points out, praise can have the opposite effect: instead of providing an incentive to improve, it stalls the interactive dialogue between teacher and student because the latter is not being challenged. In addition, praise that is perceived as being insincere has damaging repercussions on students' confidence and self-esteem (Young).

\section{QUALITATIVE FINDINGS}

The fourteen students I interviewed said they read every comment their teachers wrote and relied primarily on commentary to revise their papers. All fourteen also said that they spoke to their teachers if they had difficulty understanding a comment. Except for one, all indicated that it was as important to them to receive feedback on what they were doing well as on what needed improvement. The majority of students (nine) favored mitigated commentary, three students said they preferred "straightforward" commentary, and two said it didn't matter to them.

\section{Comments Students Find Most Helpful}

Nine of the fourteen students indicated that some form of mitigation-whether a positive phrase preceding criticism or the use of hedges such as "perhaps" or "maybe"-was helpful to them. Contrary to Hyland and Hyland's findings, none of the students interviewed doubted the sincerity of their teachers when the "but" or "however" formula was used. The majority of students pointed out that this form of mitigation is very effective. Anthony 
and Erika reflect the feelings and opinions of most. Anthony is a 32-year-old from Ghana, West Africa, and has been in the U.S. for five years. English was the mandatory language used throughout his schooling even though it is not his first language. He has a $\mathrm{C}$ average in his English class.

Anthony: Like I was saying, some comments are good; for example, like my communication professor, any time she wanna make a negative comment, she starts by saying, it's good but you should have put it this way. She first gives you a positive comment and then what you should have done. You know what I mean?

Interviewer: Yes.

Anthony: So she always goes like this, it's good but you should have done it this way, or you should have included this. I think those comments are very helpful.

Interviewer: Why are they helpful?

Anthony: It says that you are doing fine, that you should have to improve on it. So every time you see good comments like you are doing good, you should have done this way, it gives you like a sense of encouragement.

Erika is 25 and was born in this country, where she did all her schooling. She doesn't feel confident about her writing and is pleasantly surprised to have a B average in her English class.

Interviewer: Here your teacher writes, you have some good ideas; you need, however, to work on your sentence structure to make your ideas clearer. What do you think of this comment?

Erika: That I have good ideas. It makes me feel good ... that I need to work harder ... that I have some, like I understand something, but then I need more work at it.

Interviewer: Would you have preferred that the teacher only wrote what you needed more work on?

Erika: No, I think this is favorable.

Interviewer: Why?

Erika: Because it makes me feel good that I have good ideas, then it makes you think that you have to work harder in order to do better.

Interviewer: If you were a teacher, which method do you think 
would work best: giving a compliment and then write what the student needs to work on, or telling the student what's wrong?

Erika: No, I think I would do it like that because if you only put bad things, it puts the person down; it makes them not want to work harder

Interviewer: In this comment your teacher writes, you raised some good points, but how can parents, for instance, make a difference? How do you feel about this comment?

Erika: Like I felt about the last one, that I feel good that I put good points, but then also I need to work harder.

Interviewer: Do you feel in any way put down by this comment?

Erika: No. I would feel bad if like he told me I was doing good and I wasn't doing good.

Interviewer: Do you think your teacher is being honest?

Erika: Uh um.... [nodding]

Receiving encouragement was especially crucial for two students who were struggling in class and working on acquiring fluency in English. Nancy and Kim clearly expressed that mitigated commentary gave them a sense of acknowledgment for their hard work and motivated them to keep at it. What follows are excerpts of my respective interviews with them. Nancy is a 4Iyear-old single mother returning to college and clearly having a hard time balancing her schoolwork and taking care of her children. She was born in the Dominican Republic and has been in the U.S. for fifteen years.

Nancy: When somebody, in my case, when some professor corrects something and tells me, this is bad, it's not good, I feel depressed. I don't have the fuerza [strength] to continue. For example, one day I went to tutoring to correct something. A tutor said, this doesn't make sense, it's ridiculous, you know. Yeah, she told me that. I closed my eyes and I felt like something on the floor, you know. Oh my God! I'm trying to do my best and when you don't understand something, and somebody tells you something mean, it's like saying you are stupid. I don't understand anything anymore when somebody tells me stupid!

Interviewer: I guess your mind shuts down. 
Nancy: Yeah, I'm broken. For me that's not my thing. For some tutor to help me to correct my paper and say it doesn't make sense! Read to me and try to help me fix the paper, but why go to tutoring if somebody tells me it doesn't make sense, you know?

Interviewer: Here your teacher writes, You are improving, Nancy, but you still need some guidance in correct English translation. Take this essay to the writing lab as well.

Nancy: Yeah, I continue to improve but sometimes I think in Spanish and I translate, this is what she wants to tell me.

Interviewer: So here she is telling you the problem, but she is also saying a positive thing.

Nancy: Yeah, this made me feel good and continue to do my work. If she said here, you didn't improve, you have to correct this, I don't have the wish to continue, you know? Because if I don't improve, why do I have to do the work?

Kim is from a small island in South Korea. He is 26 , served in the navy in his country and attended the University of Seoul for two years. Kim has been in the U.S. for six months and wants to pursue a degree in accounting.

Interviewer: Here your teacher writes, Kim: nice job; your best writing this semester, you've worked conscientiously and it shows! How did you feel when you read this comment?

Kim: When I read this comment I felt like I can do anything. I can write, you know, something as well as American speakers. This gave me very encouragement I think. Encouragement. Encouragement very much, so I read it over and over. I need, I need to get encouragement, you know.... When I went to language school, the teacher said to me your writing level is very bad. Even though he taught English well, he never gave us any praise, encouragement. I really, really hated to enter that class.

Some days you feel good about your writing, some days you don't. Even though I have a lot of experience, I cannot write well if I feel bad. I can't.

Interviewer: I understand. You are saying it's important to feel encouraged.

Kim: Yeah, yeah, of course, of course. 
While Nancy and Kim were keenly aware of and outspoken about their need to be encouraged by their teachers, other students had difficulty recognizing such a need. Francisco, a 27-year-old "middle" student in Adam's class, exemplified the conflict that many of the students interviewed were experiencing: As grownups they believe they should not let their teacher's commentary personally affect them, yet they understandably feel hurt when their work or efforts are not acknowledged. During the interview, Francisco conceded he had done a rushed job in revising his paper on technology yet expressed disappointment about the grade he received (C) and said he would talk to Adam about it. He and I had read and discussed each comment on the paper when I raised the following issue:

Interviewer: Most of the comments your teacher gives you here are very direct, needs a title, not clearly stated, use "and so forth", you have used this "especially boys." Do you think a teacher should, at times, be less direct?

Francisco: What do you mean?

Interviewer: Should teachers occasionally write nice things on student papers?

Francisco: Probably he doesn't think there are good points in it. Interviewer: What do you think, are there good points?

Francisco: Yeah, it is my opinion, yeah, I think it is good. It is perfect to me.

Interviewer: What do you think would have helped you to feel better?

Francisco: [pause] Eh, probably a couple of good comments.

Interviewer: Why?

Francisco: That would be great because that way I would feel like, okay I'm doing bad on this, but I'm doing great on this. I need to work more on that, like subject-verb agreement, probably grammar, anything like that, but my organization is good, something like that. I think I would feel better. I would feel better, yeah.

Interviewer: So you think it's helpful?

Francisco: Yes, it would be helpful. It depends also on the person. I'm 27 years old, if we are talking about an I8-year-old kid, 20, I imagine it would be different.

Interviewer: How would it be different?

Francisco: They are more sensitive. We are talking about adult people, so ... 
Interviewer: But you seem disappointed?

Francisco: No I'm not, I'm not disappointed, I'm ready. I think I can do better.

Francisco, who was born in the Dominican Republic and has been living in the U.S. for almost nine years, acknowledged that some positive feedback would have made him feel less discouraged about his paper. At the same time he saw himself as an adult who didn't need to be patted on the back. He tried to control his discouragement by projecting self-assurance; hence he ended the conversation with an assertive statement, "I'm ready." But he soon modified it: "I think I can do better."

Bart is an ambitious 32-year-old from Sierra Leone, West Africa, who has been in the U.S. for eight years. He attended a civil engineering college in his country and plans to major in paralegal studies to pursue a degree in law. Although Bart's writing is clear and quite fluent, his essays show little or no revision, the reason why he has a C-/D+ average in the class. He stated that his full-time job and having a family leave him little time to work on the revision of his writing assignments. Bart's insistence that he did not need any positive feedback (like Francisco's) was in part related to his association of receiving praise with being a schoolchild, and in part to his disappointment at having received Cs on the two papers that were discussed.

Interviewer: Do you think it's important or not important that a teacher, besides writing critical comments-that is what you need more work on-also writes comments such as you are doing a good job, I like what you say here, this is an interesting idea?

Bart: No, no. Only what is wrong should be marked, that's what I think.

Interviewer: Why only what is wrong?

Bart: Because that's why I'm here.

Interviewer: Yes, but don't you think we learn from positive feedback too?

Bart: Yeah, but if you keep doing that, it's like dressing someone in a borrowed robe. Whatever is not marked, I know that is nice, but whenever I see comments, I know I have to make corrections there.

Interviewer: Okay.

Bart: I think that way is better. 
Interviewer: Okay, so you don't need to hear any positive comments from your teacher.

Bart: I know all the remaining parts of the essay are good.

Interviewer: Are they good or excellent? [laughs]

Bart: Yeah, excellent, [laughs] yes.

Interviewer: How do you know?

Bart: Because there is nothing to correct. Everything is correct like this opening thesis statement, this topic sentence. I know it's correct, that's why. ...

Interviewer: We are not talking about corrections; we are talking about comments on the development and organization of your ideas.

Bart: Yes.

Interviewer: And how do you know this is excellent?

Bart: Um, [pause] because I have done too many years, that's why I was able to write like this. See, it's not a day's job. It's a gradual process.

Bart's stressing his good writing skills was clearly a defensive stance in reaction to his teacher's comments that both of his papers were logically weak. Bart appeared to be trying to come to terms with a blow to his confidence by minimizing the importance of positive feedback. Bart also had difficulty with comments like this one on his technology paper, "Passionate, but too one-sided. In your world it seems there are no negatives, but aren't there?" By failing to address this comment, he was expressing disagreement. In fact, Bart defended the logic of his paper when I asked him why he had not followed up on the comment, saying he had no time to talk it over with Adam. In the course of the interview, he indicated that because he viewed the teacher as an authority figure, he could not bring himself to challenge his teacher's comments. He also stated he would have "done a better job" if he had had more time. Bart had a full-time job and was the breadwinner of the family. One question, however, remains: Would Bart have reacted differently to Adam's commentary if it had been more carefully and specifically worded? For example, what would have been Bart's reaction if Adam had elaborated on the passionate quality of his paper and given more detailed suggestions on how to tackle the one-sided aspect? 


\section{Students' Responses to Mitigated Comments}

Two of the nine students who favored mitigated commentary referred to it as a form of politeness and respect. This is the way Rhonda, an A student who emigrated from Haiti and has been living in the U.S. for three years, put it:

Interviewer: Your teacher here adds a phrase to your text and writes you may, of course, use your own words; my words here are merely a suggestion. You said earlier that you like this comment, why?

Rhonda: Well, I think it's like, I think it's a sign of respect because, you know, we are not, she is not dealing with little kids, like kindergarten or high school kids.... We are people, most people in college have children, you know, they are grown children. The same respect they give to the professor, they expect to have the same respect, too. So you are not going to deal with us the same way you deal with the little kids, so it's like, she is respecting you, she is telling you that something is wrong but at the same time she is not imposing herself, you know, that is respect, I think, and I like it.

Ana, a "weak" student from the Dominican Republic who has been in the U.S. for I3 years, also stressed the importance of politeness:

Interviewer: What is the meaning of this comment, expand this a bit more, please?

Ana: That means make it better, please, you see.

Interviewer: What if your teacher had said, expand this.

Ana: No, that's not good.

Interviewer: Why?

Ana: Because I think this is mandatory, um, not polite.

Despite the wide difference in age-Rhonda is 26 and Ana is 55-both students expect their teachers not to be authoritative or condescending but to communicate with them in a polite manner.

Four of the students who favored mitigated commentary seemed aware that their teachers used this technique to encourage and motivate students to revise, and instead of being put off by it, as the students in Hyland and Hyland's study were, they appreciated their teachers' tactfulness and 
expressed no doubt about the sincerity of the comments. Yvette, a "highmiddle" student from Trinidad, said it best:

Interviewer: Yvette, have you followed up on this comment, maybe you need to add a second quote here, Yvette. Because the question arises, "surrounded by what?"?

Yvette: I rewrote the whole thing [shows me her revision].

Interviewer: Why do you think your teacher said maybe you need to ...?

Yvette: This is not the first time she wrote maybe. It's her expertise in the field, trying to get her students, you know, to write clearer, or perhaps add a little more touch. That's the case why she used the word maybe. That's just my understanding, so I didn't have to do exactly what she said by maybe, so compare it to this one, This is an incomplete quote. It makes no sense. This is just, this is just telling me to think about what I did wrong, how could I rewrite it? How do I use the quote in quoting my son because this is a true thing, you know, I'm trying to make it right. But maybe you need to add a second quote here means I don't have to.

Interviewer: Is that the only reason why you think your teacher used the word maybe?

Yvette: She is very helpful, at the same time she uses tact [laughs].

Interviewer: And is it okay for a teacher to use tact?

Yvette: Yeah, do you know why? Because some of us are very sensitive [laughs]. Some of us are very sensitive, some of us as students.

Ken, a 23-year-old A student and one of the three who indicated that he prefers directives, made the following observation about his teacher, Adam:

Interviewer: Would you say your teacher has a tendency to write direct or indirect comments?

Ken: I think he writes moderate comments. He is in the middle. He doesn't wanna be too harsh, he doesn't wanna be too soft.

Interviewer: And what do you think about that?

Ken: I like that. He is a good teacher. 
Ken, who was born and reared in the United States, felt somewhat confident about his writing, and although he associated direct phrasing with being harsh and indirect phrasing with being soft, he was able to keep some emotional distance and appreciate his teacher's "middle" approach. However, for students like Nancy, who was struggling in class, it was harder to separate personal feelings from the perception that direct comments were intended as criticism. The following is one of many instances during our interview where she indicated that she found directives harsh and ineffective:

Interviewer: Here your teacher wrote, confused phrasing; doesn't make sense. She wrote something similar to what that tutor told you. How do you feel about this comment?

Nancy: When some professor writes to me this doesn't make sense, how can I make this to make sense because to me it makes sense?

Interviewer: How does it make you feel?

Nancy: I feel discouraged because I have to fix that, and I wanna go to the writing center and see somebody who tells me, oh, you can do it this way so it makes sense.

Interviewer: Would you have felt differently if your teacher had said, this is not very clear to me?

Nancy: Yeah, it's not very clear to me makes more sense than this doesn'tmake sense because it's something that the professor says but doesn't say directly, you know?

Interviewer: And why do you prefer the indirect way of saying it?

Nancy: It makes me feel better.

In the dialogue, Nancy indicated that the most helpful comments were those that told her why something didn't make sense and suggested how she could revise it. She also expressed the need for indirect (mitigated) criticism because it was not as discouraging as the direct approach.

Five of the students who preferred the mitigation technique indicated that one aspect they found helpful was that they were being given a choice. In one instance, Jane added the following phrase and comment to the ending of a student's text, "... if they want to encourage their sons to make the right choices in life. (Completes your analysis; you may, of course, use your own words; my words here are merely a suggestion of how to sum up your conclusion)." This is how Rhonda responded to the comment: 
Interviewer: What do you think of this comment?

Rhonda: I think it's good because first of all she is not telling me that was bad, you need to do it that way. She is telling me that, you know, if you want to, you can use the example I gave you. And I just like the way she puts the, how do you say, the comment. She is not telling me, you have to do this, you have to do that, she is telling me if you want to make it better, do it like that-do it like that-so I'm like, okay, so I don't feel she is like after me, so I like the way she puts the comments.

Rhonda is a "strong" student and here she was indicating that she welcomed the sense of being in control of her writing that the comment implied. Kim, a “weak" student in Jane's class also appreciated being given a sense of intellectual independence. This is how he put it:

Interviewer: Your teacher here writes, I think "separate" is a more precise word. What do you think of this comment?

Kim: Oh, yes, this is a translation problem.

Interviewer: How do you feel about it?

Kim: Professor Jane is a very nice professor, nice teacher, because, you know, she thinks about, she worries about me because, you know, if she said this is separate not part, oh my God! But she advised me first that I have to know the difference between separate and part. If I think that separate is better than part, that's a very good idea, then that encourages me to revise. But some professors say no, this is incorrect, use separate. So if that's it, then I am not thinking.

Interviewer: You mean you are not putting effort into the revision?

Kim: Right, right, I lost motivation.

Interviewer: Do you think she knows that separate is a better word, but she writes I think "separate" is a better word?

Kim: Yeah, yeah. Really she is, she is professional, you know. Also, she doesn't want to hurt you. She understands, you know, students, the situation, what kind of background they come from.

It was clear that Kim felt intellectually engaged by comments that involved him in the decision-making process. He was also implying that his weak English skills should not interfere with the interactive communication with his teacher. He was grateful that Jane was attentive to his need 
to be addressed as an adult and suggested-instead of telling him - what to do. Kim was also aware that Jane was sensitive to students' affective needs, their circumstances, and backgrounds. Most students, like Rhonda and Kim, indicated that although they carefully addressed both their teachers' directive as well as mitigated commentary, they preferred mitigated commentary because it made them feel they were treated with respect; it provided an intellectual interaction; and it gave them the freedom to make choices about their revisions.

\section{Students' Responses to Directive Comments}

The three students who said they found directives most helpful held a common belief that revision involved a right-wrong judgment. Bart's preference for directives was in part influenced by his disappointment with his teacher's comments, and by his defensive posture of an I-can-handle-it attitude. The other two students who said they preferred directive comments were both 23-year-olds and were also in Adam's class. Joann and Ken are native speakers of English, were doing well in class, and seemed fairly confident about their writing. However, they both seemed to have a one-direction approach to revision. The following dialogue with Ken exemplified this view:

Interviewer: Do you prefer comments that say do this, fix this, change this, or comments that say, maybe you should fix this, or try to fix this?

Ken: I like the straightforward, straightforward, the one that says, fix this, I like that.

Interviewer: Why?

Ken: Because it's blunt. It's right to the point. You don't have to go around it. The purpose of school is for the teacher to show you the correct way. If he is telling you straight, you got to fix this, you'll fix it, but if he says, maybe, I might just leave it there, you know, maybe.

Interviewer: What about try to fix this?

Ken: It's still too soft.

Interviewer: What if your teacher writes, I like this but you need to fix it?

Ken: That sounds good ... but then again that but in it kind of negates the whole sentence, you know what I mean? 
Interviewer: Yes.

Ken: Like I said, I think you should be straightforward . . . it's like, it's one thing or the other, you know.

Ken was not opposed to receiving positive comments (he made that even clearer later in the interview), but he didn't completely trust himself when comments gave him a choice. Also, he expressed little tolerance for ambiguities. His concept of writing is that things are either correct or incorrect, thus, the "but" negated the positive part of the comment. He was the only student who questioned the purpose of "but" commentary, not because he thought his teacher was insincere but because his concept of revision is rigid and one-dimensional.

Like Ken, Joann said she preferred directives yet was not opposed to receiving positive feedback:

Interviewer: Do you prefer comments that say, work on this, change this, expand on this, or do you prefer comments that say, for example, I like what you wrote, but you should expand it a little more?

Joann: More like do this, do that.

Interviewer: You seem to prefer direct comments.

Joann: Yeah, tell me what to do, and I'll do it.

Interviewer: What if your teacher combines it with a compliment like in this case where he wrote, You have done a good job, check the corrections and edit for the 2nd draft?

Joann: But he is right.

Interviewer: What do you mean?

Joann: I think that it's important to let a person know how they are doing in the class. It's important to me because if he just put check corrections and edit for 2nd draft, it's like that's it ... I think it's better to let me know, is it good or is it bad? You know, so if it's bad, I would expect him to say this is bad, I need you to do this to make it better.

Interviewer: Do you think your teacher wrote this to make you feel better?

Joann: No, no, that was his opinion ... his opinion is important to me.

In the discussion, Joann indicated an eagerness to do well in class, "tell me what to do and I'll do it," and although she seemed to imply that 
she didn't need to be reassured by her teacher, she expected him to point out what she was doing well. Like Ken, Joann had a mind-set that she was as capable to handle criticism as she was to accept compliments, and she was not going to let criticism discourage her. While both Ken and Joann's self-assurance and determination are admirable, their traditional concept of the teacher as an authority figure whose job is to tell them "what's good and what's bad" may do them disservice. Neither of them seemed aware that revision isn't always a clear cut, one-dimensional process, and that often a teacher's job is to provide responses, suggestions, and guidance on a tentative ("let's see if this will work") basis that involves students in the decision-making process.

Juan is one of two students who said it didn't matter to him whether he received mitigated or directive commentary. He is 23 , the same age as Ken and Joann, and has been in the U.S. for five years. He comes from the Dominican Republic. Here he addresses some of Jane's indirect comments:

Interviewer: What is your instructor trying to tell you by writing this comment, I'm not sure that you are on the subject here?

Juan: That I'm not staying on the subject, that I'm not talking about values. On this, on that one, on superman, I wasn't talking about what she was expecting, so.

Interviewer: What if instead of saying I'm not sure, your instructor had written you are off the topic, would that have been clearer?

Juan: For me it's the same because she is not sure, she just, she is not saying that it's correct, so it's the same.

Interviewer: Do you think she is really not sure or is she trying to be kind?

Juan: Probably.

Interviewer: Does the way it's written make a difference to you? Juan: I'm telling you, for me it's the same because she didn't say that it's right, so this is right or wrong, in the middle, so for me it's wrong. I'm off the topic.

Like Ken and Joann, Juan has a narrow concept of what revision consists of - "so this is right or wrong, in the middle, so for me it's wrong." And when asked if the comment would have been clearer if it had been phrased as a directive, he replied that it was the same to him. Throughout the interview, Juan's response to comments appeared to be tied to larger issues such as an insufficient understanding of academic discourse, and therefore, a difficulty 
in interpreting commentary accurately. Nevertheless, when asked to react to some of the positive comments Jane had written on his papers, he said they made him "feel good" because they gave him "motivation."

Vanessa is the other student who said that it didn't matter whether comments were delivered in a direct or an indirect way. She is an outstanding, 30-year-old student from Nigeria and a gifted writer who got A+ on her papers in Jane's class. She didn't represent the average two-year-college student, yet she indicated that she appreciated receiving Jane's "personal note" comments because they made her feel acknowledged and gave her the notion she was carrying on a conversation with her teacher. She also stressed the value of receiving praise because, as she put it, "it makes me feel that there is a good part of me that she sees. There is something good in what I did.... it's a kind of encouragement."

\section{CONCLUSION: A TWO-WAY COMMUNICATION}

While mitigation, or hedging, does not appear to have a noticeable impact on the extent and quality of student revisions (Treglia), it plays a critical role as a "face-saving" technique and as a tool to motivate and engage students to take an active part in revision as my findings have shown: To most students indirectness or mitigation was a way to minimize hurt feelings. This was especially crucial for L2 students like Nancy and Kim who are still in the process of becoming fluent in English. It was compelling to hear them candidly describe how discouraged they felt by comments such as "makes no sense," "say what you mean," or "this is off the subject." They repeatedly said that such comments not only made them feel unmotivated to revise but also diminished their capacity to think. Even those students who felt they didn't need to be patted on the back indicated, throughout the course of the interviews, that they were unknowingly reacting to their teachers' feedback. Although they were trying to keep a certain emotional distance from their teachers' commentary, they could not help but be affected by it as the defensive stances of Juan, Francisco, and Bart demonstrated. Out of deference to authoritative figures and hurt pride, students like Bart may not approach their teachers about what they perceive as unfair comments. However, these incidents sever the student-teacher dialogue, leaving students wondering "what did I do wrong?" or, even worse, convincing them that the teacher has misjudged their papers.

Many of the students felt that, as adults, they appreciated communicating with their teachers on an equal basis. They welcomed comments that 
didn't restrict them but let them make their own decisions, such as comments with lexical hedges, e.g., "maybe," "perhaps," "might." This was true for weak, middle, and strong students alike. They all indicated that they found most helpful specific comments that gave them a sense of direction but left it up to them to make the final call. They expressed enthusiasm at being drawn in by their instructors to become active participants in the decision-making process of revision. Students who had been exposed for the most part to directive forms of communication in previous classes seemed particularly appreciative when Jane and Adam wrote commentary that conveyed trust in their abilities to revise. This is not surprising since teacher expectation is a significant factor in student achievement. Only a few students-those who seemed not to have grasped the concept that revision is a non-linear, non-unidirectional decision-making process-said they found directives most helpful.

In sum, students found most helpful the commentary that, in addition to indicating some acknowledgment of their work, offered specific suggestions and provided choices. In other words, the overwhelming majority of students wanted to be guided and shown how to, instead of simply being told what they needed to do. Most of them appreciated the choices that mitigated commentary provided. This came across not only through what students said during their interviews but also through their enthusiastic recollection of what they understood their teachers' comments to mean, and how they went about revising their work. Their faces lit up when they explained how they interpreted their teacher's mitigated commentary and revised their papers following the teacher's lead but coming up with their own solutions.

It was beyond the purpose of this study to probe into the long-term emotional and cognitive damage that students might experience when they feel hurt by their teachers' commentary. However, the interviews indicate that students care about their teachers' comments and take them more to heart than they are even aware of. The majority of the students, in fact, said that direct commentary could potentially be counterproductive because it might be perceived as lack of respect. A longitudinal study that addresses the emotional and cognitive repercussions students experience over time when they feel offended by their teachers' commentary would provide insight into this issue. A long-term study of this type could also explore the extent to which commentary impacts students' revisions of future writing.

My findings about student responses support the approaches and recommendations of such writing scholars as Anson, Brannon and Knoblauch, 
Elbow, Ferris ("Response"), Probst, Sommers ("Responding" and "Across"), and Straub ("The Concept") that to encourage students to be responsible and develop a sense of ownership over their writing, teachers do well to avoid authoritative communication. This group of students was willing to take responsibility for revising if given a chance. Are teachers as receptive as students to mitigated commentary? If not, what are the factors that hold them back? A survey of teachers on their use or avoidance of mitigation would be pedagogically informative.

The findings of this study dispute Hyland and Hyland's conclusion that the use of mitigation can be a source of significant misunderstanding between L2 students and their teachers. Similarly, the findings do not support Ferris' hypothesis ("The Influence") that the favorable L2 student responses to mitigated comments in her study were attributable primarily to the advanced English-language proficiency of the students and to their having become aware that the use of mitigation is a form of politeness in English. My study reveals that L2 students, including those who had been living in the U.S. for only a few years, were very sensitive about comments they perceived as impolite. Also, the L2 students seemed to appreciate mitigated commentary even more than the native speakers. Although the study didn't formally explore the role that mitigation plays in the native languages and cultures of these students, in many cultures certain kinds of directness are considered rude, particularly in Asia and Latin American countries. Thus the association of politeness with indirectness is not necessarily a new concept to L2 students. Although L2 students may not be fully fluent in English, teachers should not assume that they are not capable of engaging in a mature dialogue about their writing with responders-teacher and peers (Zamel). Teachers should also be aware that politeness interacts with issues of class and social status as well as issues of self-perception. Since students' self-esteem and view of their place in society can affect the way they interact with others, including peers and teachers, it certainly can have an impact on their reaction to and interpretation of feedback.

A larger study would be required to validate the findings of this study, particularly with regard to the long-term effects of directives on students' motivation and self-esteem. Nevertheless, the data, which has been triangulated by the multi-method approach and correlated by previous studies, supports the use of mitigated commentary. A teacher does not have to mitigate every comment but should be aware that comments that combine praise with constructive criticism are an effective tool to provide students 
with the confidence and motivation they need to actively engage in the revision process.

\section{Note}

I. LI refers to students who are native speakers of English; L2 refers to students, most of whom were born and raised in a non-English speaking country, who learned English as a second or third language.

\section{Works Cited}

Anson, Chris M. "Response Styles and Ways of Knowing." Writing and Response: Theory, Practice, and Research. Ed. Christopher M. Anson. Urbana, IL: National Council of Teachers of English, 1989. 332-66.

Barry, Dave. "The Ugly Truth about Beauty." The Longman Reader. 6th ed. Ed. Judith Nadell, John Langan, and Eliza A. Comodromos. New York: Pearson Education, 2003. 422-26.

Berlin, James. "Rhetoric and Ideology in the Writing Class." The Writing Teacher's Sourcebook. Ed. Edward P. J. Corbett, Nancy Myers, and Gary Tate. New York: Oxford UP, 2000. 9-25.

Brannon, Lil, and C. H. Knoblauch. "On Students' Rights to Their Own Texts: A Model of Teacher Response." A Sourcebook for Responding to Student Writing. Ed. Richard Straub. Cresskill, NJ: Hampton Press, I999. II7-28.

Coleman, Jonathan. "Is Technology Making Us Intimate Strangers?" The Longman Reader. 6th ed. Ed. Judith Nadell, John Langan, and Eliza A. Comodromos. New York: Pearson Education, 2003. 482-86.

Creswell, John W. Qualitative Inquiry and Research Design: Choosing among Five Traditions. Thousand Oaks, CA: Sage, 1998.

Daiker, Donald. "Learning to Praise." A Sourcebook for Responding to Student Writing. Ed. Richard Straub. Cresskill, NJ: Hampton Press, I999. I5363.

Dragga, Sam. "Praiseworthy Grading: A Teacher's Alternative to Editing Error." Paper presented at the Conference on College Composition and Communication. New Orleans, 1986.

Elbow, Peter. "Options for Responding to Student Writing." A Sourcebook for Responding to Student Writing. Ed. Richard Straub. Cresskill, NJ: Hampton Press, 1999. 197-202. 
Ferris, Dana R. Response to Student Writing: Implications for Second Language Students. Mahwah, NJ: Lawrence Erlbaum, 2003.

. "The Influence of Teacher Commentary on Student Revision." TESOL Quarterly 3I (I997): 3I5-39.

. "Student Reactions to Teacher Response in Multiple-Draft Composition Classrooms." TESOL Quarterly 29.I (I995): 33-53.

Ferris, Dana R., Susan Pezone, Cathy R. Tade, and Sharee Tinti. “Teacher Commentary on Student Writing: Descriptions \& Implications." Journal of Second Language Writing 6 .2(I997): 155-82.

Giberson, Greg A. "Process Intervention: Teacher Response and Student Writing." Teaching English in the Two-Year College 29.4 (2002): 4II-I7.

Goldstein, Lynn M. Teacher Written Commentary in Second Language Writing Classes. Ann Arbor: U of Michigan P, 2005.

Guba, Egon G., and Yvonna S. Lincoln. Effective Evaluation: Improving the Usefulness of Evaluation Results through Responsive and Naturalistic Approaches. San Francisco: Jossey-Bass, I98I.

Hyland, Fiona, and Ken Hyland. "Sugaring the Pill: Praise and Criticism in Written Feedback." Journal of Second Language Writing IO.3 (200I): I85$2 \mathrm{I} 2$.

Ivanic, Roz, Romy Clark, and Rachel Rimmershaw. "What Am I Supposed to Make of This? The Messages Conveyed to Students by Tutors' Written Comments." Student Writing in Higher Education: New Contexts. Ed. M. Lea and B. Stierer. Buckingham, UK: SRHE and Open UP, 200o. 47-65.

Knoblauch, Cyril H., and Lil Brannon. Rhetorical Traditions and the Teaching of Writing. Upper Montclair, NJ: Boynton/Cook, I984.

Lea, Mary, and Brian Street. "Student Writing and Staff Feedback in Higher Education: An Academic Literacies Approach." Student Writing in Higher Education: New Contexts. Ed. M. Lea and B. Stierer. Buckingham, UK: SRHE and Open UP, 2000. 32-46.

Mutch, Alistair. "Exploring the Practice of Feedback to Students." Active Learning in Higher Education 4.I (2003): 24-38.

Onore, Cynthia. "The Student, the Teacher, and the Text: Negotiating Meanings through Response and Revision." Writing and Response: Theory, Practice, and Research. Ed. Christopher M. Anson. Urbana, IL: National Council of Teachers of English, I989. 23I-60.

Perpignan, Hadara. "Exploring the Written Feedback Dialogue: A Research, Learning and Teaching Practice." Language Teaching Research 7.2 (2003): 259-78.

Probst, Robert E. “Transactional Theory and Response to Student Writing.” 
Writing and Response: Theory, Practice, and Research. Ed. Christopher M. Anson. Urbana, IL: National Council of Teachers of English, I989. 68-79.

Purves, Alan C. "The Teacher as Reader: An Anatomy." College English 46.3 (I984): 259-65.

Rubin, Lillian. “'I Just Think Maybe You Could ...:' Peer Critiquing through Online Conversations." Teaching English in the Two-Year College 29.4 (2002): 382-92.

Shaughnessy, Mina P. Errors and Expectations: A Guide for the Teacher of Basic Writing. New York: Oxford UP, I977.

Sommers, Nancy. "Across the Drafts." College Composition and Communication 58.2 (2006): 248-57.

. "Responding to Student Writing." A Sourcebook for Responding to Student Writing. Ed. Richard Straub. Cresskill, NJ: Hampton Press, I999. IO7-I6.

Stern, Lesa A., and Amanda Solomon. "Effective Faculty Feedback: The Road Less Traveled." Assessing Writing II.I (2006): 22-4I.

Straub, Richard. "The Student, the Text, and the Classroom Context: A Case Study of Teacher Response." Assessing Writing 7.I (2000): 23-55.

. "The Concept of Control in Teacher Response: Defining the Varieties of 'Directive' and 'Facilitative' Response." A Sourcebook for Responding to Student Writing. Ed. R. Straub. Cresskill, NJ: Hampton Press, I999. I29-52. . "Students' Reactions to Teacher Comments: An Exploratory Study." Research in the Teaching of English 3I (I997): 9I-II9.

Treglia, Maria O. "A Study of Teacher-Written Commentary on Student Revisions and Perceptions in College Writing Classes." Diss. New York $\mathrm{U}, 2006$.

Weaver, Melanie R. "Do Students Value Feedback? Student Perceptions of Tutors' Written Responses." Assessment \& Evaluation in Higher Education 3I (2006): 379-94.

Young, Pat. “'I Might As Well Give Up': Self-Esteem and Mature Students' Feelings about Feedback on Assignments." Journal of Further and Higher Education 24.3 (2000): 409-I8.

Zamel, Vivian. "Toward a Model of Transculturation." TESOL Quarterly 3I.2 (I997): 34I-52. 


\section{APPENDIX A \\ Operational Definition of Mitigated Commentary}

Mitigation is a form of politenessintended tobuffer and mediate theemotional involvement and possible sense of inadequacy related to receiving critical responses to one's writing (Rubin). Criticism can be softened by the use of praise (compliments), paired act patterns, lexical and syntactic hedges, and personal attributions (adapted from Ferris ["The Influence"]; Hyland and Hyland).

\section{Praise}

Make a positive comment, statement, or exclamation Examples: A very nice start to your essay!

You have done an impressive job of finding facts and quotes to support your argument.

\section{Paired act patterns}

I. Preceding a negative comment with a positive one (praisecriticism)

Example: Vocabulary is good but grammar is not accurate and often makes your ideas difficult to understand.

2. Combining critical remark with a suggestion (criticismsuggestion)

Example: This is a very sudden start. You need a more general statement to introduce the topic.

3. Praise-criticism-suggestion triad

Example: References very good. Two small problems: (I)

Bibliography (at end of essay) include initials of authors. (2) Be careful about referencing inside the essay. 


\section{Hedges}

I. Lexical hedges (e.g., maybe, please, might, a little)

Examples: You might want to expand your introduction.

Some of the material seemed a little longwinded and I wonder if it could have been compressed a little.

2. Syntactic hedges (construct criticism in interrogative form)

Examples: Can you add an example here?

The first two paragraphs - do they need joining?

\section{Personal attribution}

Express commentary as a personal response

Examples: I'm sorry, but when reading the essay, I couldn't see any evidence of this really. Perhaps you should have given me the outline to look at with the essay.

My concern in this essay is that you introduce several terms in the introduction but do not provide a definition for any. 


\section{APPENDIX B}

\section{Protocol for Interview with Students}

I. When your teacher returns your essay, do you read all of the written comments or just some of them?

2. During the process of revision how much do you rely on the teacher's comments? Do you go back to your teacher and ask her or him to clarify a comment you may not have understood?

3. How do you usually feel after reading your teacher's comments?

$$
\text { Encouraged Same as before Discouraged }
$$

4. How do you feel when you finish writing a draft? Are you optimistic about having done a good job or do you usually feel you could have done better?

5. What are some types of comments you find helpful? (Student will point them out in the copies of her or his essays that I bring to the interview.)

6. Now show me in the essays any comments you didn't find useful and tell me why.

7. Do you prefer that your teacher write a lot of comments, a moderate number, or very few? Explain the reason for your preference.

8. Do you feel you have learned from your teacher's comments? Could you give me some examples?

9. What is one thing that a teacher can do to help you improve your writing? 


\section{APPENDIX C}

\section{Student Assignments}

The instructors assigned students two reading selections, "Is Technology Making Us Intimate Strangers?" by Jonathan Coleman and "The Ugly Truth About Beauty" by Dave Barry. The two assignments under study were based on the following prompts:

Coleman believes that technology "enables us to avoid others." Focusing on one or two specific technologies, write an essay in which you argue against this view. Show instead that technology can enhance interpersonal relations. Acknowledge Coleman's viewpoint near the beginning of the essay. Like Coleman, support your position with vigorous images, heartfelt commentary, and lively examples.

Barry blames Barbie dolls for setting up "a difficult appearance standard" for girls to emulate. Many would argue that the toys that boys play with also teach negative, ultimately damaging values. Write an essay exploring the values that are conveyed to boys through their toys. Brainstorm with others, especially males, about the toys of their youth or the toys that boys have today. Identify two to three key negative values to write about, illustrating each with several examples of toys. 


\section{News and Announcements}

\section{National Survey of Basic Writing Programs}

Sponsored by the Conference on Basic Writing, the National Survey of Basic Writing Programs is intended to gather information nationwide about Basic Writing programs, policies, teaching practices, demographics, and the effects of state and local legislation on them. Approved at the CBW workshop at the 2008 Conference on College Composition and Communication, the survey will be available on CompFAQs starting September 2008. The initial survey results will be presented at the CBW workshop at CCCC in 2009. The database will provide national information for teachers, researchers, and program administrators about the history, structures, and practices of Basic Writing in the U.S. Its effectiveness, however, depends on how many surveys are completed. We urge program administrators to complete the Survey for the Basic Writing program or courses at your institution and to encourage colleagues at other institutions to do the same. You can fill in part of the survey, save it, and return to complete it at a later date. Even partial completion will contribute to the collection of national data.

\section{Conference on Basic Writing Award for Innovation}

The Conference on Basic Writing's Award for Innovation recognizes writing programs for innovations that improve educational processes for basic writers through creative approaches. Please note that only innovations that have been implemented will be considered for the award.

CBW wants to recognize those college and university programs that are implementing new or unique ways to improve the success of their basic writing students. Is your program doing something especially useful and effective in terms of assessment, placement, pedagogy, curriculum, community outreach, etc.? If so, please nominate yourself for the $2009 \mathrm{CBW}$ Award for Innovation.

SELECTION PROCESS: Recipients of the Conference on Basic Writing's Award for Innovation Award will be determined by a review group. Awards will be given to approaches that clearly benefit students at the winning institution, and that may be extended to other institutions. AWARD CRITERIA:

- Originality - the creativity and uniqueness of the innovation

- Portability - the extent to which the innovation lends itself to application in other institutions or contexts 
- $\quad$ Results and Benefits-specific details, data, and observations derived from the innovation, focusing on specific educational benefits to students

APPLICATION MATERIALS: ALL application materials must be submitted in electronic form, and all applications will be acknowledged. Please send:

- A descriptive title of the innovation, along with the name, address, phone number, and email of the contact person.

- An explanation of how the course/program in which the innovation is centered includes students labeled "basic writers" by the institution and, if applicable, a brief (I paragraph maximum) explanation of how students are labeled as such.

- A complete description of the innovation including:

(I) justification of the creativity and uniqueness of the innovation compared to traditional methods; (2) evidence or examples of portability to other basic writing programs;

(3) the measurements and monitoring used; (4) results indicating a significant benefit in achievement in educational goals or outcomes.

- Note that Innovation documentation is limited to five (5) single-spaced pages or less (excess pages will not be read!) in II-point font or larger. Graphs and charts are accepted as part of the page limitation.

\section{IMPORTANT DATES}

December I, 2008: Nominations due January 2009: Award recipient notified

March 2009: The Winner will be honored with the presentation of a plaque at the CBW Special Interest Group (SIG) at CCCC in San Francisco. The winner will be invited to give a brief presentation about the winning program to the SIG attendees.

SEND APPLICATIONS / DIRECT QUESTIONS TO:

Greg Glau, Northern Arizona University (g_glau@yahoo.com)

\section{Conference on Basic Writing CCCC Fellowship}

The Conference on Basic Writing is pleased to announce the 2009 CBW/CCCC Fellowship, a \$50o award given to a teacher of basic writing to subsidize travel to the Conference on College Composition and Communication in San Francisco in March 2009, and participate in the Conference on Basic Writing Pre-Conference Workshop. The CBW/CCCC Fellowship is 
intended to support basic writing (including preparatory and developmental writing) instructors who might otherwise have difficulty attending CCCC. Priority will be given to applicants who clearly demonstrate how attending the 2009 CBW workshop and CCCC will benefit their own professional development, their students, and their colleagues.

Fellowship applications should include a comprehensive two-page letter that addresses the following key issues:

- How will attending the CBW Workshop and CCCC benefit the interests and needs of the students with whom you work?

- How do you plan to share the information and ideas gathered at CCCC with colleagues?

- How will this experience help you to become more active in advocating for students in basic writing (or other preparatory/developmental writing) courses?

A completed Fellowship application should include the letter described above, a current curriculum vitae, and, if applicable, the title and abstract of an accepted 2009 CCCC presentation.

Please direct questions, concerns, and completed Fellowship applications by December I, 2008, to:

\author{
Dr. Sonya L. Armstrong \\ Northern Illinois University \\ Department of Literacy Education \\ I48 Gabel Hall \\ Dekalb, IL 60II5 \\ Sarmstrong@niu.edu
}




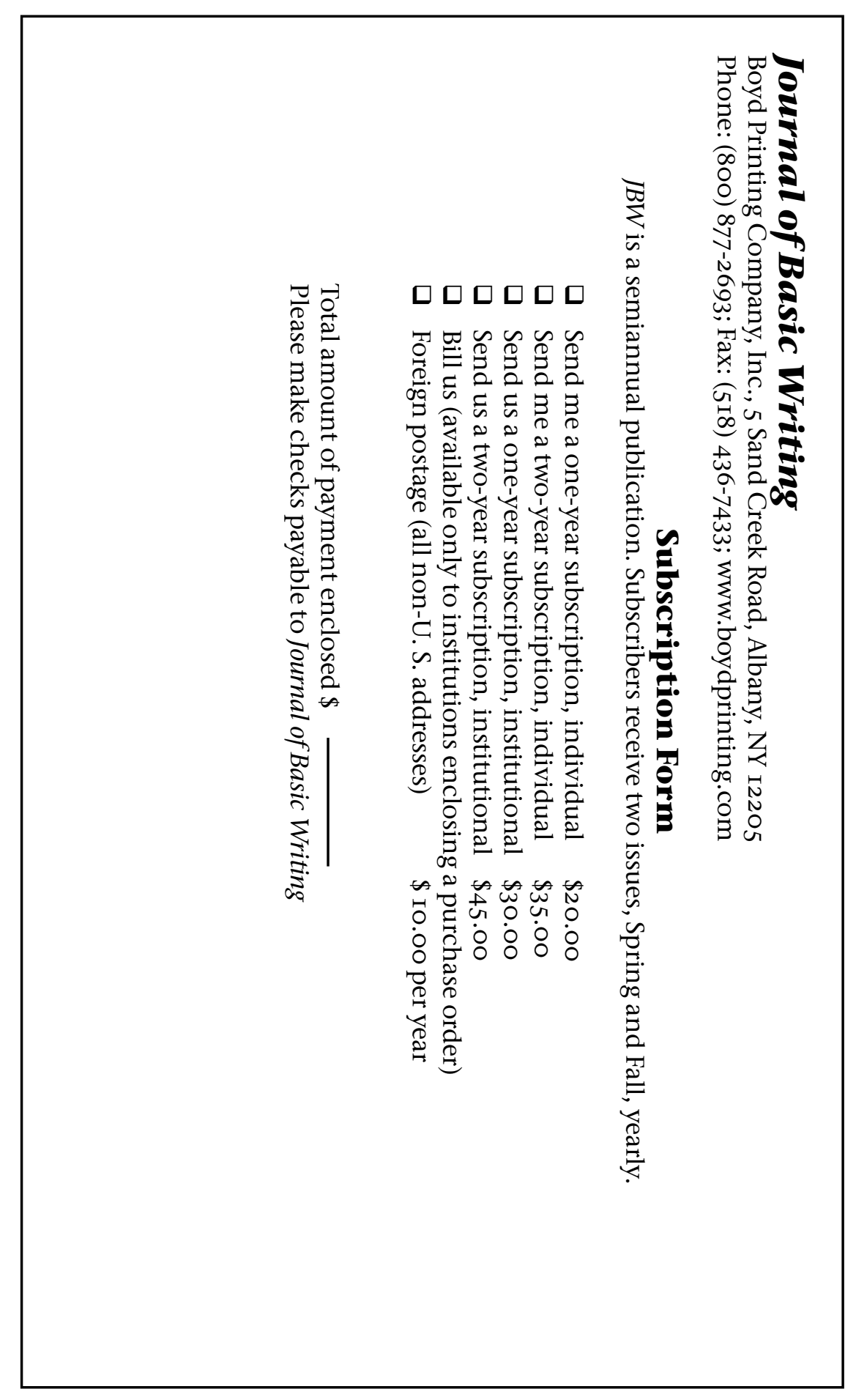



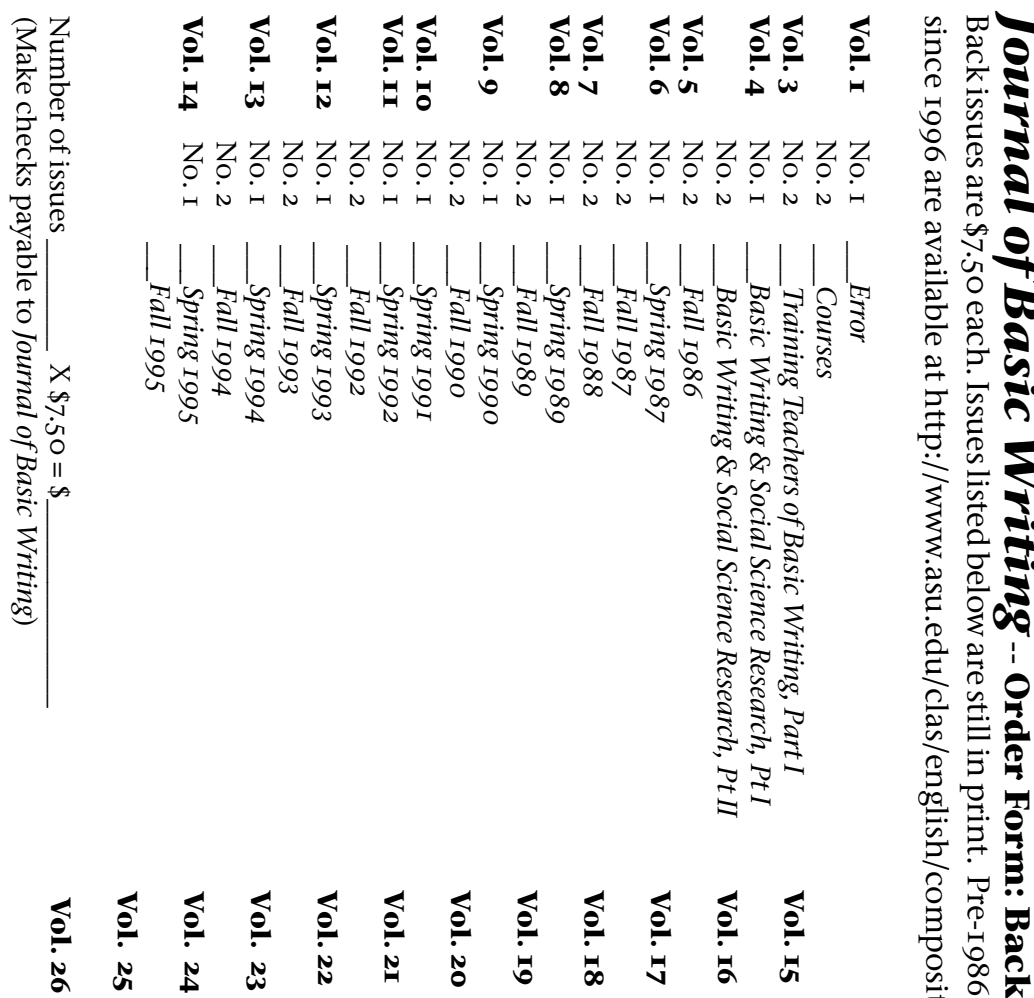

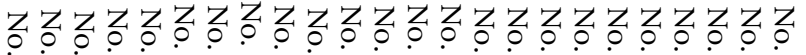

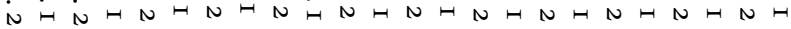
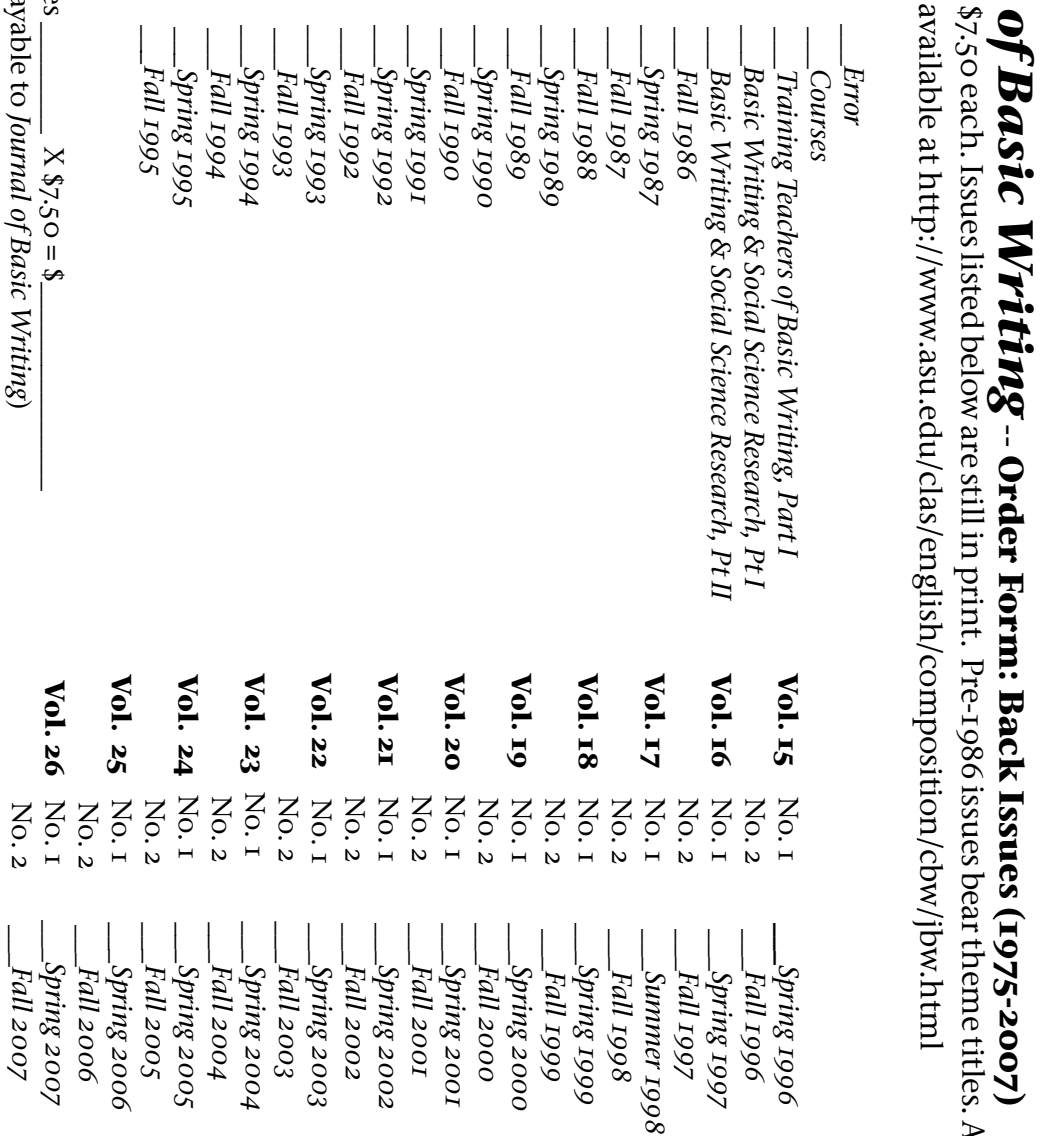

己
0
0
0
0
0
0
0
0
0
0
0
0
0
0
0
0
0
0
0
0
0 


\section{How is this publication thinking about the future?}

By becoming part of the past.

This publication is available from

ProQuest Information and Learning

in one or more of the following ways:

- Online, via the ProQuest* information service

- Microform

- CD-ROM

- Via database licensing

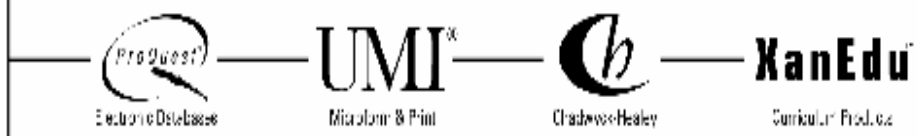

Fir more intormation, riall

I-800-52I-0600, cxt. 2888 (US) ur 0I-734-76I-4700 (Lint:ruttoust) sinv.il.proquest.rom

From:Pro Quest 


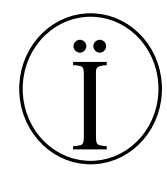

The paper used in this publication meets the minimum requirements of the American National Standard for Information Science Permanence of Paper for Printed Library Materials, ANSI Z39.48-1984.

The text stock is also recycled. 